\title{
Influência dos espessantes na rugosidade da superfície da dentina e resistência ao cisalhamento de três sistemas adesivos.
}

\section{DANIELA CASTILIO}

Tese apresentada à Faculdade de Odontologia de Bauru da Universidade de São Paulo, como parte dos requisitos para obtenção do título de Doutora em Odontologia, área de Dentística, opção Materiais Dentários.

(Edição Revisada)

BAURU

2005 


\section{Influência dos espessantes na rugosidade da superfície da dentina e resistência ao cisalhamento de três sistemas adesivos.}

\section{DANIELA CASTILIO}

Tese apresentada à Faculdade de Odontologia de Bauru da Universidade de São Paulo, como parte dos requisitos para obtenção do título de Doutora em Odontologia, área de Dentística, opção Materiais Dentários.

(Edição Revisada)

Orientador: Prof. Dr. Paulo Amarante de Araújo

BAURU

2005 


\section{Castilio, Daniela}

C278i Influência dos espessantes na rugosidade da superfície da dentina e resistência ao cisalhamento de três sistemas adesivos./ Daniela Castilio

Bauru, 2005.

159 p: il.; $30 \mathrm{~cm}$.

Tese (Doutorado) -- Faculdade de Odontologia de

Bauru, $\quad$ Universidade de São Paulo

Orientador: Prof. Dr. Paulo Amarante de Araújo

Autorizo, exclusivamente para fins acadêmicos e científicos, a reprodução total ou parcial desta dissertação/tese, por processos fotocopiadores elou meios eletrônicos

Assinatura do autor:

Data: 


\section{DANIELA CASTILIO}

21 de julho de 1973

Bauru - SP

Filiação

1991-1995

1996-1998

1996-1998

1996

$1998-2000$

2001-2005
Nascimento

Celso Castilio

Sueli Aparecida Castilho Castilio

Curso de Graduação em Odontologia na Universidade do Sagrado Coração - Bauru $-\mathrm{SP}$.

Curso de especialização em Prótese Dental, promovido pela PROFIS.

Residência Odontológica na Área de Prótese Dental no Hospital de Pesquisa e Reabilitação de Lesões Lábio-Palatais, da Universidade de São Paulo, promovido pela PROFIS.

Professora do Departamento de Odontologia da Universidade do Sagrado Coração.

Curso de Pós-Graduação em reabilitação Oral, em nível de Mestrado, na Faculdade de Odontologia de Bauru.

Curso de Pós-Graduação em Dentística, opção Materiais Dentários, em nível de Doutorado, na Faculdade de Odontologia de Bauru. 


\section{A Dens}

"Que nos deu o Dom da vida, nos presenteou com a liberdade, nos abençoou com a inteligência, nos deu a graça de lutarmos para a conquista de nossas realizações. A Ele cabe o louvor e a glória, cabe a nós, somente agradecê-lo." 


\section{Dedico este trabalho}

Ao meu esposo José Henrique que nos momentos difíceis sempre esteve ao meu lado, companheiro de mais uma trajetória de nossas vidas, obrigada pelo amor e incentivo.

....hoje eu gostaria que vibrasses comigo, não porque eu venci, mas porque vencemos juntos, vencemos mais um desafio em nossas vidas. Que diante dos próximos, Deus permita estarmos juntos, para, mais fortes, podermos enfrentá-los. 
Agradeço aos meus pais queridos, Sueli e Celso, meus maiores incentivadores a lutar pelos meus objetivos, meus ídolos, que representam para mim exemplos de seres humanos, honestidade, responsabilidade e caráter, responsáveis pela minha formação moral e profissional, muito obrigada pelo amor, carinho e amizade.

Agradeço ainda ao restante de minha família, Sra Delma e Sr José Martins, meus segundos pais, e ao meu irmão Régis, que também participaram de minha ascensão até este estágio profissional. 


\section{Agradecimentos especiais}

Ao Prof Dr Paulo Amarante de Araújo, pela orientação experiente e amiga durante o desenvolvimento deste trabalho. Como é difícil ser mestre, ser amigo, guia, companheiro e ao mesmo tempo instrutor que transmite conhecimentos teórico-científicos. A você que soube ser tudo isto, só me resta agradecer, pois fostes verdadeiramente um mestre.

Aos colegas de Pós-Graduação Anhurada e Renato, pela amizade enriquecedora e incessante contribuição na execução deste trabalho.

Ao Prof Dr. Marco Antônio Húngaro Duarte, exemplo eterno de dedicação, conhecimento e competência, meus agradecimentos pelo auxílio na elaboração e sugestões prestadas durante a análise estatística.

Ao Prof Dr. José Carlos Yamashita pelo auxílio prestado na análise Microscópica em Piracicaba, minha eterna gratidão. 


\section{AGRADECIMENTOS}

Ao Núcleo de Apoio à Pesquisa/Microscopia Eletrônica da ESALQ- USP, na pessoa do Prof. Dr. Elliot Watanabe Kitajima por proporcionar o uso do Microscópio Eletrônico de Varredura

À Universidade do Sagrado Coração, em especial a Ir. Marizabel Leite, pelo incentivo e contribuição para realização do curso de Pós Graduação.

À Faculdade de Odontologia de Bauru, da Universidade de São Paulo, representada pela Diretora Maria Fidela de L. Navarro.

Aos Professores do Departamento, Dr. Paulo A. S. Franciscone, César Antunes de Freitas, Dra Maria Tereza A. A. Bastos, Dr. Ricardo M. de Carvalho, pela amizade e ensinamentos.

Às minhas colegas do curso de Pós Graduação, Rosa e Luiza, que dividiram comigo os desafios enfrentados para alcançar este objetivo. 
Aos Professores do Departamento de Prótese da Universidade do Sagrado Coração: Ana Aida, Fátima, Gerson, Gilmar, Ivete, João, José Fernando, Juliana, Pedro, Regina, Sérgio, Simone e Walter, pelo companheirismo e incentivo.

Aos funcionários do Departamento, Sandra, Lourisvalda e Alcides e Edimauro, que estiveram sempre dispostos a ajudar no que fosse preciso.

A todos os funcionários da Pós Graduação e da Biblioteca, pela atenção e cordialidade.

Ao Departamento de Bioquímica, em especial a Telma e Ovídio, que tiveram participação nesta pesquisa auxiliando no preparo dos produtos experimentais.

Ao Departamento de Prótese, em especial ao Reivanildo, pela ajuda e disposição nos ensaios de resistência ao cisalhamento. 


\section{SUMÁRIO}

LISTA DE ABREVIATURAS E SÍMBOLOS $\quad x$

LISTA DE TABELAS Xii

LISTA DE GRÁFICOS Xiv

LISTA DE FIGURAS $\quad$ XV

RESUMO $\quad x x$

1- INTRODUÇÃO 1

2- REVISÃO DE LITERATURA 6

3- PROPOSIÇÃO 88

4- MATERIAIS E MÉTODOS 89

5- RESULTADOS 106

6- DISCUSSÃO

7- CONCLUSÕES 141

$\begin{array}{ll}\text { ANEXOS } & 142\end{array}$

$\begin{array}{ll}\text { REFERÊNCIAS BIBLIOGRÁFICAS } & 147\end{array}$

$\begin{array}{lr}\text { ABSTRACT } & 159\end{array}$ 


\section{LISTA DE ABREVIATURAS E SÍMBOLOS}

\%- porcentagem

${ }^{\circ} \mathrm{C}$ - grau Celsius

$\mu \mathrm{l}$ - microlitro

$\mu \mathrm{m}$ - micrometro

ADA- American Dental Association

ANOVA- Análise de variância

BisEMA- Bisfenol A polietilenoglicol dieter dimetacrilato

BisGMA- Bisfenol glicedil metacrilato

BPDM- bisfenil dimetacrilato

$\mathrm{cm} /$ minuto- centímetros por minuto

Fig.- figura

g- gramas

$\mathrm{H}_{3} \mathrm{PO}_{4}$ - ácido fosfórico

HEMA- hidroxietilmetacrilato

HMDS- hexametildisilizane

$\mathrm{HNO}_{3}$ - ácido nítrico

Kgf- kilograma força

LAT- tempo de ativação da luz

M- molar

MEV- Microscópio Eletrônico de Varredura

ml- mililitros

mm- milímetros 
$\mathrm{mm} / \mathrm{min}$-- milímetros por minuto

$\mathrm{mm}^{2}$ - milímetros quadrado

MMA- metilmetacrilato

MPa- Mega Pascal

$\mathrm{mW} / \mathrm{cm}^{2}$ - densidade de potência

$\mathrm{NaOCl}$ - hipoclorito de sódio

NTGMA- N- p-tolyl- glicina glicedil metacrilato

PENTA- éster fosfonado pentacrilato

pH- potencial hidrogênico

PMMA- polimetilmetacrilato

Ra- rugosidade aritmética

S- segundos

SBMP- Scotchbond Multipurpose

SBS- resistência ao cisalhamento

SiC- carbeto de silício

$\mathrm{SiO}_{2}$ - óxido de sílica

TBB- tri- $n$ - butil borano

TEGDMA- trietilenoglicol dimetacrilato

TEM- Microscópio Eletrônico de Transmissão

UDMA- Uretano dimetacrilato

WID- profundidade de identação 


\section{LISTA DE TABELAS}

página

TABELA 1- $\quad$ Preparo dos espécimes (KANCA, 1992b).

TABELA 2- $\quad$ Tratamentos do esmalte e dentina humanos (BARKMEIER, ERICKSON, 1994).

TABELA 3- $\quad$ Tratamento do esmalte e dentina bovino (BARKMEIER, 35 ERICKSON, 1994).

TABELA 4- $\quad$ Primers experimentais. Composição em peso\%. (ARAÚJO; 58 ASMUSSEN, 1997).

TABELA 5- $\quad$ Grupos testados.

TABELA 6- Teste "T "de Student- Amostras pareadas antes e após o 106 condicionamento ácido.

TABELA 7- Média e Desvio padrão das três formulações do ácido na 107 rugosidade superficial, após o condicionamento.

TABELA 8- $\quad$ Média e Desvio padrão dos grupos realizados com a resina 109 Beautifil.

TABELA 9- Comparação individual pelo teste de Tukey entre as 109 formulações dos ácidos em relação a cada sistema adesivo na resistência ao cisalhamento, dos grupos restaurados com a resina Beautifil.

TABELA 10- Comparação individual pelo teste de Tukey entre os sistemas adesivos em relação a cada formulação de ácido empregado nos grupos restaurados com a resina Beautifil. 
TABELA 11- Média e Desvio padrão dos grupos realizados com a resina Filtek Z $250^{\mathrm{TM}}$ e teste de Tukey.

TABELA 12- Comparação individual pelo teste de Tukey entre as formulações dos ácidos em relação a cada sistema adesivo na resistência ao cisalhamento, dos grupos restaurados com a resina Filtek $\mathrm{Z} 250^{\mathrm{TM}}$.

TABELA 13- Comparação individual pelo teste de Tukey entre os sistemas adesivos em relação a cada formulação de ácido empregado, nos grupos restaurados com a resina Filtek $Z$ $250^{\mathrm{TM}}$.

TABELA 14- Quantificação dos tipos de falhas apresentadas pelos espécimes, considerando o sistema adesivo utilizado.

TABELA 15- Quantificação dos tipos de falhas apresentadas pelos espécimes, considerando a formulação de ácido utilizado. 


\section{LISTA DE GRÁFICOS}

página

Gráfico 1- Médias das forças de resistência adesiva ao cisalhamento 108 dos grupos realizados com a resina composta Beautifil, através dos 3 sistemas adesivos e combinados aos 3 ácidos (polímero, sílica e comercial), sendo que na legenda a primeira letra corresponde aos sistemas:Gluma A, Gluma $\mathrm{B}$, e adesivo comercial (C).

Gráfico 2- Médias das forças de resistência adesiva ao cisalhamento dos grupos realizados com a resina composta Filtek $Z$ $250^{\mathrm{TM}}$, através dos 3 sistemas adesivos combinados a três formulações de ácido (polímero, sílica e comercial), sendo que na legenda a primeira letra corresponde aos sistemas:Gluma A, Gluma B, e adesivo comercial (C). 


\section{LISTA DE FIGURAS}

página

Figura 1- Ácido fosfórico 37\% líquido, utilizado para formulação dos 89 ácidos experimentais.

Figura 2 Balança de precisão.

Figura 3- Materiais utilizados na formulação do Gluma A.

Figura 4- Materiais utilizados na formulação do Gluma B.

Figura 5- Sistema adesivo comercial Prime \& Bond 2.1 (C).

Figura 6- Resinas compostas utilizadas neste estudo.

Figura 7- Seqüência de inclusão. Através de uma matriz metálica (a) foi 95 confeccionada uma matriz de silicone (b) e com resina epóxi foi realizada a inclusão da porção coronária (c), e após a exposição da dentina em lixadeira, obtivemos o espécime para os testes.

Figura 8- Rugosímetro utilizado para análise da rugosidade superficial da dentina.

Figura 9- Demarcação da área a ser condicionada e restaurada.

Figura 10- Condicionamento com ácido fosfórico 37\% comercial.

Figuras Dispositivo utilizado para condensação do material restaurador, 100 11 e 12- numa vista superior e lateral.

Figura 13- Condensação da resina composta no interior da matriz.

Figura 14- Fotoativação da resina composta. 
Figura 15- Espécime pronto para o teste de resistência ao cisalhamento.

Figura 16- Máquina de Ensaio Universal Kratos.

Figura 17- Espécime acoplado no dispositivo para o teste de resistência ao cisalhamento.

Figura 18- Máquina de corte.

Figura 19- Espécime após o seccionamento.

Figura 20- Superfície condicionada com ácido fosfórico 37\% gel espessado com sílica. Smear layer foi removida e os túbulos dentinários abertos. Resíduos de sílica podem ser observados. (1000x)

Figura 21- Superfície condicionada com ácido fosfórico $37 \%$ gel comercial. Smear layer foi removida e os túbulos dentinários abertos.. (1000x)

Figura 22- Superfície condicionada com ácido fosfórico 37\% gel espessado com polímero. Smear layer foi removida e os túbulos dentinários abertos. (1000x)

Figura 23- Fotomicrografia ilustrando a superfície da dentina tratada com ácido fosfórico comercial vista em uma secção longitudinal. Note a abertura dos túbulos dentinários, mas mesmo após a lavagem ficaram resíduos de sílica na superfície dentinária (seta). (2000 x)

Figura 24- Fotomicrografia ilustrando a superfície dentinária após o condicionamento com ácido experimental espessado com sílica vista em uma secção longitudinal. Note a abertura dos túbulos dentinários, mas mesmo após a lavagem ficaram resíduos de 
sílica na superfície dentinária (seta). (2000 x)

Figura 25- Fotomicrografia ilustrando a superfície da dentina após o condicionamento com ácido experimental espessado com polímero. Os túbulos dentinários apresentavam-se abertos, porém sem resíduos do agente condicionante. (2000 x)

Figura 26- Fotomicrografia ilustrando a interface dentina/resina composta Filtek Z $250^{\mathrm{TM}}$ produzida pelo Gluma A, após o tratamento com $\mathrm{HCl}$ e $\mathrm{NaOCl}$. A formação dos tags de resina pode ser observada (seta). (1500 x)

Figura 27- Fotomicrografia ilustrando a interface dentina/resina composta Filtek Z $250^{\mathrm{TM}}$ produzida pelo Gluma 2 (B), após o tratamento com $\mathrm{HCl}$ e $\mathrm{NaOCl}$. Os tags de resina são mais longos (seta) e a camada híbrida mais espessa (H). (1500 x)

Figura 28- Fotomicrografia ilustrando a interface dentina/resina composta Filtek Z $250^{\mathrm{TM}}$ produzida pelo Gluma B, não submetida a desproteinização com NaOCl. (2500 x)

Figura 29- Fotomicrografia ilustrando a interface dentina/resina composta Beautifil produzida pelo adesivo comercial (C), não submetida a desproteinização com NaOCl. (2500 x)

Figura 30- Fotomicrografia da interface unida com Gluma A restaurada com a resina composta Filtek Z 250. Camada híbrida ácido resistente é fina e com muitos tags de resina curtos. (3000 x)

Figura 31- Fotomicrografia da interface unida com Gluma B, restaurada com a resina composta Filtek Z 250. Camada híbrida ácido resistente é mais espessa e com muitos tags de resina longos. Há presença de ramificações laterais. (3000 x) 
Figura 32- Fotomicrografia da interface unida com adesivo comercial restaurada com a resina composta Beautifil. Camada híbrida ácido resistente é mais espessa e os tags de resina são longos. Há presença de ramificações laterais ${ }^{*}$ ). (3000 x).

Figura 33- Fotomicrografia da interface dentina/resina do sistema Gluma A, 124 restaurado co resina composta Beautifil. Observamos uma fenda (seta) na interface adesiva, mas há formação de tags de resina $\left(^{*}\right) .(3000 x)$

Figura 34- Fotomicrografia da superfície tratada com ácido fosfórico 37\% 128 experimental espessado com sílica. A dentina intertubular esta porosa e rugosa na embocadura dos túbulos. Note a presença de resíduos de sílica após a lavagem (seta), (*) rede de fibras de colágeno exposta. $(8000 \mathrm{x})$

Figura 35- Secção transversal da interface unida com o sistema comercial 135 (C) e restaurada com a resina Filtek $Z 250^{\mathrm{TM}}$. Formação dos tags de resina (seta). $\mathrm{R}$ (resina), $\mathrm{H}$ (camada híbrida), D (dentina). (1500 x)

Figura 36- Fotomicrografia da interface dentina/resina no sistema Gluma A, 136 restaurada com a resina Beautifil. Os tags são em menor número, mais curtos e desorganizados. (1500 x)

Figura 37- Fotomicrografia da interface dentina/resina no sistema Gluma B, 136 restaurada com a resina Beautifil. Os tags de resina estão em maior número e se apresentam mais longos. (1500 x)

Figura 38- Fotomicrografia da interface dentina/resina no sistema comercial (C) restaurada com a resina Beautifil. Os tags de resina estão em maior número. (1500 x) 
Figura 39- Fotomicrografia da interface dentina/resina no sistema Gluma A, restaurada com a resina Beautifil. Houve a formação dos tags de resina, onde a média dos comprimentos dos tags foi de 38 $\mu \mathrm{m} .(1500 \mathrm{x})$

Figura 40- Fotomicrografia da interface dentina/resina no sistema Gluma B. A maioria dos tags formados eram longos e com comprimento de até $96,69 \mu \mathrm{m} .(1500 \mathrm{x})$.

Figura 41- Fotomicrografia da interface dentina/resina no sistema comercial (C). Formação de tags de resina sendo que o tag mais longo apresentou-se com um comprimento de $100,43 \mu \mathrm{m}$. $(1500 \mathrm{x})$

Figura 42- Fotomicrografia da interface unida com o sistema Gluma A em 138 que poucas ramificações laterais são visualizadas. (6000 x)

Figura 43- Secção transversal da interface unida com o sistema Gluma B. 138 Tags de resina presentes com várias ramificações laterais $\left({ }^{*}\right) \cdot(5500 x)$

Figura 44- Gluma B: Formação de tags com muitas ramificações laterais. 138 $(15000 x)$ 


\section{RESUMO}

Este estudo teve como objetivo determinar a influência dos espessantes na rugosidade da superfície da dentina e resistência ao cisalhamento de três sistemas adesivos. Foram utilizadas 144 coroas de incisivos bovinos. A rugosidade da superfície da dentina foi avaliada antes e após o condicionamento com três diferentes formulações de ácido fosfórico 37\%. Os ácidos experimentais foram espessados com sílica silanizada e polímero, sendo o comercial espessado com sílica coloidal. Três sistemas adesivos foram utilizados em combinação com as três diferentes formulações de ácido fosfórico 37\%. O sistema adesivo comercial foi o Prime \& Bond 2.1, à base de acetona; os experimentais foram formulados à base de água, sendo adicionado, o tetrahidrofurano, no Gluma B. Metade das restaurações foram realizadas com a resina composta Filtek Z $250^{\mathrm{TM}}$ e a outra metade com a resina composta Beautifil. Os espécimes foram armazenados por $24 \mathrm{~h}$ em água deionizada à $37^{\circ} \mathrm{C}$ e então submetidos ao teste de resistência ao cisalhamento na máquina de ensaio Kratos, a uma velocidade de deslocamento de $0,5 \mathrm{~mm} / \mathrm{min}$. Alguns espécimes foram preparados para análise em MEV da penetração de resina no interior dos túbulos dentinários. Os dados foram analisados através dos testes de ANOVA, a um critério de classificação e Tukey. O ácido espessado com sílica aumentou significantemente a rugosidade superficial da dentina $(P<0,05)$. Os espessantes não influenciaram na resistência ao cisalhamento dos dois materiais restauradores. Para a resina composta Filtek $Z$ $250^{\mathrm{TM}}$ houve diferença entre os sistemas adesivos somente nos grupos condicionados com ácido espessado com polímero. A resistência ao cisalhamento do sistema Gluma B, empregado com a resina Beautifil, apresentou maiores valores quando comparado ao Gluma $A$, e sem diferença quando comparado ao sistema comercial (C). Houve a formação da camada híbrida e tags de resina em todos os grupos estudados. 


\section{1- INTRODUÇÃO}

A união dos materiais restauradores à estrutura dental tem sido 0 principal objetivo de muitas pesquisas desde que BUONOCORE, em 1955, estabeleceu as bases para a união ao esmalte, mudando os conceitos puramente mecânicos da Odontologia Restauradora até então. Nos últimos 30 anos, um incremento nas pesquisas vem ocorrendo para a obtenção de materiais que formem uma verdadeira união adesiva com as estruturas dentais. O condicionamento ácido alterou as características morfológicas do esmalte tornando-o mais reativo, com isso simplificou procedimentos, diminuiu o desgaste de tecido sadio, aumentou a retenção, melhorou a adaptação e diminuiu a microinfiltração marginal nos materiais resinosos, a partir do embricamento mecânico da resina nas microporosidades do esmalte condicionados pelo ácido.

Enquanto a união ao esmalte é tida na Odontologia como um procedimento estabelecido e seguro, uma união à dentina ainda permanece um desafio à longo prazo. Nos últimos anos, inúmeras pesquisas têm sido dirigidas na busca de um material ou sistema adesivo que se ligue à dentina, promova seu selamento e permaneça inalterado por um longo período de tempo na cavidade bucal sendo este um ambiente desfavorável, pois apresenta umidade, variações térmicas e desafios mecânicos (JOHNSON et al., 1991).

A composição da dentina é muito diferente a do esmalte, devido à maior concentração de proteína (colágeno) e água presente nesse substrato. Essas características fazem com que a dentina seja um substrato úmido e inóspito para adesão das resinas (PASHLEY, 1989), particularmente as de 
características hidrofóbicas como as resinas dos primeiros sistemas adesivos. Por muito tempo, os mecanismos de adesão à dentina procuraram evitar a exposição do colágeno e da umidade natural do substrato, na interface dentina/resina, fundamentando-se no desenvolvimento de sistemas que buscavam uma adesão química às porções mineralizadas da smear layer e da dentina. Apesar de reconhecidas melhorias terem sido conseguidas com essa abordagem, os resultados adesivos ainda eram inadequados quando comparados aos conseguidos no esmalte (BARKMEIER; COOLEY, 1992). Nos últimos 20 anos, a melhor compreensão da morfologia e fisiologia da dentina como um substrato adesivo criou oportunidades para melhorias significantes nos sistemas adesivos.

Os princípios para união à dentina foram estabelecidos por NAKABAYASHI et al. (1982) e baseia-se em uma retenção micro-mecânica com a infiltração de monômeros resinosos na rede de colágeno exposta pela desmineralização, criando uma estrutura mista resina/colágeno, a "camada híbrida". A introdução de agentes adesivos hidrofílicos e o conceito de reforçar a dentina desmineralizada pela infiltração de monômeros adesivos nos espaços interfibrilares (NAKABAYASHI et al., 1982), resultando na formação da camada híbrida, tornaram-se elementos principais no estudo e aperfeiçoamento dos mecanismos de adesão à dentina.

Os ácidos foram comercializados na forma líquida por vários anos, mas atualmente a maioria dos condicionadores ácidos encontra-se em forma de gel. Os fabricantes adicionam espessantes nos ácidos para facilitar o manuseio. A vantagem do gel é a facilidade clínica no controle da difusão sobre a superfície dentinária, onde o efeito desmineralizante é clinicamente observado com as 
bolhas de gás acumuladas dentro do gel. Como resultado da dentina condicionada com ácido, uma camada de colágeno desnaturado e partículas de smear layer residual podem formar na superfície de dentina e prevenir a completa exposição da matriz de colágeno (PASHLEY et al., 1993). Os ácidos géis espessados com micropartículas de sílica deixam resíduos na superfície de dentina que não podem ser completamente removidas, nem com vigorosa lavagem (PERDIGÃO, 1994, KANCA, 1993).

A resistência adesiva e a capacidade de selamento de um sistema adesivo com superfícies de dentina são medidas de sua eficiência. Deste modo, fica evidente que a penetração de resina intertubular e intratubular é muito importante na obtenção de uma adesão dentinária eficiente (PASHLEY et al., 1995a). Se a resina não infiltra apropriadamente a matriz de colágeno desmineralizada, o resultado da resistência adesiva pode ser baixo e as fibrilas de colágeno desprotegidas estão sujeitas à hidrólise e degradação lenta, levando a um insucesso do procedimento restaurador a longo prazo (PASHLEY; CARVALHO, 1997). Além disso, se a resina não penetrar nos túbulos dentinários abertos e selá-los há um aumento no risco de sensibilidade dentinária e irritação pulpar pela infiltração de produtos bacterianos na direção da polpa através dos túbulos dentinários (PASHLEY; CARVALHO, 1997, SANO et al., 1994). Os adesivos ou agentes adesivos dentinários que contêm 35\% de HEMA (hidroxietil metacrilato) no primer aplicados em dentina desmineralizada melhoram a difusão pela dentina cálcio-reduzida aumentando sua penetrabilidade e características da superfície para melhor aceitar monômero aplicado. Adicionalmente, o HEMA é extremamente hidrofílico, uma característica importante quando se considera o conteúdo de água da dentina 
vital e o fluido dentro dos túbulos dentinários. A resistência de união foi aumentada quando o primer HEMA foi utilizado (NAKABAYASHI; WATANABE; GENDUSA, 1992).

A rugosidade superficial da dentina pode aumentar a molhabilidade da superfície dentinária, facilitando a penetração do sistema adesivo (TOLEDANO et al., 1999). A rugosidade superficial pode também aumentar a área da superfície e afirmaram sendo um fator contribuinte para altos valores de resistência ao cisalhamento (RETIEF, em 1991, GWINNETT, em 1994) e pode afetar a resistência adesiva do agente adesivo (COLI, et al., 1999).

Apesar da capacidade dos testes in vitro em predizer a performance clínica dos materiais seja questionável, eles são considerados de grande valia no desenvolvimento de novos produtos e no controle de algumas propriedades, mesmo porque a rápida evolução dos agentes de união e dos materiais restauradores resinosos dificulta a avaliação, in vivo, à longo prazo. A dificuldade dos testes de resistência serem feitos na cavidade bucal tem levado a maioria dos pesquisadores a usar dentes extraídos. Entretanto, tem sido extremamente difícil obter dentes humanos extraídos livres de cárie em número suficiente para estudos in vitro além da questão ética (RETIEF, 1991). Como um substituto para dentes humanos, os dentes bovinos vêm sendo utilizados em muitas investigações e têm como vantagens o tamanho e sua disponibilidade (NAKAMICHI; IWAKU; FUSAYAMA, 1983, RETIEF et al., 1990, FOWLER, et al, 1992, SCHILKE et al., 1999, LOPES et al., 2003, TORIl et al, 2003). Apesar disso, a conveniência de dentes bovinos como substituto para os testes de adesão em dentina humana não tem sido comprovada. Diferentes declarações foram encontradas na literatura sobre a aplicabilidade de dentina 
coronária bovina, a qual é comumente utilizada em testes de adesão (RETIEF, et al., 1990). Outros autores afirmam que a dentina de dentes bovinos não pode ser comparada com dados obtidos de dentes humanos porque a química e principalmente a estrutura de dentes bovinos não é totalmente idêntica a dos dentes humanos (TITLEY et al., 1988, PASHLEY et al., 1991).

A microscopia eletrônica de varredura (MEV) tem sido amplamente utilizada para estudar ou a superfície do substrato ou a interface de união entre dentina e sistemas adesivos (VAN MEERBEEK et al., 1992b, TITLEY et al., 1995a, TITLEY et al., 1995b). Os ensaios de resistência de união vêm sendo o método de escolha na avaliação da força, sob a ação da qual a junção adesiva se rompe, destacando-se os testes de resistência à tração e ao cisalhamento (NAKAMICHI; IWAKU; FUSAYAMA, 1983, VAN NOORT et al., 1989, RETIEF, 1991, JOHNSON et al., 1991, FOWLER et al., 1992).

Com base em todas as afirmativas aqui apresentadas, decidiu-se desenvolver 0 presente trabalho com 0 intuito de contribuir para 0 esclarecimento sobre o comportamento na rugosidade superficial e resistência ao cisalhamento dos espessantes utilizados nos agentes condicionantes. Nos ensaios de resistência ao cisalhamento os agentes condicionantes foram combinados a dois sistemas adesivos experimentais e um comercial. A MEV foi utilizada para análise da morfologia interfacial destes materiais. 


\section{2- REVISÃO DA LITERATURA}

BUONOCORE, em 1955, relatou que uma das maiores desvantagens dos acrílicos e de outros materiais restauradores era a falta de adesão à estrutura dental. Um material com tais características, sem necessidade de preparos cavitários retentivos, e o selamento de cicatrículas, fissuras e lesões cariosas incipientes seria efetivo. O autor cita algumas tentativas de se obter uma união entre os materiais restauradores e a estrutura dental: o desenvolvimento de novos materiais com propriedades adesivas; modificação dos materiais existentes na época tornando-os adesivos; uso de revestimentos como materiais de interface adesiva entre a restauração e o dente; alteração da superfície dental pelo tratamento químico para produzir uma nova superfície à quais os materiais existentes pudessem aderir. Neste estudo, BUONOCORE testou duas substâncias, solução ácida oxálica a 10\% e solução de ácido fosfórico a 85\%, para tratar as superfícies do esmalte na tentativa de aumentar a retenção do material restaurador ao dente. Observando os resultados, o autor sugeriu o uso do tratamento com ácido fosfórico que pareceu fornecer melhores resultados e é mais simples de usar.

Em 1970, RETIEF, por meio de uma extensa revisão da literatura, analisou as várias pesquisas que tentaram produzir um material restaurador que se unisse adequadamente a estrutura dentária e prevenisse infiltração marginal. Fez considerações sobre a dificuldade em se obter adesão intraoralmente devido à natureza destrutiva do ambiente oral. Incluiu como problemas para esta adesão a heterogeneidade da superfície do esmalte e da 
dentina, o ambiente aquoso que faz com que o adesivo seja capaz de se unir ao dente sem que a água interfira nas suas propriedades, a rugosidade dos preparos cavitários, possibilitando a formação de bolhas de ar reduzindo a área de contato entre o adesivo e o dente, representando locais de concentração de "stress" e de pouca resistência adesiva, a presença de "debris" na superfície, as forças mastigatórias, as variações rápidas do $\mathrm{pH}$ oral, as variações térmicas e o potencial tóxico do próprio material foram os aspectos enfocados e considerados para determinar as características do adesivo dentinário ideal. Segundo o autor, este adesivo ideal deveria produzir uma união permanente com o esmalte e a dentina, polimerização à temperatura bucal com o mínimo de contração, minimizar a expansão ou sorção de água, ser eficientemente forte para resistir às forças mastigatórias, possuir o mesmo coeficiente de expansão térmico da estrutura dentária, não ser tóxico a polpa e aos tecidos gengivais e, resistir a qualquer tipo de degradação na cavidade oral.

NAKABAYASHI; KOJIMA; MASUHARA, em 1982, sugeriram que um embricamento mecânico formado pela penetração de prolongamentos de resina, "tags", dentro dos túbulos dentinários poderia resultar em uma adesão diferente pela falta de união entre estes e as paredes dos túbulos. Afirmaram ser necessário aproveitar as características hidrofílicas e hidrofóbicas de monômeros que contenham metacrilatos (Phenyl-P, 4-Meta, Co-polímero MMA/TTB) com a capacidade de infiltrar a rede de fibrilas de colágeno expostas na dentina intra e intertubular para promover e aumentar a força de união. Por isso, estudaram a efetividade do monômero 4-Meta em MMA/TBB na adesão de um cilindro de acrílico ao esmalte e dentina bovina e humana 
condicionadas com uma mistura aquosa de ácido cítrico e cloreto férrico. Após a ciclagem térmica, foram realizados testes de resistência à tração e uma análise com o microscópio eletrônico de varredura. Descobriram que o monômero infiltrava nas fibrilas de colágeno expostas e polimerizava no local formando uma zona mista ácido-resistente de resina permeada pelo monômero. Foi denominada camada híbrida e considerada determinante na união da resina composta à dentina aumentando a resistência de união. Descreveram, portanto uma adesão micromecânica que ocorre pela infiltração do monômero da resina na superfície dentária, e quando esse monômero se polimeriza, produz uma dentina reforçada por resina que é composta por colágeno da dentina e hidroxiapatita que está infiltrada e circundada pelo polímero.

$\mathrm{Na}$ tentativa de encontrar um substituto para dentes humanos nos testes de adesão, NAKAMICHI; IWAKU; FUSAYAMA, em 1983, compararam a resistência adesiva de dentes bovinos e dentes humanos utilizando 5 cimentos odontológicos e duas resinas compostas. Os autores também estudaram o efeito da profundidade da dentina e do tempo de estocagem dos dentes após a extração na resistência de união da dentina (menos que 5 dias e mais que 6 dias). A adesão com esmalte e a camada superficial de dentina não mostraram diferenças estatisticamente significante entre dentes bovinos e humanos com quaisquer materiais utilizados, mas os valores médios foram sempre mais baixos com dentes bovinos. A adesão com a dentina bovina diminuiu consideravelmente com a profundidade da dentina. A resistência adesiva com dentina bovina foi de 1,6 a 10,7 vezes maior em dentina 
superficial que em profunda. Os autores determinaram que a densidade mais baixa dos túbulos dentinários, em conexão com pouca dentina intertubular por unidade de área, foi responsável pela resistência adesiva mais baixa em dentina profunda.Um tempo de estocagem maior dos dentes sempre mostrou valores médios de união com a dentina um pouco maior que os dentes extraídos recentemente. Somente a resina com adesivo quimicamente ativado e com condicionamento ácido apresentou diferenças significantes com relação ao tempo de estocagem. Os autores concluíram que os dentes bovinos foram úteis nos testes de adesão como substitutos para dentes humanos utilizando esmalte e dentina superficial.

ARAÚJO; ASMUSSEN, em 1989, realizaram várias modificações na formulação do chamado Gluma resin, sistema formulado à base de acetona com o propósito de obter um pré-tratamento de mais fácil aplicação clínica. A quantidade de acetona nas formulações foi alterada ou a acetona como também parte da água foram substituídos por um dos vários componentes voláteis. Algumas alterações de $\mathrm{pH}$ da mistura também foram realizadas e então testadas. Espécimes de dentina foram condicionadas com uma solução de glicina e oxalato de alumínio. As superfícies foram então tratadas com as misturas do Gluma resin modificado e restauradas com resina composta e então submetidas ao teste de resistência ao cisalhamento. Um dos solventes utilizados na substituição da acetona foi o tetrahidrofurano e os grupos que apresentavam esse solvente em sua formulação apresentaram valores aceitáveis de resistência ao cisalhamento. Altos valores de resistência ao 
cisalhamento foram obtidos nos grupos onde as formulações apresentavam pH reduzido, ou seja, pH ácido.

Em 1989, VAN NOORT et al., examinaram vários métodos de análise e medida da resistência adesiva e discutiram alguns procedimentos padrões e de controle para estes testes. A falta de valores consistentes para a resistência adesiva à dentina em testes de cisalhamento ou tensão, que são procedimentos experimentais superficialmente idênticos, tem levado a uma ambigüidade na interpretação dos dados. Estas variações na resistência adesiva são consideradas usualmente por estarem relacionadas com os diferentes procedimentos adesivos. Utilizando uma análise de elemento finito os autores calcularam a sensibilidade da resistência adesiva em diversas condições de teste. A resistência adesiva em testes de tensão ou cisalhamento é altamente dependente da geometria do corpo-de-prova, tipo de carga utilizada e da dureza dos materiais envolvidos. Os autores afirmam que há necessidade de padronização dos testes de resistência adesiva para que as medidas possam ser comparadas com outros trabalhos e demonstraram que não há uma tensão ou cisalhamento uniforme na interface entre a dentina e a resina composta.

Com a finalidade de avaliar e comparar a capacidade de união dos sistemas adesivos Scotchbond 2/Silux, Gluma/Lumifor e Tenure/Perfection, RIGSBY et al., em 1990, determinaram a microinfiltração qualitativa e quantitativa, além do tamanho das fendas marginais em restaurações de classe $\mathrm{V}$, padronizadas e confeccionadas usando estes sistemas. Um total de 90 caninos humanos extraídos foi utilizado neste estudo, sendo distribuídos em 30 
para cada teste. Os sistemas adesivos dentinários foram aplicados seguindo as recomendações dos fabricantes e as restaurações das cavidades realizadas com as respectivas resinas compostas. Para os testes de microinfiltração, selaram os espécimes com restaurações de verniz/amálgama e aplicaram duas camadas de esmalte sobre toda a superfície do dente, $1 \mathrm{~mm}$ além da margem da restauração, com objetivo de que o corante penetrasse somente nesta área. Antes de avaliar a microinfiltração qualitativa, os dentes foram termocicladas (500 ciclos) embebidos em fucsina básica a $0,5 \%$ entre $8^{\circ} \mathrm{C}$ e $55^{\circ} \mathrm{C}$, sendo usado o mesmo procedimento no caso da microinfiltração quantitativa, porém trocando o corante por azul de metileno a 2\%. A dimensão das fendas marginais foi observada através do microscópio eletrônico de varredura. Os resultados revelaram que o Scotchbond 2 apresentou os valores mais baixos em todos os testes, não apresentando diferenças estatisticamente significantes com o Tenure, mas ambos apresentaram valores mais baixos que o Gluma.

RETIEF et al., em 1990, determinaram a resistência adesiva ao cisalhamento e microinfiltração do Scotchbond 2/Silux com a dentina e avaliaram através de MEV a penetração da resina dentro dos túbulos dentinários de dentes humanos e bovinos. A resistência adesiva ao cisalhamento foi determinada na dentina oclusal de 25 molares permanentes humano e na dentina vestibular de 25 incisivos inferiores bovinos. Os espécimes foram incluídos em resina acrílica e lixados em uma politriz com lixas de granulação 180 e 600 para expor a dentina superficial. O Scotchprep Dentin Primer, o qual consiste de uma solução aquosa de ácido maleico e hidroxietilmetacrilato (HEMA) foi aplicado na superfície de dentina por 60 
segundos e a secagem foi realizada, por 15 segundos, com ar comprimido. $O$ Scotchbond 2 LightCure Dental Adhesive o qual consiste de um monômero hidrofílico e um monômero hidrofóbico (BisGMA), foi aplicado sobre a superfície condicionada, o excesso removido com um suave jato de ar e fotopolimerizado por 30 segundos. Um molde de teflon com 3,5mm de diâmetro e $1,5 \mathrm{~mm}$ de profundidade foi adaptado à superfície de dentina, a resina composta Silux foi condensada no interior do molde e cada incremento foi fotoativado por 30 segundos. Os espécimes foram levados a uma máquina de teste universal e a carga de cisalhamento foi aplicada através de uma haste em forma de faca com uma espessura de $0,5 \mathrm{~mm}$, o qual foi posicionada na base do cilindro de resina composta, numa velocidade de deslocamento de $0,5 \mathrm{~mm} /$ minuto. Microinfiltração de restaurações classe $\mathrm{V}$ realizadas na superfície vestibular de raízes de 15 caninos humanos e 15 incisivos bovinos foi determinada quantitativamente. Os dentes restaurados foram termociclados (500x) em uma solução de azul de metileno entre $8^{\circ} \mathrm{C}$ e $50^{\circ} \mathrm{C}$ com um tempo de 15 segundos cada banho. O corante extraído em $50 \%$ de $\mathrm{HNO}_{3}$ e a concentração do corante foi determinada espectrofotometricamente. A penetração da resina no interior dos túbulos dentinários foi avaliada em um MEV. A resistência adesiva ao cisalhamento do Scotchbond 2/Silux à dentina humana foi significantemente maior $(P=0,0096)$ e a microinfiltração significantemente menor $(P=0,0004)$ que com dentina bovina apesar do fato do sistema restaurador ter penetrado mais em dentina de dente bovino. Os resultados deste estudo sugerem que os dentes bovinos obtidos de animais com mais de 2 anos não são substitutos viáveis para os dentes humanos na avaliação laboratorial de sistemas adesivos. 
Na tentativa de padronizar os testes de adesão de laboratório devido a grande variação de metodologias que dificulta e não permite a comparação dos resultados dos diferentes estudos, RETIEF, em 1991, descreveu a metodologia de testes de cisalhamento, microinfiltração marginal e avaliação da dimensão do gap marginal na interface dente/restauração. Com relação aos testes de cisalhamento, o autor considera que as forças sofridas pela restauração clinicamente não são reproduzidas em laboratório, mas o considera atualmente mais preciso, apesar de concordar que a resina composta unida à superfície de dentina ao sofrer carregamento ou tensão, tem o estresse distribuído ao longo da interface de forma extremamente irregular. Quanto ao fato de alguns pesquisadores estarem usando dente bovino em testes de adesão pela dificuldade de se conseguir dentes humanos extraídos e intactos, citam vários resultados de trabalhos que concluíram não haver diferenças significantes entre os testes de cisalhamento no esmalte e dentina de ambos. O período de estocagem dos dentes da realização dos preparos também foi comentado, e com base em alguns estudos concluíram não haver diferença na estocagem de dois dias e 6 meses. Os líquidos para estocagem mais comum são:- formalina, cloramina, álcool, soro fisiológico e timol, de acordo com o autor, somente ocorreram diferenças significantes nos testes de cisalhamento quando os dentes foram estocados em álcool 70\%. Considerou como decisivo a seleção da área do dente a ser preparado devido ao tamanho dos túbulos e relatou que nas superfícies proximais de molares não foram notadas diferenças significantes quando comparados com a dentina da superfície oclusal. A rugosidade superficial da dentina também pode influenciar nos testes de cisalhamento, entretanto considerou este fator muito controverso na literatura. 
Outro parâmetro crítico que afeta consideravelmente a adesão, segundo o autor é a espessura da dentina depois de preparado, vários estudos comprovaram que quanto mais próximo da polpa, menores são os valores encontrados, provavelmente pelo diâmetro e número dos túbulos dentinários desta região. A área de demarcação para a união também pode afetar a adesão, e o excesso de material nas margens desta área pré-determinada pode aumentar significantemente o valor do teste, citou como diâmetro ideal para o teste uma área circular de 3mm. A aplicação do sistema adesivo, de acordo com o autor deve seguir as instruções do fabricante. Sua última consideração sobre os testes de cisalhamento foi sobre as bases aplicadoras da força que pode ser retangular ou em forma de ponta de faca, alguns estudos mostraram que a segunda apresentou resultados maiores. Sugeriu que para ficar mais fácil a comparação entre os dados de trabalhos diferentes, os resultados fossem expressos em MPa. Ao examinar a literatura com relação aos testes de microinfiltração encontrou uma enorme variação de testes, a começar pela localização das margens do preparo que podem ser abrangendo esmalte e dentina ao longo da junção amelo-dentinária, entretanto a ADA, estipulou que para testes com materiais adesivos dentinários, o preparo deverá ser exclusivamente em dentina. Os procedimentos restauradores devem seguir instruções do fabricante e a restauração realizada em 2 fases e a resina aplicada de forma obliqua que reduz em aproximadamente $25 \%$ o gap marginal. O acabamento das restaurações pode ser realizado 15 minutos após o final da polimerização e depois estocado em água destilada por 24 horas antes da ciclagem, diminuindo substancialmente o gap marginal. A ciclagem ideal segundo o autor seria de 500 ciclos com banhos entre $\pm 50^{\circ} \mathrm{C}$ e $\pm 8^{\circ} \mathrm{C}$, 
permanecendo 15 segundos em cada banho, isto porque nenhum alimento permanece intra-oralmente por um tempo maior que este. Com relação a metodologia de leitura da infiltração citou os métodos qualitativo e quantitativo, sendo este último mais preciso. Finalmente ao analisar testes que avaliam a dimensão dos gaps marginais na interface dente/restauração recomendou o método de van Dijken e Horstedt, que utilizam réplicas de resina epóxi.

FOWLER et al, em 1992, examinaram três variáveis associadas com testes de adesão: (1) o tipo de teste (cisalhamento e tensão); (2) o desenho do aparelho do teste de tensão e (3) o tipo de substrato (humano e bovino). Os dentes foram incluídos em resina acrílica e antes da preparação de cada espécime, as superfícies dos dentes foram lixadas em papel de carbeto de silício de granulação 400 sob irrigação, secos por 20 s. e então as superfícies foram tratadas como indicado pelo sistema adesivo utilizado. Os materiais utilizados foram Scotchbond, Silux (resina composta de micropartículas fotopolimerizável), Ketac-Fil e Vitrebond. O sistema Scotchbond 2 foi utilizado em esmalte e dentina, sendo que em superfícies de esmalte foi realizado o condicionamento ácido antes da aplicação do agente de união e nas superfícies de dentina foi realizado a aplicação do primer antes do agente de união. Para este sistema as restaurações foram realizadas com Silux em incrementos de $2 \mathrm{~mm}$ e fotoativadas por $60 \mathrm{~s}$. O KetacFil foi aplicado diretamente em superfícies de esmalte e nas superfícies de dentina, antes da aplicação do cimento, foi realizado um condicionamento por 10 s. com Ketac condicionater . O Vitrebond é um cimento designado para uso em dentina, o cimento foi proporcionado e aplicado sobre superfícies de dentina e então 
fotoativado por $60 \mathrm{~s}$. Todos os espécimes foram armazenados em um umidificador a $37^{\circ} \mathrm{C}$ por 2 semanas e então submetidos aos testes de resistência de união. Cada grupo consistiu de 10 espécimes. Após os testes, foram examinados sob microscópio óptico para determinar o modo de falha. Uma análise de variância a um critério foi utilizada para comparar os dados obtidos para cada material quando testado: (1) em testes de tensão e cisalhamento; (2) testes de tensão \#1 e \#2 (dentes bovinos); (3) esmalte e dentina humana e bovina. Não houve diferenças significantes na resistência de união entre os testes de tensão e cisalhamento. Entretanto, o teste de cisalhamento produziu falhas adesivas mais verdadeiras, portanto este tipo de teste pode ser o eleito para analisar a resistência de união. A resistência de união em esmalte com Scotchbond e Ketac-Fil e em dentina com Ketac-Fil diferiram significantemente quando testados pelos dois aparelhos de testes de tensão. As medidas de resistência de união obtidas com esmalte humano e bovino foram essencialmente comparáveis, já os valores com dentina variaram. Os autores afirmaram que pareceu ser uma tendência para valores mais altos de resistência de união com dentina bovina que com humana.

Em 1992, RETIEF et al., determinaram os efeitos do condicionamento ácido com ácido fosfórico em dentina na resistência ao cisalhamento e na microinfiltração quantitativa em um sistema adesivo dentinário experimental, e avaliaram os efeitos dos procedimentos restauradores na dentina por meio de microscópio eletrônico de varredura. 30 primeiros e segundos molares permanentes foram usados para a avaliação da resistência ao cisalhamento. Em 15 desses dentes foi aplicado Dentina Conditioner na dentina por 30 
segundos $(A)$, enquanto nos outros 15 dentes remanescentes a smear layer foi removido pela aplicação de $\mathrm{H}_{3} \mathrm{PO}_{4}$ à $37 \%$ por 20 segundos (B). Os primers $1 \mathrm{e}$ 2 foram misturados e aplicados como condicionador dentinário seguido da aplicação do adesivo dentinário antes da colocação em três incrementos da resina Bisfil-M. Os espécimes foram estocados em soro fisiológico a 37\%, por 24 horas antes da aplicação do carregamento para o teste de cisalhamento na máquina Instron com velocidade de $0,5 \mathrm{~mm} /$ minuto. Preparos de classe $\mathrm{V}$ circulares foram realizados na raiz de 30 caninos permanentes, 15 restaurados usando o Dentin Conditioner (C) e 15 remoção da smear layer com o $\mathrm{H}_{3} \mathrm{PO}_{4}$ (D). Depois de restaurados, os dentes foram colocados em solução salina a temperatura ambiente por 24 horas. Passado este período, os mesmos foram polidos e preparados para a ciclagem térmica. A ciclagem foi realizada em solução de azul de metileno a $2 \%$ em temperaturas de $8^{\circ} \mathrm{C}$ e $50^{\circ} \mathrm{C}$, permanecendo 15 segundos em cada banho por 500 vezes. A microinfiltração foi determinada quantitativamente por meio de um método espectofotométrico. Os autores encontraram os seguintes resultados: A) $14.2 \pm 2.2 \mathrm{MPa}$; B) $7.2 \pm$ 4.2 MPa: C) $30.0 \pm 28.6 \mu \mathrm{g}$ de corante por restauração: D) $10.3 \pm 8.2 \mu \mathrm{g}$ de corante por restauração. Concluíram então que a remoção da "smear layer" com $\mathrm{H}_{3} \mathrm{PO}_{4}$ reduziu a resistência ao cisalhamento da dentina mas diminuiu a microinfiltração significantemente.

BARKMEIER; COOLEY, em 1992, realizaram uma avaliação laboratorial dos sistemas adesivos. Avaliações in vitro de adesivos com esmalte condicionado por ácido têm mostrado excelente resistência de união e a eliminação virtual de microinfiltração marginal. Os sistemas adesivos mais 
recentes utilizam um condicionador de dentina para modificar ou remover a smear layer com subseqüente aplicação de um agente de união resinoso. Os valores de resistência adesiva têm melhorado com a evolução dos sistemas adesivos de dentina e a microinfiltração nas margens cemento/esmalte tem sido significantemente reduzida ou prevenida com os novos sistemas. Embora os testes de laboratório dos sistemas adesivos proporcionem um mecanismo para investigar e comparar sistemas mais recentes desenvolvidos, estudos clínicos são essenciais para documentar o desempenho dos materiais em longo prazo.

ASMUSSEN; UNO, em 1992, descreveram os aspectos químicos e físico-químicos de união da dentina com sistemas adesivos. Embora a adesão com a dentina pareça similar à união do esmalte condicionado, a resistência de união mecânica com a dentina estabelecida é significantemente baixa. Para obter resistência de união adequada, especialmente de agentes adesivos formulados, deve ser aplicado com a dentina condicionada antes da resina composta. Os agentes de união da dentina podem agir: 1- por reação química ou 2- por sua habilidade em penetrar não somente nos túbulos dentinários, mas também a dentina intertubular. A atividade química provavelmente pressupõe um certo grau de interpretação, ligando os dois modos de união. Os autores concluíram que várias possibilidades químicas, de união de resina com a dentina, têm sido descritas na literatura. É hipotetizado que as reações químicas requerem compatibilidade entre dentina ou dentina condicionada e resina adesiva com respeito aos parâmetros de polaridade e solubilidade. 
ERICKSON, em 1992, descreveu as interações dos sistemas adesivos e concluiu que as interações de superfície de vários componentes dos sistemas adesivos são consistentes com um mecanismo de união micromecânica. A desmineralização da superfície de dentina é seguida pela penetração de um promotor de adesão para proporcionar energia de superfície compatível com boa penetração do monômero. A completa adesão ocorre quando o agente de união penetra dentro da superfície desmineralizada, condicionado pelo primer e é então polimerizado. Isto resulta em uma camada de dentina reforçada ou camada híbrida consistindo de polímero, colágeno e hidroxiapatita. A formação de uma boa união requer que componentes dos sistemas adesivos sejam otimizados para complementar um ao outro e que sejam adequadamente aplicados.

Estudos clínicos com o objetivo de estabelecer a eficiência dos materiais restauradores adesivos são extremamente limitados em número comparados aos estudos de laboratório relatados. DUKE, em 1992, relatou as dificuldades em se realizar estudos clínicos dos sistemas adesivos e concluiu que os estudos clínicos teriam grande dificuldade em acompanhar os passos do desenvolvimento. As discussões deveriam continuar e então um consenso sobre as medidas validadas no desempenho clínico. Alguns métodos permanecem extremamente subjetivos e requer avaliações por períodos mais longos para tirar conclusões significativas.

VAN MEERBEEK et al., em 1992a, revisaram a literaratura correspondente aos fatores que afetam a adesão com tecidos mineralizados. Fatores relacionados com a estrutura físico-química dos aderentes e com as 
propriedades inerentes aos materiais resinosos restauradores e discutiram os mecanismos de união dos sistemas adesivos.

Com o propósito de avaliar a interferência da "smear layer" na união com a dentina, DAVIS et al., em 1992, compararam a resistência de união de sistemas adesivos dentinários (All bond, Prisma Universal Bond 2, Mirage Bond e Scotchond 2) que atuam sobre a smear layer sem removê-la. As supefícies foram condicionadas com ácido fosfórico a 10\%; ácido poliacrílico a 40\%, ou eliminando totalmente a smear layer. A dentina oclusal exposta de 120 molares humanos extraídos foi cortada com uma broca, produzindo uma textura superficial e uma smear layer similar às encontradas clinicamente. Após a aplicação dos sistemas adesivos foram confeccionados cilindros de resina composta e então fotoativados na superfície de dentina. Prontos, os corpos de prova foram armazenados em água a $37^{\circ} \mathrm{C}$ por 24 horas, sendo realizados posteriormente os testes de resistência ao cisalhamento. Os menores valores de resistência de união apareceram nos grupos condicionados com ácido poliacrílico quando comparados com os outros dois grupos, os quais foram similares estatisticamente. Os autores concluíram que o ácido fosfórico prepara melhor a dentina para os agentes adesivos do que o ácido poliacrílico. Também observaram que o emprego destes sistemas adesivos, como indica o fabricante, sem remover totalmente a smear layer, somente tratando-a, resultou em valores semelhantes ao da sua completa eliminação.

Em 1992, CHRISTENSEN, enumerou e discutiu vários fatores clínicos que interferem na adesão ao dente que podem ser ou não controlados pelo dentista. Entre eles, citou a contaminação indesejável por saliva e/ou sangue 
da superfície adesiva, o que produz inadequada união mesmo em dentina úmida. Também explicou sobre os efeitos da contaminação da água e óleo provenientes da seringa, do ar ou da peça de mão (alta rotação), assim como os efeitos da desidratação dentinária e a influência do uso de bases ou forramentos. Afirmou que a presença de rugosidades nas superfícies dos tecidos dentinários aumenta a área para adesão sendo um fator favorável como as retenções secundárias que evitam o deslocamento da restauração. Concluiu que os profissionais devem permanecer atentos a esses fatores e orientar a prática clínica ao controle dos mesmos para atingir o sucesso dos serviços por eles prestados.

KANCA, em 1992b, examinou o efeito de vários métodos de secagem da dentina na resistência adesiva ao cisalhamento da versão All-Etch do sistema adesivo All-Bond. Foram formados 6 grupos de 10 espécimes cada um e os diferentes tratamentos de superfície estão apresentados na TABELA 1. Após o condicionamento da superfície com ácido foi realizado a aplicação de 4 camadas do Primer $(A+B)$, secagem por 5 s e então uma camada uniforme de resina sem partícula foi aplicada e fotopolimerizada por 20 s. Um cilindro de resina composta foi fixado na superfície tratada e a resistência ao cisalhamento foi medida em uma máquina de teste universal Instron com uma velocidade de deslocamento de $5 \mathrm{~mm} /$ minuto. As superfícies de dentina úmidas mostraram uma maior resistência ao cisalhamento que as superfícies secas. Isto sugere que quando as superfícies estão completamente molhadas, não há interação com água e a mistura de primer é depositada na superfície aparentemente sem a mesma intimidade de adaptação. 
TABELA 1: Preparo dos espécimes (KANCA, 1992b).

\begin{tabular}{|c|c|c|c|}
\hline Grupos & Ácido fosfórico (s) & Lavagem (s) & Secagem(s) \\
\hline 1 & $10 \%, 30$ & 10 & 10 \\
\hline 2 & $10 \%, 30$ & 10 & 3 \\
\hline 3 & $10 \%, 30$ & 10 & Secos \\
\hline 4 & $37 \%, 15$ & 10 & 10 \\
\hline 5 & $37 \%, 15$ & 10 & Secos \\
\hline $6^{*}$ & $37 \%, 15$ & 10 & 10 \\
\hline
\end{tabular}

*esmalte

Neste mesmo ano (1992a), KANCA também investigou a resistência de união com dentina obtida com sistema de união experimental variando o solvente do primer e o estado da superfície de dentina. Os três primers consistiam de: 20\% HEMAlágua; 20\% HEMA / etanol; 20\% HEMA / acetona. As superfícies de dentina foram condicionadas com ácido fosfórico 10\% por 30 seg.e lavagem por $10 \mathrm{~s}$. Os 3 diferentes primers foram aplicados por 10 seg. em dentina seca, por 5 segundos, ou úmida, onde o excesso de água foi removido com papel absorvente. Uma fina camada de agente adesivo foi aplicada e fotoativada por $20 \mathrm{~s}$. Um molde de teflon, com $2,5 \mathrm{~mm}$ de altura e $4 \mathrm{~mm}$ de diâmetro, foi posicionado sobre a superfície de dentina e uma resina composta foi condensada em um único incremento e fotopolimerizada por 40 s. As matrizes foram removidas e após estocagem por 24 horas em água a $37^{\circ} \mathrm{C}$ os espécimes foram submetidos ao ensaio de resistência de união ao cisalhamento em uma máquina universal com uma velocidade de deslocamento de $5 \mathrm{~mm} /$ minuto. Os mais altos valores de resistência de união 
foram obtidos com o primer HEMA/acetona em superfície de dentina úmida (22,4 MPA). Os valores mais baixos foram obtidos quando o primer HEMA/água foi aplicado em dentina úmida (0 MPa), onde todos os espécimes falharam antes de serem submetidos ao ensaio de cisalhamento. O primer HEMA/álcool em superfície de dentina úmida resultou em resistência de união mais alta (16,2 MPa) que HEMA/álcool em superfície seca (5,4MPa). O autor concluiu que a umidade da superfície de dentina pode ter um efeito significante na adesão; o solvente do primer pode ter um efeito significante na adesão da dentina; a interação do solvente do primer com a umidade da superfície pode resultar em melhor molhamento da superfície pelo primer; a acetona parece ser o solvente de maior sucesso na superfície de dentina úmida, o sistema adesivo dentinário de maior sucesso seria aquele que esta apto para funcionar na presença de umidade.

A interface entre a resina adesiva e a superfície de dentina pré-tratada foi investigada por VAN MEERBEEK et al., em 1992b. A interface dentinaresina de diferentes sistemas adesivos foi condicionada com um raio de íon argônio para que a subestrutura pudesse ser analisada pelo microscópio eletrônico de varredura. Baseado nestas observações microscópicas os autores classificaram os sistemas adesivos morfologicamente em três grupos e esclareceram seus mecanismos de adesão. Discos de dentina, sem qualquer esmalte remanescente, com aproximadamente 1 a 1,5mm de espessura foram utilizados. A padronização da smear layer foi realizada com lixas d'água de granulação 600 por um minuto em uma politriz com irrigação constante. Na metade da superfície dentinária exposta foi aplicado uma fina camada de verniz 
e ficou protegida de interagir com o sistema adesivo, servindo como uma referência para comparação entre o nível de superfície original e a superfície tratada. Foram aplicados vários sistemas adesivos sendo que 5 espécimes de dentina foram utilizados para cada sistema. Uma camada de resina composta de baixa viscosidade foi aplicada sobre a superfície de dentina. Os espécimes foram estocados em uma solução fixadora de formaldeído 10\% por no mínimo 8 horas. Na linha de aplicação do verniz os espécimes foram seccionados e incluídos em resina epóxi. O polimento dos espécimes foi realizado com lixas de granulações crescente de 600, 1200 e 4000 e pastas de diamante com granulações de 3 e $1 \mu \mathrm{m}$, então foram colocadas no ultra-som por um tempo de 3 minutos para remoção dos resíduos deixados pelo polimento. Os espécimes foram atacados com um raio de íon-argônio por 30 segundos e montados em stubs de alumínio e cobertos com ouro para observação em MEV. O primeiro grupo de produtos removeu ou pelo menos dissolveu morfologicamente a smear layer abrindo os túbulos dentinários. O bombardeamento realizado com íon-argônio deslocou claramente uma camada de dentina impregnada por resina. Em hipótese o condicionamento com ácidos ou agentes quelantes desmineralizaram a camada superficial da dentina até uma certa profundidade deixando atrás uma rica matriz de colágeno. Monômeros hidrofílicos são então capazes de alterar este arranjo de fibrilas de colágeno facilitando a penetração da resina adesiva e resultando em uma ligação mecânica entre o colágeno e a resina adesiva. O segundo grupo somente modificou ou pelo menos preservou a smear layer. Neste caso, nenhuma camada híbrida foi observada e os túbulos dentinários foram obliterados com partículas globulares até uma certa profundidade. O terceiro grupo é formado por poucos produtos que dissolveram 
parcialmente a smear layer, criando uma fina camada de dentina impregnada por resina e um smear plug impregnado por resina. Este estudo mostrou claramente que os sistemas adesivos recentes induziram a alterações estruturais na morfologia da superfície de dentina, criando uma interface retentiva, chamada de zona de interdifusão, entre a camada de dentina profunda, não condicionada e o material restaurador. A zona de interdifusão favorece a copolimerização com a resina composta devido a presença conveniente de monômeros dentro da zona de interdifusão. Simultaneamente, esta camada pode oferecer uma proteção em potencial ao tecido pulpar caso impeça a passagem normal de microorganismos e toxinas.

A durabilidade à longo prazo da resina adesiva com a dentina de dentes bovinos mantendo a smear layer foi investigada por WATANABE; NAKABAYASHI, em 1993. Através de lixas d'água com granulações de 180 e 600 foi realizado o desgaste dos espécimes até a exposição de dentina, estes foram secos e receberam a aplicação da resina adesiva que foi polimerizada por 60 segundos. Seguida a aplicação da resina adesiva uma resina composta foi colocada na superfície de dentina e fotopolimerizada por 60s. Os espécimes foram estocados por 1 dia, 6 meses e um ano em água a $37^{\circ} \mathrm{C}$. A resistência adesiva ao cisalhamento foi medida nos intervalos de tempo e os resultados foram de 6,7 MPa após 1 dia de estocagem, 4,1 MPa após 6 meses e 2,8 MPa após 1 ano de estocagem. Exames microscópicos das interfaces após a fratura sugeriram que a imersão em água por longo tempo enfraqueceu a união entre a resina adesiva e dentina com smear layer porque não houve difusão suficiente da resina adesiva através da smear layer. Os autores sugerem que 
se o phenyl P/TEGDMA é capaz de penetrar parcialmente o substrato de dentina não tratada então é muito melhor remover completamente a smear layer e desmineralizar o substrato dentinário para estimular a impregnação do monômero e formação da camada híbrida.

A infiltração de monômeros resinosos na dentina quimicamente condicionada é considerada a chave para melhorar a união na interface dentina/resina. A relação entre a quantidade de resina penetrada na dentina e resistência adesiva tem sido especulada e debatida. GWINNETT, em 1993, desenvolveu um método para medir a contribuição que a hibridização tem na resistência adesiva de resinas compostas unidas à dentina. Foram estabelecidos 4 grupos cada qual contendo 10 terceiros molares superiores. Foram seccionados 30 dentes na região média da coroa e a dentina foi lixada com lixa d'água de granulação 600. Grupo I: smear layer intacta; grupo 2: smear layer removida com um Profy Jet (ação abrasiva do ar); Grupo 3: superfície de dentina foi condicionada com ácido fosfórico 10\% por 20 segundos; Grupo 4: dentina exposta por uma fratura transversa no meio da coroa. As superfícies de dentina foram tratadas com All Bond 2 e incrementos de $1 \mathrm{~mm}$ de resina P50 foram adicionadas á superfície e fotoativadas por 1 minuto. Os testes de resistência ao cisalhamento foram realizados com uma máquina universal Instron a uma velocidade de $5 \mathrm{~mm} /$ minuto. As características da morfologia interfacial e de superfície foram caracterizadas através da análise em MEV. O limite de valores ocorreu com o mínimo registrado para o grupo no qual o primer foi adicionado com a smear layer intacta e o maior valor registrado para o grupo condicionado com ácido. O condicionamento ácido da 
dentina removeu a smear layer, abriu e aumentou o diâmetro dos túbulos e criou porosidade na região intertubular no qual foi evidente a exposição da matriz de dentina. Visto que a penetração de resina foi encontrada somente em túbulos dentinários do grupo 4 e também em dentina intertubular do grupo 3, o autor concluiu que a infiltração de resina pode contribuir em aproximadamente um terço da resistência adesiva ao cisalhamento deste sistema utilizado.

STANINEC; KAWAKAMI, em 1993, estudaram a efetividade de dois sistemas adesivos dentinários de baixa viscosidade. Os sistemas contêm éster fosfato baseados em: 1) Bis-GMA/HEMA e 2) PMDM/NTG-GMA, e examinaram o efeito da baixa viscosidade destes sistemas. Os testes realizados foram: 1) cisalhamento e tração em vários intervalos de tempo depois de restaurados; e 2) microinfiltração por testes de penetração de corante. Foram utilizados molares humanos e para os testes de cisalhamento, o esmalte oclusal foi removido e a dentina ficou exposta. A área de união foi preparada e a resina composta foi condensada no interior de uma matriz, proporcionando cilindros de $2 \mathrm{~mm}$ de altura. Estes espécimes foram divididos em 4 grupos de acordo com os materiais restauradores: -T-M-Marathon-one; K-LVR-P- Clearfil photo posterior + resina de baixa viscosidade; K-P-Clearfil photo posterior; SB-P50P50. Para os testes de tração, os dentes com a dentina oclusal exposta foram montados em um jig, a área de adesão foi delimitada com uma matriz Mylar de $5 \mathrm{~mm}$ de diâmetro, e uma cavidade biselada com $5 \mathrm{~mm}$ foi confeccionada sobre esta área. Nos testes de tração e cisalhamento foram utilizados 16 espécimes para cada grupo e foram determinadas imediatamente após a fabricação. Os outros espécimes foram estocados em 100\% de umidade em temperatura 
ambiente por 1 e 24 horas. Outros 16 espécimes para cada grupo foram estocados por 1,3 e 6 meses antes dos testes de união. $O$ teste de cisalhamento foi realizado com uma ponta em forma de faca movendo-se paralela a superfície testada, em uma máquina de teste a 0,5mm/minuto. Para o teste de microinfiltração 40 molares humanos foram utilizados. Cavidades de classe $\mathrm{V}$ foram confeccionadas nas faces vestibular e lingual destes; a margem oclusal localizou-se em esmalte e a cervical em cemento. As cavidades foram divididas em 4 grupos de 20 dentes cada e restauradas com os mesmos materiais já citados. Depois de restaurados os dentes foram estocados em água destilada por 24 horas e então polidos com discos de Soflex. Os espécimes foram termociclados por 1000 ciclos em banhos de $4^{\circ} \mathrm{C}$ e $60^{\circ} \mathrm{C}$, permanecendo 60 segundos em cada banho. Os dentes foram então cobertos com esmalte para unha, exceto a restauração e $0,5 \mathrm{~mm}$ ao seu redor em seguida imersos em solução de fucsina básica por 24 horas a $37^{\circ} \mathrm{C}$. Depois de removidos da solução, foram lavados e seccionados no centro da restauração no sentido vestíbulo-lingual, as duas metades dos espécimes foram examinados em um microscópio com 100 x de aumento; os resultados foram expressos em mm. Depois da análise dos resultados, os autores concluíram que: significantes mudanças na força de cisalhamento em relação ao tempo ocorreram entre os grupos T-M e SB-P50, mas não entre K-LVR-P e K-P. KLVR-P e T-M, que tiveram menor infiltração marginal e a maior força de cisalhamento no teste imediato. A adição de resina de baixa viscosidade resultou em significante menor infiltração e maior força de cisalhamento no grupo K-LVR-P quando comparado ao grupo K-P. Nos testes de tração, mudanças com relação ao tempo entre cada grupo foram geralmente menores 
do que nos teste de cisalhamento. A quantidade de infiltração observada correlacionou com a força de cisalhamento.

Em 1993, SWIFT; DENEHY; BECK, compararam várias concentrações de ácido fosfórico e o ácido maleico utilizado no Scotchbond Milti-Purpose como condicionadores de dentina. Utilizaram 15 molares humanos extraídos, a superfície proximal dos dentes foi desgastada com ponta diamantada para expor a dentina. Os dentes foram então montados em uma base de resina acrílica e divididos em 5 grupos de 10 espécimes cada e condicionados por 15 segundos com os seguintes agentes: Grupo 1: condicionador do Scothbond Multipurpose (ácido maleico a 10\%) e considerado o grupo controle; Grupo 2: Condicionador gel do Scotchbond (ácido fosfórico à 35\% com Sílica); Grupo 3: Uni-Etch (ácido fosfórico a 32\%); Grupo 4: All-Etch (ácido fosfórico a 10\%); Grupo 5:- Etch "N" Seal (ácido fosfórico à 25\% com cristais de oxalato de alumínio). O primer e o adesivo utilizados foi o do sistema do Scotchbond Multi-Purpose conforme instruções do fabricante. A resina composta utilizada foi a Z-100, que foi condensada dentro de um cilindro plástico de $2.9 \mathrm{~mm}$ de diâmetro e $3 \mathrm{~mm}$ de profundidade e fotopolimerizada por 60 segundos. Os moldes foram então removidos e os espécimes estocados em água destilada por 48 horas e depois termociclados 300 vezes em banhos de água de $5^{\circ} \mathrm{C}$ e $55^{\circ} \mathrm{C}$, por 30 segundos em cada temperatura, entre os banhos havia um intervalo de 10 segundos. Terminada a termociclagem, os espécimes foram levados à máquina Instron em uma velocidade de $0,5 \mathrm{~cm} /$ minuto. Depois de fraturados os espécimes foram analisados com microscopia eletrônica (SEM). Os resultados foram expressos em MPa e foram os seguintes: Grupo 1: 
17.3; Grupo 2: 17.2; Grupo 3: 15.2; Grupo 4: 13.6 e Grupo 5: 5.2. Os autores concluíram então que o condicionador recomendado pelo Scochbond Multipurpose (ácido maleico 10\%) obtiveram uma força de adesão semelhante ao ácido fosfórico nas concentrações de 10\%, 32\%, ou 35\%; e que o uso do condicionador do Scotchbond Multi-Purpose necessita maiores investigações.

Com o intuito de verificar a possibilidade de se utilizar o ácido fosfórico para condicionamento total combinado com o sistema adesivo Scotchbond Multi-Uso, BECK; SWIFT; DENEHY, em 1993, avaliaram a resistência ao cisalhamento desse adesivo. As superfícies de dentina foram condicionadas com ácido fosfórico a 35\%, 32\% e 10\% e com Etch' n' Seal (ácido fosfórico 35\% com oxalato de alumínio), e com o ácido maleico a 10\% que serviu como grupo controle. O tempo de condicionamento foi de 15 segundos e utilizaram a dentina proximal de molares humanos extraídos. Os espécimes foram submetidos à ciclagem térmica em água com 300 ciclos, variando entre $5^{\circ} \mathrm{C}$ e $55^{\circ} \mathrm{C}$. A análise estatística mostrou que a medida dos valores da resistência de união do Etch' n'Seal, foi significantemente menor que os demais agentes, os quais obtiveram valores semelhantes entre si. A análise da microscopia eletrônica de varredura demonstrou que, tanto o ácido maleico como o ácido fosfórico $(10 \%, 32 \%$ e 35\%), removem completamente a smear layer e descalcifica a dentina subjacente, entretanto o Etch'n'Seal, promoveu a formação de um precipitado na superfície obliterando os túbulos dentinários. Concluíram que o uso do ácido maleico e fosfórico determina semelhante resistência de união quando o sistema adesivo Scotchbond Multi-Uso é utilizado. 
Com o propósito de estudar a permeabilidade dentinária dos agentes adesivos, PASHLEY et al., em 1993, observaram através do MEV, o efeito produzido pela aplicação do ácido fosfórico a 37\%, por 30 segundos, sobre a superfície de dentina oclusal humana coberta ou não por smear layer. A mesma superfície, após condicionada e lavada, foi mantida visivelmente úmida ou deixada seca usando jatos de ar por 30 segundos. Para controle utilizaram metade da superfície dentinária de cada espécimes, de ambos os grupos, a qual não foi descalcificada. As microfotografias mostraram que na superfície da dentina fraturada sem smear layer sendo seca ou úmida, houve um aumento no diâmetro dos túbulos dentinários, pela perda da dentina peritubular e no número das porosidades na dentina inter e intratubular. Com maior aumento, constataram a presença de muitas fibrilas de colágeno expostas. Porém observaram que a área descalcificada embaixo da superfície era ainda mais porosa, já que no topo, as fibrilas de colágeno se condensavam e colapsavam formando uma fina cobertura (similar a crosta) ainda maior nos espécimes que foram secos com ar. No caso do grupo onde a dentina estava coberta por smear layer, as imagens demonstraram que após aplicação do ácido eram eliminados completamente aqueles debris, inclusive a smear layer, acompanhado de um aumento dos túbulos dentinários e do número de porosidades na superfície dentinária subjacente. No entanto, dentro deste grupo, os espécimes que foram secos com ar, apresentaram uma superfície com regiões alternadas porosas e não porosas. As fibrilas de colágeno superficiais apareciam mais condensadas e cobertas por uma camada amorfa de colágeno solto residual (smear layer de colágeno) proveniente da descalcificação da smear layer o que, segundo os autores, complicava a 
penetração da resina adesiva. Concluíram que o condicionamento ácido restringe o potencial de porosidades na dentina pela criação de uma fina camada de fibrilas de colágeno condensadas na superfície e zona descalcificada que aumenta quando existe a smear layer de colágeno residual, diminuindo ainda o número de porosidades especialmente quando se utiliza ar para secar a dentina. Portanto, o substrato dentinário ideal para conseguir uma boa penetração da resina adesiva será aquela dentina descalcificada visivelmente úmida. Se a dentina desmineralizada se mantém úmida, as fibrilas de colágeno não se condensam. As fibrilas colapsadas podem reexpandir-se com água e também com a aplicação de monômeros hidrofílicos como o HEMA.

Considerando a interface dente/restauração, DUKE, em 1993, constatou que o desenvolvimento tem ocorrido em vários sistemas adesivos dentinários com primers hidrofílicos, permitindo uma maior penetração de adesivo na superfície da dentina condicionada com ácidos, promovendo um aumento na resistência de união à contração de polimerização e mudanças térmicas. Dentro destes sistemas adesivos, o autor menciona o Scotchbond Multi-Uso (3M) que utiliza como condicionador o ácido maleico a 10\% seguido de um"primer hidrofílico (HEMA) e do adesivo, criando uma união mecânica pela formação da camada híbrida. Comenta que ainda existem controvérsias se deve ou não eliminar a smear layer. Conclui que a microinfiltração pode ser reduzida significativamente usando um adesivo pré-polimerizável e a técnica incremental para condensar a resina composta. 
Com o intuito de investigar se o condicionador afeta a resistência de união com a dentina, KANCA em 1993, examinou os efeitos de vários condicionadores ácidos na resistência adesiva de 3 sistemas adesivos. Foram utilizados 120 molares humanos incluídos em resina acrílica no interior de um anel de alumínio de $1 \mathrm{~cm}$ de diâmetro. Os espécimes foram divididos em 4 grupos: 1- Tenure; 2- Método de Kanca; 3- All Bond 2 aplicado em dentina seca por 2 seg.; 4- AllBond 2 aplicado em dentina seca por 5 segundos. Três condicionadores foram aplicados na superfície de dentina: 1- ácido fosfórico 37\% espessado por sílica; 2- condicionador composto por ácido fosfórico e oxalato; 3- ácido fosfórico $38 \%$ líquido sem sílica ou oxalato. Os condicionadores foram aplicados por 20 s. e lavados por 5s. Cada grupo de 30 espécimes foi dividido em grupos de 10 sendo a variável o condicionador ácido. Os sistemas adesivos foram fotoativados por 20 s. e as restaurações foram efetuadas com o auxílio de uma matriz. Após 24 horas os espécimes foram testados em uma máquina universal a uma velocidade de $5 \mathrm{~mm} /$ minuto. Amostras foram preparadas para verificar através de MEV o possível efeito do condicionador na superfície da dentina. Para todos os sistemas adesivos a mais baixa resistência de união foi obtida com o condicionador contendo oxalato. A mais alta resistência de união para todos os sistemas foi observada quando a dentina foi condicionada com ácido fosfórico líquido sem sílica ou oxalato. O sistema All Bond 2 teve a mais baixa resistência de união quando aplicado em dentina seca quando comparado com dentina úmida. $\mathrm{O}$ autor sugeriu que a resistência de união varia devido ao depósito de vários minerais ou sais dos condicionadores na superfície de dentina. 
Em 1994, BARKMEIER; ERICKSON, avaliaram a resistência ao cisalhamento de uma resina composta (P50) ao esmalte e a dentina utilizando o sistema adesivo Scotchbond Multi-Purpose. As forças adesivas foram testadas em esmalte e dentina humanos e bovinos. Para os dentes humanos foram utilizados 50 dentes, que após o preparo das superfícies vestibulares foram divididos em 5 grupos de 10 dentes cada e receberam tratamentos diferentes em esmalte. A união à dentina também foi testada em um grupo com 10 espécimes. (TABELA 2).

TABELA 2: Tratamentos do esmalte e dentina humanos (BARKMEIER, ERICKSON, 1994).

\begin{tabular}{c|c|c|c|}
\hline Grupos & Condicionador & Primer & Adesivo \\
\hline Esmalte & & & \\
\hline 1 & $\mathrm{H}_{3} \mathrm{PO}_{4} 37 \%$ & - & Enamel Bond \\
\cline { 2 - 4 } 2 & $\mathrm{H}_{3} \mathrm{PO}_{4} 37 \%$ & - & Adesivo SBMP \\
\cline { 2 - 4 } 3 & $\mathrm{H}_{3} \mathrm{PO}_{4} 37 \%$ & SBMP Primer & Adesivo SBMP \\
\cline { 2 - 4 } 4 & Àc. maleico $10 \%$ & - & Adesivo SBMP \\
\cline { 2 - 4 } 5 & Àc. maleico 10\% & SBMP Primer & Adesivo SBMP \\
\hline Dentina & & & \\
\hline 6 & Àc. maleico 10\% & SBMP Primer & Adesivo SBMP \\
\hline
\end{tabular}

$\mathrm{Na}$ avaliação do esmalte e dentina bovina também testaram o efeito da secagem extrema com ar do Primer e a secagem agressiva do Adesivo para diminuir sua espessura. Utilizaram 50 incisivos bovinos e foram divididos em dois grupos para esmalte e três para dentina. Cada grupo recebeu um tratamento diferente (TABELA 3). 
TABELA 3:Tratamento do esmalte e dentina bovino (BARKMEIER, ERICKSON, 1994).

\begin{tabular}{|c|c|c|c|}
\hline Grupo & Condicionador & Primer & Adesivo \\
\hline Esmalte & & - & \\
\hline 7 & $\mathrm{H}_{3} \mathrm{PO}_{4} 37 \%$ & - & SBMP \\
\cline { 2 - 4 } 8 & Àc. maleico & & SBMP \\
\hline Dentina & & Primer SBMP & SBMP \\
\hline 9 & Àc. maleico & SBMP \\
\cline { 2 - 4 } 10 & Àc. maleico & Primer SBMP; secagem extrema & SBM \\
\cline { 2 - 4 } 11 & Àc. Maleico & Primer SBMP & SBMP;secagem extrema \\
\hline
\end{tabular}

Depois de preparados os espécimes foram estocados em água destilada a $37^{\circ} \mathrm{C}$ por 24 horas e a seguir levados à máquina de ensaio Instron a uma velocidade de $5 \mathrm{~mm} / \mathrm{minutos}$. A força foi aplicada paralela e exatamente na área de união. Os resultados foram calculados em MPa e a área de união depois de fraturado observada em um microscópio para detectar o tipo de falha. Analisando os resultados obtidos, os autores chegaram a algumas conclusões: 1) os resultados sugerem que o condicionamento do esmalte com ácido maleico a 10\% e ácido fosfórico a 37\% promovem resistências adesivas iguais; 2) o uso do primer do SBMP no esmalte humano condicionado com ácido maleico a 10\% ou ácido fosfórico a 37\% reduziu a resistência de união; 3) a resistência de união do esmalte bovino foi aproximadamente $35 \%$ mais baixa que ao esmalte humano; 4) a resistência de união da dentina bovina foi similar a encontrada na dentina humana quando o sistema adesivo foi utilizado seguindo as instruções do fabricante; 5) a redução da união a dentina encontrada com a secagem agressiva com ar do adesivo, aconteceu 
provavelmente devido a polimerização inadequada do adesivo por causa da inibição pelo oxigênio.

GWINNETT, em 1994, investigou o padrão no qual a zona de colágeno desmineralizada representa na resistência de união interfacial da resina composta unida com a dentina utilizando 3 sistemas adesivos comerciais em combinação com 3 diferentes agentes ácidos condicionadores. O experimento consistiu de duas partes. A primeira esta relacionada com o padrão no qual os diferentes tratamentos ácidos têm na resistência de união resina/dentina. A segunda parte foi designada para testar se a zona de colágeno contribuiu diretamente ou não na resistência de união interfacial. Foram estabelecidos 3 grupos para a primeira parte sendo: (1) All Bond 2/ Bisfil; (2) Optibond Dual Cure/ XRV e (3) Scotchbond Multi-Purpose / Z100, contendo 4 subgrupos de 10 dentes cada no qual a dentina foi exposta em um plano transverso no meio da coroa. As superfícies de dentina foram polidas com papel de carbeto de silício de granulação 320 e condicionadas com ácido maleico 10\% (15s.), ácido fosfórico 10\% (20s.), ácido nítrico (60s.) e ácido fosfórico 10\% (20s.) seguido por hipoclorito de sódio (120 s). Os espécimes foram estocados em água $37^{\circ} \mathrm{C}$ por 24 horas e então sujeitos ao ensaio de cisalhamento a uma velocidade de $5 \mathrm{~mm} /$ minuto. Os valores médios e desvios padrões para os grupos não mostraram diferenças estatisticamente significantes $(P<0,05)$. 0 autor concluiu que o tipo de condicionador ácido não afetou significantemente a resistência de união. Além disso, a zona rica em colágeno não contribuiu diretamente para a resistência de união interfacial, no qual é provavelmente 
derivada da difusão direta da resina dentro dos poros, na dentina abaixo parcialmente desmineralizada.

Os ácidos em forma de gel são na grande maioria espessados com sílica, o qual pode deixar resíduos de partículas na superfície dentinária. Alguns ácidos mais recentes são espessados com polímero, o qual relatam não deixar resíduos na superfície. PERDIGÃO; DENEHY; SWIFT, em 1994, examinaram superfícies de esmalte e dentina através de MEV que tinham sido condicionadas com ácidos espessados com sílica ou polímero. Os autores determinaram se o tipo de espessante dos ácidos afetou a força adesiva ao cisalhamento de resina composta com dentina e esmalte. Os ácidos espessados com sílica deixaram partículas na superfície de dentina e estas partículas não foram removidas pela lavagem com água. Há poucas evidências deste contaminante na superfície de esmalte. Superfícies de esmalte e dentina condicionadas com ácidos espessados com polímero pareceram estar livres e sem contaminação. Não houve diferença significante na resistência adesiva dos espécimes condicionados com os géis espessados com polímero ou sílica tanto para o esmalte como para a dentina. A contaminação com sílica não afetou desfavoravelmente a adesão.

Analisando os adesivos com relação a prevenção da infiltração marginal, RETIEF, em 1994, por meio de uma revisão, relatou que todas as resinas compostas contraem durante a polimerização, resultando no desenvolvimento de tensão e/ou estresse na interface dente/restauração. A maior parte do estresse de contração ocorre nos primeiros 15 minutos depois da iniciação da polimerização, mas com as resinas ativadas pela luz ele ocorre 
segundos após a irradiação. A tensão de estresse pode romper a união adesiva do sistema restaurador das paredes cavitárias resultando em microinfiltração na interface dente/restauração. As propriedades das resinas que incluem contração de polimerização durante o endurecimento, diferenças no coeficiente de expansão térmico dos dentes e restauração, e sorpção de água da restauração exposta ao ambiente oral, a colocação ocupa um importante papel na determinação das dimensões do gaps marginal e daí a microinfiltração. A microinfiltração na interface esmalte/restauração tem sido eliminada pela técnica do condicionamento ácido. Entretanto, a microinfiltração na interface dentina/restauração, é muito mais difícil de ser eliminada. Nenhum dos sistemas adesivos restauradores elimina a microinfiltração da margem gengival das restaurações que se estendem ou são localizadas abaixo da junção cemento/esmalte. Segundo o autor a microinfiltração é reduzida pelo uso da técnica incremental de restauração mas é aumentada quando o dente restaurado é submetido a estresse mastigatório ou carregamento oclusal. Nenhum dos sistemas adesivos previne o desenvolvimento de gaps marginais na interface dentina/restauração quando avaliados 10 minutos depois de colocados na cavidade, mas a expansão higroscópica resultante da imersão em água ou solução salina resulta em uma significante redução das dimensões dos gaps marginais. Um aumento nas margens cavo-superficiais reduz as dimensões dos gaps marginais mas não é dependente da profundidade da cavidade. A proporção do volume da cavidade para a área das paredes cavitárias e o volume da restauração tem uma influência significante nas dimensões do gaps marginal. A utilização de uma técnica restauradora 
incremental e o atraso no acabamento e polimento da restauração reduz significantemente as dimensões dos gaps marginais.

WATANABE; NAKABAYASHI, em 1994, descreveram os métodos in vitro utilizados para medir adesão dentinária, considerando a eficiência, vantagens e desvantagens dos mesmos. O substrato dentinário, as condições de armazenagem, assim como os métodos utilizados para análise de microscopia eletrônica de varredura para testar resistência de união e microinfiltração são alguns dos fatores que podem influenciar quando se examina a união à superfície dentinária em laboratório. Explicaram que a ciclagem térmica permite estudar o efeito da diferença entre os coeficientes de expansão térmica dos tecidos dentinários e o material restaurador sobre a microinfiltração e a estabilidade adesiva. Sendo o ideal a utilização de temperaturas entre $5^{\circ} \mathrm{C}$ e $60^{\circ} \mathrm{C}$ e 15 segundos em cada banho porque simulam de maneira mais próxima as condições in vivo. Concluíram que ainda estão investigando condições experimentais padronizadas in vitro que possam simular as condições in vivo.

Uma possível relação entre o grau de polimerização da resina composta e a resistência adesiva (SBS) da dentina tratada com Gluma foi investigada por YANAGAWA; FINGER, em 1994. Uma resina composta do tipo híbrida foi polimerizada na superfície de dentina tratada com Gluma em espessuras de 1, 2, 3 e 5mm, respectivamente, com sete diferentes tempos de ativação da luz (LAT) de 3 a 180 segundos. A resistência adesiva ao cisalhamento dos espécimes foi determinada 10 minutos após o término da ativação da luz. O grau de polimerização da resina próxima a interface da 
dentina foi determinada pela Profundidade de Identação Wallace (WID) dos espécimes polimerizados sob as mesmas condições do teste de resistência adesiva ao cisalhamento, entretanto, separada da superfície de dentina por uma fina placa de vidro. Uma relação consistente foi encontrada para a resistência adesiva (SBS) versus tempo de ativação da luz (LAT) e profundidade da identação (WID) versus tempo de ativação da luz (LAT) pela análise de regressão $(y=A+B / x)$. Quando um molde com uma espessura de $2 \mathrm{~mm}$ foi usado para a condensação da resina composta, a ativação da luz por um tempo maior que $60 \mathrm{~s}$ tinha um efeito insignificante no aumento da SBS e diminuição do WID, respectivamente. Quanto mais longo o tempo de ativação da luz mais alto é o resultado da resistência adesiva (SBS). Essa relação é mais acentuada quanto mais espessa a camada de resina composta que é penetrada pela ativação da luz. Houve uma maior correlação linear entre SBS e WID $(r=-0,93)$, indicando que quanto menor a WID maior é a SBS.

UNO; FINGER, em 1995a, investigaram o efeito do gel condicionante nas diferentes concentrações de ácido fosfórico e variando a quantidade de sílica como espessante na compatibilidade e eficiência na adesão com a dentina quando usados em combinação com Gluma Primer e Sealer. A resistência ao cisalhamento, performance marginal nas cavidades dentinárias e resistência a microinfiltração em cavidades mistas foram usadas como parâmetros para determinar a eficácia do Gluma/Pekafill em dentina pré-tratada com condicionadores de 5, 10, 20 ou 35\% ácido fosfórico e diferentes quantidades de sílica como espessante (0, 5 e 10\%) com duração de 15, 30, 60 ou 120 segundos de aplicação. O espessamento da camada híbrida foi 
determinado ao longo da margem da cavidade dentinária por microscopia óptica. Este estudo mostrou que nem a concentração do ácido fosfórico e a quantidade de sílica como agente espessante para os ácidos em forma de gel, nem o tempo de condicionamento teve um efeito diferente na resistência adesiva ao cisalhamento com a dentina, na performance marginal e na capacidade de selamento do sistema Gluma/resina composta. A quantidade de sílica no condicionador não teve influência na espessura da camada híbrida $(\mathrm{P}<0,05)$. Os autores concluíram que o condicionamento da dentina com ácido fosfórico como pré-tratamento para o adesivo Gluma é altamente efetivo.

Testes de adesão de agentes adesivos dentinários foram revisados por PASHLEY et al., em 1995b. Os autores discutiram os tipos de substratos utilizados para os testes de adesão, o preparo da superfície de dentina, as variáveis envolvidas no condicionamento, aplicação do primer e agente adesivo. O tipo (substância e pressão) e o tempo de estocagem devem ser considerados, pois pode ocorrer uma contaminação da superfície de dentina antes do procedimento adesivo. Os tipos de testes de adesão mais utilizados foram discutidos e o método mais fácil é o de resistência ao cisalhamento, mas há uma forte tendência de ocorrer uma flexão em muitos testes de cisalhamento. A substituição de uma resina composta de alto módulo de elasticidade por uma de mais baixo módulo pode aumentar significantemente a resistência ao cisalhamento. Muitos estudos realizados com o intuito de padronizar estas variáveis foram discutidos pelos autores e dentre estes foi observado um grande número de falhas coesivas em dentina com valores em torno de 25-30 MPa, mas a dentina desmineralizada apresenta uma resistência 
três vezes maior que esta, portanto isso sugere que a distribuição do estresse não é uniforme durante os testes. Um dos novos métodos citado pelos autores é o teste de microtração no qual a área de união é muito pequena e por esta razão este método tende a produzir valores mais altos de resistência de união. A razão para este aumento na resistência de união com diminuição da área da superfície unida é provavelmente devido a presença de defeitos ou estresses na interface unida ou dentro do substrato. Há um número de vantagens e desvantagens do método de microtração. A maior vantagem é que as falhas obtidas podem ser exclusivamente do material se a área de união for em torno de $1 \mathrm{~mm}^{2}$. As desvantagens do método de microtração são que o método é tecnicamente difícil, laborioso sendo que muitas uniões podem falhar durante o preparo do espécime. Os autores concluíram que novos métodos devem ser desenvolvidos para que os resultados sejam confiáveis e que os métodos convencionais não podem ser usados amplamente para detectar uma melhora no desenvolvimento de produtos ou procedimentos de união.

A morfologia interfacial de dois sistemas adesivos em dentina superficial e profunda foi avaliada por YOSHIYAMA et al., em 1995, através de MEV. A resistência adesiva a micro tensão dos sistemas adesivos também foi determinada em dentina superficial e profunda. Foram preparados discos de dentina superficial e profunda no mesmo dente. All-Bond 2 ou Imperva Bond foram aplicados em dentina, condicionada ou não, superficial e profunda e os dois discos foram unidos entre si dentro da configuração da técnica de sanduíche reversa. A análise microscópica revelou que o All-Bond 2 e Imperva Bond aplicados sob condição de condicionamento total formou camadas 
infiltradas por resina mais espessas em dentina profunda(4-8 $\mu \mathrm{m})$ que em dentina superficial $(2-4 \mu \mathrm{m})$. Os adesivos aplicados em dentina não condicionada formaram camadas infiltradas por resina muito finas (menor que $0,5 \mu \mathrm{m})$ em ambos substratos de dentina. A resistência adesiva a micro-tensão do All-Bond 2 e Imperva Bond foram mais que 20MPa independente da profundidade de dentina e não foram significantemente diferentes. Nos espécimes não condicionados, a resistência adesiva de ambos sistemas para dentina profunda foi significantemente mais baixa que para dentina superficial. Os resultados sugeriram que para os sistemas com condicionamento total a dentina profunda afetou a espessura da camada de dentina infiltrada, mas a espessura da camada não tinha uma relação significante com a resistência adesiva a micro-tensão. Os autores afirmaram que a técnica de condicionamento ácido pode evitar a diminuição da resistência adesiva observada em dentina profunda não condicionada.

Com o objetivo de examinar a dentina condicionada e a estrutura da camada híbrida por meio de um microscópio eletrônico de varredura, TITLEY et al., em 1995a, utilizaram terceiros molares superiores e inferiores recém extraídos, e incisivos bovinos extraídos. A dentina foi exposta e os dentes divididos em quatro grupos de dentes humanos e quatro grupos de dentes bovinos para examinar o efeito dos agentes condicionadores e a infiltração dos adesivos. Grupos de oito dentes bovinos por sistema de resina foram preparados e usados no teste de cisalhamento. Para examinar o efeito do condicionamento as superfícies dentinárias foram tratadas com os seguintes materiais: a- ácido fosfórico gel a 35\% por 60 segundos; b- ácido fosfórico gel a 
32\% por 15 segundos; c- ácido fosfórico gel a 10\% por 15 segundos; d- ácido maleico gel 10\% por 15 segundos; e- solução aquosa de ácido maleico a 25\% por 45 segundos; e f- Scotchbond 2 (contém ácido maleico a 2.5\% e HEMA). Para examinar a penetração do adesivo foram aplicadas duas camadas de SBMP, de acordo com instruções do fabricante. Para os testes de cisalhamento, grupos de oito dentes bovinos foram usados para cada material: All/Bond 2, Scotchbond 2, Scotchbond Multipurpose, e Prisma Universal Bond 3. As resinas utilizadas foram Silux Plus e Z100. Os espécimes foram então estocados em água destilada a $37^{\circ} \mathrm{C}$ por um período de 1 dia, sete dias ou 180 dias, depois de cada período, os dentes foram testados. Os dentes foram analisados em MEV. Esta análise mostrou que a aplicação de várias concentrações de ácidos na superfície da dentina removeram a smear layer e produziram vários graus de desmineralização na dentina intertubular e intratubular. O exame dos espécimes naturalmente secos tratados com ácido fosfórico e ácido maleico demostrou uma desmineralização da camada de colágeno colapsada, com isto produzindo uma superfície densa com nenhuma porosidade entre as fibrilas de colágeno. Com base nos resultados, os autores concluíram que o excesso de dessecação da dentina condicionada por ar ou por prolongado período de secagem natural causa um colapso do colágeno da dentina inter e intratubular, a qual resulta em uma aparente redução na porosidade da superfície. Os resultados também sugerem que o grau de colapso existente na zona de interdifusão pode atuar como um impedimento da difusão da resina, independente da molhabilidade que o monômero hidrofílico confira ao colágeno. Essas observações indicam que com os sistemas resinosos examinados por este trabalho, uma interpenetração micromecânica 
de união é estabelecida entre o adesivo e o colágeno da zona de dentina desmineralizada. Embora múltiplas aplicações do primer pareçam aumentar a força de união, encontraram pequenas evidências que sugerem que a molhabilidade do colágeno é aumentada por este processo, desde que não se tenha observado evidências de aumento de penetração do adesivo apesar de um aumento significante na força de união. Como resultado destes achados, os autores questionaram se um extenso grau de desmineralização produzido pela concentração dos ácidos comerciais é necessário, particularmente porque nenhum sistema adesivo testado infiltrou completamente a zona desmineralizada.

TITLEY et al., em 1995b, examinaram in vitro a ultra estrutura e a composição dos tags de resina em dentina, usando o microscópio eletrônico de varredura e um corante vital. Utilizaram terceiros molares humanos extraídos e incisivos bovinos extraídos. A superfície dentinária dos dentes foi exposta para a realização dos testes. Para o tratamento da superfície dentinária utilizaram soluções aquosas de ácido maleico em várias concentrações: 10, 5, 2.5, 1 e 0,5\% e ácido fosfórico em concentrações de 37, 10, 5 e 1\%. Cada ácido foi aplicado por 15 s. e lavados por 30 s. Foram realizados 13 espécimes de dente bovino por grupo sendo que 10 destes foram incluídos em resina. A superfície foi levemente seca, sem provocar ressecamento na dentina e duas de primer do SBMP foram aplicadas de acordo com as instruções do fabricante. Uma fina camada do adesivo do SBMP foi aplicado sobre esta área e a resina Z100 foi condensada por meio de uma matriz cilíndrica. Os dentes restaurados que foram embebidos em cilindros de resina foram estocados em água a $37^{\circ} \mathrm{C}$ por 
24 horas antes do teste de cisalhamento. Os dentes que não foram utilizados foram tratados e restaurados como nos grupos anteriores. Estes três dentes foram preparados para serem examinados pelo MEV. Para o teste de cisalhamento, os dentes foram acoplados em uma Máquina Universal de testes, a ponta do teste foi colocada em contato com a interface dente/resina e a velocidade utilizada foi de $0,5 \mathrm{~mm} /$ minuto e a célula de carga de $50 \mathrm{Kg}$. Depois de avaliados os resultados, os autores concluíram que os tags de resina mostraram resina e glicosaminoglicanas revestindo os túbulos dentinários. A análise no MEV sugeriu três mecanismos de formação de tags de resina, dois dos quais provavelmente se encontre in vivo.

MIEARSS JR.; CHARLTON; HERMESCH, em 1995, avaliaram os efeitos da umidade da dentina e dois tempos diferentes de estocagem na resistência ao cisalhamento, na união entre resina composta e dentina tratada com Scotchbond Multi-Purpose. A superfície de 60 molares humanos extraídos foram reduzidas, promovendo um flat na superfície dentinária, e então foram proporcionalmente divididos em quatro grupos de 15 espécimes cada. Os dentes foram condicionados, lavados, e então ou deixados com a superfície visivelmente úmida ou seca com ar. O primer e adesivo foram aplicados de acordo com as instruções do fabricante e os cilindros de resina composta foram unidos ao dente. Dois dos grupos (um úmido, um seco) foram estocados por 24 horas em água destilada a $37^{\circ} \mathrm{C}$ enquanto os outros dois grupos foram estocados por 90 dias em água destilada à $37^{\circ} \mathrm{C}$. Terminados os períodos de estocagem, os espécimes foram submetidos a um carregamento a 0,5mm/min. Os valores médios da força de união e o desvio padrão foram medidos em 
MPa: dentina seca a 24 horas: $13.30 \pm 5.1$, dentina a 90 dias $13.07 \pm 3.8$, dentina

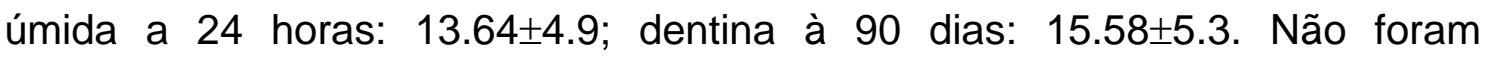
encontradas diferenças estatisticamente significantes para a união entre dentina úmida e seca ou diferentes tempos de estocagem.

ORTEGA, em 1995, avaliaram a resistência adesiva do sistema Scotchbond Multi Uso/Z-100, em esmalte, empregando ácido fosfórico nas concentrações de 37\%, 10\% e ácido maleico a 10\% como condicionadores. Observaram que não houve diferenças estatisticamente significantes na resistência ao cisalhamento entre os grupos onde o ácido fosfórico foi empregado. Entretanto, a utilização do ácido maleico a 10\%, levou a uma significante redução da resistência adesiva em relação aos grupos testados.

Considerando os princípios que regem e controlam as variáveis que geram os estresses desenvolvidos nas interfaces das restaurações de resina composta, CARVALHO et al., em 1996a, por meio de uma revisão da literatura, descreveram os fatores que podem interferir na infiltração da resina adesiva no interior da camada desmineralizada, e a influência desta infiltração na adesão entre o material restaurador e a estrutura dentária. A contração de polimerização sofrida pela resina poderá criar estresses que rompem a união junto às paredes cavitárias e essa competição entre o estresse mecânico sofrido pela polimerização e a união dos adesivos às paredes cavitárias, consiste em uma das principais causas das falhas marginais e subsequente microinfiltração nestas restaurações. Os autores explicaram os efeitos da smear layer e a desidratação da superfície dentária desmineralizada. Relataram que o grau de estresse desenvolvido poderá ser controlado pela 
extensão e configuração da cavidade (fator C), pelo emprego de bases, tamanho, forma e posição dos incrementos do material. Deve ainda ser considerada a natureza química ou fotopolimerizável das resinas compostas, considerando que o tipo de polimerização influencia a capacidade de escoamento do material. As resinas fotopolimerizáveis apresentam polimerização rápida ou imediata, o que permite menor escoamento quando comparadas às resinas de ativação química, por não existir um tempo maior correspondente à fase gel. Teoricamente, quanto menor o escoamento, maior será o estresse gerado durante a contração de polimerização, fator que, pode ser decisivo para o sucesso da restauração. Como conclusão, os autores relatam que os estresses gerados nas resinas compostas e nos agentes de união são bem mais complexos sob condições clínicas. Os altos valores do estresse gerado pela contração de polimerização, resultantes de alguns estudos, cujas cavidades possuem configurações específicas, superaram a força adesiva da resina à dentina esclarecendo talvez o alto e freqüente índice de falhas e de formação de gaps observados em vários estudos utilizando sistemas adesivos. Por outro lado, existem vários fenômenos e procedimentos, relacionados à configuração no emprego de resinas quimicamente ativadas de baixo módulo linear e tempo de sorpção de água, os quais, contribuem para reduzir a contração de polimerização, oferecendo às restaurações melhor qualidade e longevidade.

Durante os procedimentos adesivos restauradores, as superfícies de dentina são tratadas com condicionadores ácidos para remover a smear layer e descalcificar a superfície para expor as fibrilas de colágeno da matriz logo 
abaixo. Estas superfícies descalcificadas são então secas com ar ou tratadas com solventes que desidratam e podem modificar as propriedades físicas da matriz de dentina. MACIEL et al, em 1996, testaram a hipótese de que a desidratação por uma variedade de métodos aumenta o módulo de elasticidade da matriz de dentina descalcificada. Foram utilizados dentes humanos e os espécimes de dentina foram cortados de forma retangular para testar o módulo de elasticidade pela técnica do cantilever. Os $2 \mathrm{~mm}$ finais do espécime foram cobertos com esmalte de unha para protegê-lo da descalcificação. A descalcificação foi feita com uma solução à base de EDTA por 5 dias. A rigidez foi medida pelos métodos cantilever e de tensão convencional. Os espécimes testados pelo método cantilever foram expostos seqüencialmente em água, acetona, álcool, HEMA e glutaraldeído. Os espécimes testados pelo método convencional foram expostos ou a água, acetona ou HEMA ou foram deixados secar ao ar. Os resultados indicaram que a rigidez da matriz de dentina humana descalcificada é muito baixa (7MPa) se os espécimes são lavados com água. Como são desidratados, ou quimicamente em solventes orgânicos miscíveis em água ou fisicamente no ar, a rigidez aumenta 20 a 38- dobras na força baixa ou 3 a 6 dobras na força alta. Estes aumentos no módulo de elasticidade foram rapidamente revertidos pela rehidratação em água. A exposição ao glutaraldeído também produziu um aumento na rigidez que não foi reversível quando os espécimes foram colocados em água.

A melhora na resistência adesiva dos sistemas adesivos simplificados foi estudada por TJAN; CASTELNUOVO; LIU, em 1996. Os autores mediram e compararam a resistência adesiva ao cisalhamento de três pares de sistemas 
adesivos. Os sistemas estudados foram Optibond $\mathrm{x}$ Optibond FL, All-Bond $2 \mathrm{x}$ One-Step e Tenure x Tenure Quik. 60 molares inferiores extraídos foram seccionados perpendicular ao longo eixo do dente $1 \mathrm{~mm}$ acima da junção cemento-esmalte para expor a superfície de dentina. Os espécimes foram divididos em 6 grupos iguais. Todos os sistemas adesivos foram aplicados na superfície de dentina exposta seguindo as recomendações de cada fabricante. Após a aplicação dos sistemas adesivos um cilindro de resina composta com 0,5cm de diâmetro foi unido a cada espécime. Os espécimes foram estocados por 7 dias em água a $37^{\circ} \mathrm{C}$ e termociclados em 300 ciclos de $5^{\circ} \mathrm{C}$ e $55^{\circ} \mathrm{C}$ com uma duração de 30 segundos cada ciclo. Com uma carga de $0,5 \mathrm{~mm} /$ minuto em uma máquina universal os espécimes foram submetidos ao teste de resistência ao cisalhamento. Os resultados indicaram que a conversão de sistemas adesivos de múltiplas etapas para os simplificados foi desvantajoso para o AllBond 2. O aumento na resistência adesiva entre sistemas de várias etapas e simplificados foi observada somente para os sistemas Optibond e Optibond FL com 23,3 MPa e 28,3 MPa, respectivamente. Todos os outros pares testados mostraram uma diminuição na resistência adesiva ao cisalhamento, não sendo estatisticamente significante para os sistemas Tenure/ Tenure Quik. O mais alto valor de resistência adesiva dos sistemas de múltiplas etapas foi obtido pelo All-Bond 2 com 29,5 MPa e para os sistemas de etapa simplificada o maior valor foi de 28,3 MPa para o Optobond FL. Tenure e Tenure Quik mostraram os menores valores de resistência ao cisalhamento com 6,4 MPa e 4,4 MPa, respectivamente. 
A microscopia eletrônica de varredura tem sido utilizada extensivamente para caracterizar o substrato e os mecanismos de união dos sistemas adesivos com a dentina. Durante o preparo dos espécimes para microscopia eletrônica de varredura a secagem é necessário para obter alto vácuo, portanto um método ideal de secagem deve ser utilizado para evitar a contração dos espécimes e preservar suas dimensões originais. CARVALHO et al, em 1996b, avaliaram o efeito de 3 diferentes métodos de secagem na contração dos espécimes de dentina desmineralizadas durante o preparo para microscopia eletrônica de varredura. Discos de dentina medindo aproximadamente $0,7 \times 0,7 \times 5,0 \mathrm{~mm}$ foram preparados de coroas de terceiros molares humanos extraídos. Os espécimes foram desmineralizados em EDTA 0,5M por 3 dias e seu volume medido com um micrometro digital sob um microscópio de dissecação. Os espécimes foram distribuídos em grupos experimentais e quimicamente desidratados em acetona. Os métodos de secagem utilizados foram hexamethyldisilizane (HMDS), Peldri II ou método do ponto crítico. As dimensões dos espécimes foram medidas novamente após cada etapa e as alterações em volume foram expressas como uma porcentagem do volume original desmineralizado. O efeito da fixação dos espécimes em formalina $10 \%$ antes da desidratação com acetona foi também investigado para cada procedimento de secagem. A desidratação em acetona causou uma pequena, mas significante redução no volume dos espécimes desmineralizados fixados em formalina, já nos espécimes não fixados não houve alterações significantes. Em geral, todos os três procedimentos de secagem causaram alguma contração nos espécimes de dentina desmineralizados. Os espécimes não fixados exibiram uma contração 
volumétrica de 15 a 20\% após secagem com qualquer um dos métodos. Os espécimes fixados contraíram mais que os não fixados após a secagem (25 a 35\%). Indiferente a técnica de secagem, os espécimes contraíram ainda 10 a 20\% quando mensurados na câmara à vácuo do MEV. Entre os três métodos de secagem avaliados, o HMDS mostrou ser a alternativa mais útil à secagem em ponto crítico no preparo dos espécimes para análise em MEV.

CARVALHO et al, ainda em 1996c, investigaram as alterações dimensionais na dentina humana após desmineralização. 40 espécimes foram desmineralizadas em solução de ácido cítrico 10\% e cloreto de ferro 3\% por 8 horas. Os espécimes foram divididos em 4 grupos (A,B,C e D) de 10 espécimes cada. Grupos A e B foram usados para verificar as alterações volumétricas após secagem com ar e imersão ou em água ou solução aquosa de $50 \%$ de HEMA ou $100 \%$ de HEMA seguido pela secagem com ar. Grupos C e D foram usados para investigar a habilidade do HEMA $100 \%$ ou etilenoglicol 100\% em prevenir a contração de dentina desmineralizada durante a exposição ao ar. A desmineralização causou uma pequena, mas não significante redução no volume da dentina (1,9\%). A secagem com ar, reduziu o volume da dentina em 65,6\%. Quando desmineralizados, os espécimes contraídos foram imersos em água por 24 horas e recuperaram seu volume original; a imersão em HEMA 100\% não expandiu novamente a matriz de colágeno contraída; a imersão em HEMA 50\% contraiu 50\% quando exposto ao ar por 24 horas. HEMA $100 \%$ e $100 \%$ de etilenoglicol foram efetivos em prevenir a contração da dentina desmineralizada. 
A relação entre o tempo de condicionamento ácido com diferentes ácidos no padrão de condicionamento da dentina foi investigada por UNO; FINGER, em 1996. Os autores estudaram a profundidade de desmineralização na dentina intertubular e a capacidade de expansão das fibrilas de colágeno colapsadas devido a penetração do primer e da resina adesiva. Foram utilizados 2 ácidos comerciais e 4 ácidos experimentais espessados com 5\% $\mathrm{SiO}_{2}$ (porcentagem em peso). Os ácidos experimentais apresentavam concentrações de 5, 10, 20 e 35\% de ácido fosfórico. A profundidade da desmineralização da dentina foi determinada pelo método direto e indireto. No método direto os autores avaliaram a smear layer através de um microsocópio de profundidade antes e após o condicionamento com os diferentes ácidos. A diferença entre a primeira e segunda leitura representou a perda vertical de substância entre o topo da smear layer e a superfície de matriz de colágeno colapsada. No método indireto, a camada híbrida foi avaliada através de um MEV. Neste método, foram testados somente os ácidos experimentais com um tempo de condicionamento de 30 segundos, já o ácido fosfórico $20 \%$ foi testado também nos tempos de 15, 60 ou 120 segundos. Os espécimes para análise indireta receberam a aplicação de um sistema adesivo (primer + resina adesiva) e uma camada de resina composta. Neste método os autores avaliaram a- distância entre a superfície de smear layer original e o topo da camada híbrida; b- espessura da camada híbrida; c- profundidade de desmineralização. A profundidade de desmineralização aumentou tanto para o tempo de condicionamento como para as concentrações numa relação logarítimica. Houve uma boa relação entre os resultados dos procedimentos diretos e indiretos. A média da camada híbrida resultante de diferentes 
concentrações de ácidos após 30 segundos de condicionamento foi 6,2; 8,6; 9,7 e 9,1 1 m para concentrações de 5, 10, 20 e 35\%, respectivamente.

FINGER; UNO, ainda em 1996, investigaram os efeitos dos componentes ativos do Gluma Primer, que contém 5\% de glutaraldeído e 35\% de HEMA, ou dissolvido em água ou acetona na resistência de união e adaptação da margem da cavidade quando usados em dentina molhada ou seca, respectivamente. Os espécimes foram aplainados em papel de carbeto de silício de granulação 240 até 600 para expor uma área de dentina suficiente para união do cilindro restaurador com 3,5mm de diâmetro. Os dentes foram condicionados com ácido fosfórico $20 \%$ por 30 s. e lavados com água deionizada por 30 seg. Foram utilizadas 4 técnicas para aplicação dos sistemas adesivos: 1- técnica úmida ( o excesso de água removido com bolinha de algodão); 2- técnica convencional (ar comprimido por 2 s.); 3- técnica seca (ar comprimido por 10 s.); 4- técnica do remolhamento (após secagem por 10 seg. a dentina foi remolhada por $30 \mathrm{seg}$. e o excesso removido com bolinha de algodão). Os primers foram aplicados por 20 s., secos e a resina de união Gluma Sealer foi aplicada e fotoativada por 20 s. As restaurações foram realizadas e após 24 horas em água deionizada, os espécimes foram submetidos ao teste de cisalhamento em uma máquina universal com uma velocidade de deslocamento de $1 \mathrm{~mm} /$ minuto. Foram preparados 5 espécimes para cada uma das 8 condições testadas. O desempenho marginal foi determinado em restaurações realizadas em dentina na superfície proximal sendo 6 restaurações por grupo. A inspeção das margens foi realizada em um microscópio óptico com um aumento de 500x. A resistência de união dos 
grupos preparados pela técnica úmida foi aproximadamente 18MPa, independente do solvente do primer. A técnica convencional proporcionou uma resitência de união quase tão alta $(16,5 \mathrm{MPa})$ e a técnica do remolhamento foi altamente efetiva com os dois solventes estudados. A técnica seca mostrou uma resistência de união moderada para o primer dissolvido em água e pobre em acetona. As margens das cavidades dos espécimes tratados com primer à base de acetona não apresentaram gaps com a técnica úmida. Os outros 7 grupos mostraram entre 2 e 6 "aps em cada grupo dos 6 espécimes. Os autores concluíram que a acetona é um excelente solvente e uma boa alternativa para a água que é usada na solução Gluma Primer original. A acetona tem a vantagem de evaporar mais rapidamente que a água, portanto facilita a utilização do sistema gluma e garante uma união eficiente.

A interface resina/dentina formada por dois adesivos, Optibond e Scotchbond Multipurpose (SBMP), foram ultramorfologicamente examinadas por um microscópio de transmissão (TEM) por VAN MEERBEEK et al., em 1996. A informação ultraestrutural das secções não desmineralizadas e desmineralizadas foram correlacionadas. Foi hipotetizado que a diferença na formulação química dos dois adesivos poderia resultar em uma diferente aparência morfológica da camada híbrida. O exame da ultraestrutura pelo TEM provou que cada um dos dois sistemas adesivos foi capaz de estabelecer uma união micromecânica entre dentina e resina com a formação de uma camada híbrida. O Optibond apresentou uma camada híbrida com uma ultraestrutura relativamente uniforme, e ácido resistente. Estes três parâmetros foram encontrados com mais variáveis na camada híbrida formada pelo SBMP. Uma 
característica do SBMP foi a identificação de uma fase amorfa depositada na superfície externa da camada híbrida. Ambos os adesivos testados utilizam o conceito do condicionamento total, suas formulações químicas específicas resultam em diferenças na ultraestrutura interfacial que provavelmente promove diferentes mecanismos de interligação adesiva. Os autores relataram, porém que a significância clínica destes achados morfológicos ainda eram desconhecidos.

Muitos investigadores têm realizado uma variedade de pesquisas para determinar as propriedades da avaliação dos sistemas adesivos dentinários. Os métodos as variáveis dos testes utilizadas em 50 artigos publicados de resistência de união foram analisadas por AL-SALEHI; BURKE, em 1997. Entre os trabalhos analisados, os testes de cisalhamento predominaram sendo utilizados em $80 \%$ dos estudos. Superfícies de dentina de molares humanos foram os substratos eleitos na maioria das vezes ( $88 \%$ das investigações). O tempo de estocagem dos espécimes que predominou, antes dos testes de resistência de união, foi de 24 horas. Entretanto, um número de variáveis não foram registrados em um grande número de artigos, entre estes a espessura do filme, o tipo de dentina testada e a condição da superfície (molhada, úmida ou seca). O modo de falha foi registrado em somente $42 \%$ das investigações acessadas. Os autores concluíram que há pouca padronização dos métodos dos testes em estudos de resistência de união à dentina e que o número de variáveis são muitas vezes não relatados ou registrados.

ARAÚJO; ASMUSSEN, em 1997, investigaram o agente Gluma, nos sistemas adesivos, quando aplicados com superfície de dentina seca, úmida e 
molhada. Na tentativa de aumentar a efetividade do sistema, o pré-tratamento tradicional por EDTA foi substituído pelo ácido fosfórico e o primer Gluma foi modificado por meio de água ou acetona. O sistema Gluma envolve o uso consecutivo de 1) um condicionador; 2) um primer e 3) uma resina adesiva antes da aplicação da resina composta. Os condicionadores utilizados foram baseados em ácido fosfórico ou em EDTA. A resistência adesiva com a dentina foi medida em dentes humanos extraídos que foram incluídos em resina epóxi. As superfícies de dentina foram obtidas pelo desgaste com lixas de crescentes granulações até a 1000, no estágio final. As superfícies de dentina foram lavadas, secas com jato de ar e então condicionadas. Após a lavagem por 15 segundos, a dentina foi mantida: 1) seca (secagem com ar por 10 segundos); 2) úmida (dentina pressionada com papel absorvente); 3) molhada (remoção da água com bolinha de algodão úmida). Foi aplicado sobre a superfície o primer Gluma 3 ou um dos primers mostrados na TABELA 4. Após 30 segundos o excesso de primer foi removido com jato de ar. Um molde de teflon foi adaptado à superfície de dentina e o gluma 4 Sealer foi aplicado, a resina composta Pekafill condensada no interior do molde e polimerizada por 60 segundos. Os espécimes foram estocados em água por 24 horas e levados a uma máquina de testes Universal Instron para o teste de resistência adesiva ao cisalhamento com uma velocidade de deslocamento de $0,5 \mathrm{~mm} / \mathrm{min}$. Foram registrados valores de resistência ao cisalhamento entre 12 e 22MPa. Os autores afirmam que um discreto umedecimento da dentina melhora 0 desempenho do adesivo Gluma, mas o excesso de umidade pode diminuir os valores de resistência ao cisalhamento em até $25 \%$. 
TABELA 4: Primers experimentais. Composição em peso\%. (ARAÚJO; ASMUSSEN, 1997).

\begin{tabular}{|c|c|c|c|c|}
\hline PRIMER & HEMA & Glutaraldeído & Água & Acetona \\
\hline $\mathrm{a}-1$ & 64 & 9 & 27 & 0 \\
\hline $\mathrm{a}-2$ & 32 & 4,5 & 13,5 & 50 \\
\hline $\mathrm{b}-1$ & 50 & 7 & 43 & 0 \\
\hline $\mathrm{b}-2$ & 25 & 3.5 & 21,5 & 50 \\
\hline $\mathrm{c}-1$ & 42 & 6 & 52 & 0 \\
\hline $\mathrm{c}-2$ & 21 & 3 & 26 & 50 \\
\hline $\mathrm{d}-1$ & 35 & 5 & 60 & 0 \\
\hline $\mathrm{d}-2$ & 17,5 & 2,5 & 30 & 50 \\
\hline
\end{tabular}

PASHLEY; CARVALHO, em 1997, revisaram a literatura com o propósito de discorrer sobre a relação existente entre a permeabilidade dentinária e a difusão dos agentes adesivos, indicando a importância das características estrutural e morfológica da dentina na criação de uma engrenagem mecânica ou camada híbrida e a influência dos procedimentos adesivos. Tanto a permeabilidade intratubular como a intertubular na dentina condicionada foram por eles consideradas indispensáveis para que a resina pudesse penetrar os túbulos e a rede de fibrilas de colágeno expostas. Secar com ar é um procedimento que tem sido sempre usado, mas que pode produzir um efeito adesivo sobre esta permeabilidade devido à contração da rede de fibrilas de colágeno expostas, aumentando a rigidez das mesmas, diminuindo as dimensões dos espaços interfibrilares (porosidades) e, assim comprometendo a completa e adequada interpretação dos agentes adesivos para formar a zona de dentina impregnada de resina, manisfestaram, portanto, 
a importância de reumedecer a dentina desidratada com ar ou deixá-la visivelmente úmida antes da aplicação do primer. A presença de água permite a manutenção das fibrilas de colágeno expandidas e uma melhor atuação dos agentes primers hidrofílicos. Acreditam também que o uso de um sistema que seja condicionador e primer ao mesmo tempo daria resposta às complicações dos sistemas com procedimentos separados.

Em 1997, CHAN et al., avaliaram a resistência ao cisalhamento da união resina/dentina bovina por um período curto (24 horas) e longo (180 dias) período de estocagem, a dentina foi condicionada com várias diluições de soluções aquosas de ácido fosfórico (1.0; 5.0; 10.0 e 37.0\%) e ácido maleico $(0.5 ; 1.0 ; 2.5 ; 5.0$ e $10.0 \%)$ e ácido maleico a $10.0 \%$ em forma de gel. A superfície da dentina foi preparada usando disco de papel com granulação 600 irrigada com água. A superfície da dentina foi condicionada em grupos de 10 dentes usando as várias diluições do ácido fosfórico e maleico. Foi utilizado o sistema Scotchbond Multipurpose aplicado em superfície úmida, o primer e o adesivo foram aplicados sobre a superfície da dentina confinados ao cilindro de gelatina. Um cilindro de resina Z100 foi então fotoativado e os espécimes foram então estocados em água por 24 horas ou 180 dias antes do teste de cisalhamento. Os resultados mostraram que uma alta força de união foi conseguida usando ácidos mais diluídos do que os comercialmente avaliados. Indicaram também que o ácido fosfórico não é o ácido de escolha para o sistema SBMP, e que o ácido maleico parece ser o condicionador de escolha para o sistema SBMP. 
Em 1997, CAGIDIACO; FERRARI; DAVIDSON investigaram as diferenças entre a dentina condicionada com ácido orgânico e inorgânico, em condições clínicas e laboratoriais. Para o teste in vitro utilizaram 16 dentes anteriores extraídos por problema periodontal. Cavidades cilíndricas com diâmetro de $3 \mathrm{~mm}$ e profundidade de $2 \mathrm{~mm}$ foram confeccionadas e divididas em 2 grupos. O grupo 1 foi condicionado com ácido fosfórico em gel a 36\% por 15 segundos e lavados por 20 segundos. As amostras foram secas e fixadas com solução de formaldeído a $10 \%$ por 12 horas, e então fraturadas ao meio seguindo o longo eixo dos dentes na superfície lingual com instrumento manual. O grupo 2 seguiu os mesmos passos do grupo 1 com exceção do ácido, que neste grupo utilizaram a solução aquosa de ácido maleico a 10\%. Para o teste in vivo os autores utilizaram 8 dentes anteriores com sérios problemas periodontais indicados para extração, entretanto com vitalidade pulpar. As mesmas etapas do teste in vitro foram seguidas para os testes in vivo. O Grupo 3 foi condicionado como o Grupo 1; e o Grupo 4 como o Grupo 2. Depois foram cuidadosamente extraídos e tratados como nas amostras in vitro. As amostras foram examinadas e comparadas por meio de um microscópio eletrônico de varredura. Depois de observadas as fotomicrografias os autores concluíram que os dois condicionadores ácidos são similarmente efetivos na completa remoção da smear layer e na desmineralização da dentina, proporcionando porosidades na rede de fibrilas de colágeno; o condicionamento in vitro e in vivo produz dentina micromorfologicamente similares e que o ácido fosfórico a $36 \%$ e ácido maleico a $10 \%$ foram similarmente efetivos na desmineralização dentinária. 
MATOS et al., em 1997, verificaram a ação de soluções ácidas na superfície dentinária, assim como avaliaram e mediram a extensão da desmineralização em profundidade, usando microscopia eletrônica (MEV). Discos de dentina de $3 \mathrm{~mm}$ de espessura foram obtidos do terço médio de terceiros molares humanos extraídos. Todos os discos de dentina foram preparados com ponta diamantada para formação da smear layer. Em seguida foram aplicados vários ácidos sobre a superfície da dentina. Em um grupo utilizaram ácido fosfórico à 10\% e nos outros à 35\% e 37.5\%, e em outro ácido maleico a 10\%, por 15 segundos, lavados e secos. O grupo controle não recebeu tratamento algum. Os discos de dentina foram então fraturados, observados na superfície horizontal e também na superfície fraturada para avaliar a profundidade da desmineralização. Os espécimes foram imersos em 4\% de glutaraldeído fosfonado, e preparados para exame em MEV a 2000 vezes e 4000 vezes de aumento. Fotomicrografias foram realizadas para analisar a superfície horizontal da remoção da smear layer e a superfície fraturada para observar a profundidade da desmineralização. Depois de analisar as fotomicrografias os autores observaram que ocorreu a remoção da smear layer e a desmineralização e abertura dos túbulos dentinários com todas as concentrações de ácido fosfórico testadas, mas com o ácido maleico a 10\% ocorreu somente a remoção superficial da smear layer. O maior grau de desmineralização foi encontrado com o ácido fosfórico na concentração de $10 \%$ e $35 \%$ e uma menor desmineralização com 37,5\%, encontrando uma

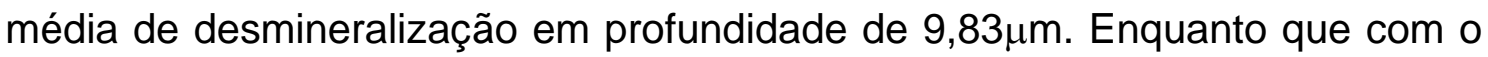
ácido maleico ocorreu a remoção da smear layer, mas não do smear plug, portanto não desmineralizando a dentina em profundidade. 
GOES et al., em 1998, compararam as mudanças micromorfológicas na superfície de esmalte e dentina depois do condicionamento por 15 ou 60 segundos com ácido fosfórico à 35\% e 10\%, e ácido maleico a 10\%, todos em forma de gel. 36 molares humanos extraídos foram utilizados, todos com a face vestibular hígida. As raízes dos dentes foram removidas e cada coroa foi montada horizontalmente com a face vestibular exposta. Os espécimes foram então divididos em dois grupos (Grupo I- esmalte e Grupo II= dentina) com 18 dentes cada grupo. Estes dentes foram então divididos dentro de 3 subgrupos de 6 dentes cada, baseados no tipo e concentração do ácido usado e o tempo de aplicação. A superfície do esmalte e dentina receberam os seguintes tratamentos: ácido fosfórico à 35\%; ácido fosfórico à 10\% e ácido maleico a 10\%. Os condicionadores foram aplicados por 15 e 60 segundos. Depois de condicionados os espécimes foram lavados com água destilada por 15 segundos e secos com ar por mais 15 segundos. A seguir os espécimes foram preparados para serem analisados ao microscópio eletrônico de varredura. Fotomicrografias foram então realizadas para as observações e comparações. Observaram que todas as superfícies condicionadas (esmalte e dentina) sofreram mudanças micromorfológicas independente do tipo do ácido, tempo e concentrações do condicionador. A superfície do esmalte atacado com ácido fosfórico $35 \%$ e $10 \%$ por 15 e 60 segundos mostraram padrão de condicionamento similar. Os corpos dos prismas foram preferencialmente removidos deixando a periferia dos prismas relativamente intactos, o mesmo acontecendo na superfície da dentina. O ácido maleico a 10\% necessita de um tempo maior de condicionamento para promover retentividade no esmalte. E o mesmo ácido na dentina revelou resíduos de smear layer na superfície depois 
de 15 ou 60 segundos de aplicação, provavelmente porque o ácido é orgânico e tem alto peso molecular o que requer um tempo maior para reação na superfície da dentina.

TAY; GWINNETT; WEI, em 1998, investigaram a ultraestrutura da interface dentina/resina quando sistemas de dois frascos contendo NTGMA (Np-tolyl- glicina glicedil metacrilato) no primer e BPDM (bifenil dimetacrilato) foram usados com diferentes concentrações de água como uma parte do solvente do primer: (1) uma versão experimental do All Bond 2 com nenhuma água no primer A; (2) uma versão comercial do All Bond 2 com 5\% de água no primer A; (3) uma versão do All Bond 2 com 17\% de água no primer A. 36 discos de dentina com $1 \mathrm{~mm}$ de espessura foram condicionados com ácido fosfórico $10 \%$ por 20 s e lavados por 20s. Eles foram divididos em 3 grupos sendo o A condicionado e a superfície seca por 30s; Grupo B secagem por 3 s; Grupo C secagem com ar até que a dentina ainda se mantivesse visivelmente úmida. As três categorias de primers foram aplicadas para cada disco de dentina em 8 a 10 camadas, resultando em nove subgrupos. Discos de cada subgrupo foram unidos para formar pares de discos usando uma resina quimicamente polimerizada. Os discos foram preparados para análise em TEM. Com o uso da versão primer livre de água, hibridização abaixo do ótimo foi observada sempre que a dentina foi seca antes da união (Grupos 1A e 1B). Na versão 5\% de água, uma dissecação prolongada resultou em uma hibridização comprometida (Grupo 2A), enquanto glóbulos de resina foram observados na superfície da camada híbrida quando a técnica úmida foi utilizada (Grupo 2C). Na versão $17 \%$ de água, uma superfície com característica globular pôde ser 
observada, como ocorre no fenômeno do sobre molhamento (Grupos 3B e 3C). Entre os dois extremos de espectro morfológico de condições de união, as diferentes versões de primers exibiram diferentes limites de sensibilidade. Houve uma mudança na "janela da oportunidade" para ótima hibridização e selamento tubular, dependendo da quantidade de água no primer investigado.

Diferentes sistemas adesivos foram analisados, através do MEV, quanto à formação de tags, profundidade de descalcificação e camada híbrida por YOUSSEF et al, em 1998. Foram utilizados 20 pré-molares íntegros que foram divididos em 4 grupos. As superfícies de dentina foram preparadas, segundo as recomendações dos fabricantes com 4 diferentes sistemas: Scotchbond Multipurpose, Super D-Liner II, Prime \& Bond 2.1, Clearfil Liner Bond 2. Após a aplicação dos adesivos os espécimes foram restaurados com resina composta, seccionados ao meio e preparados com ácido cítrico 85\% para análise no MEV. Os três primeiros sistemas apresentaram tags longos e camadas híbridas relativamente grossas quando comparados com Clearfil Liner Bond 2. Os autores afirmaram que o mais importante é qualidade da camada híbrida e não a quantidade (espessura). Baseados nos resultados obtidos as conclusões foram: 1- Os sistemas adesivos que utilizam condicionamento ácido com concentrações elevadas promovem uma descalcificação relativamente profunda, tanto que a camada híbrida apresenta-se grossa quando comparada à daqueles que não possuem ataque ácido (Clearfil Liner Bond 2); 2- embora a MEV mostre tags extremamente longos parece aceitável na literatura o fato destas estruturas influenciarem muito pouco na força de adesão dos sistemas adesivos em geral; 3- a formação de tags longos é conseqüência da limpeza e 
lisura da superfície causada pelo condicionamento ácido, que permite melhor escoamento do adesivo para o interior dos túbulos dentinários.

No estudo realizado por COLI et al., em 1999, o objetivo foi definir a morfologia e a rugosidade da dentina em diferentes áreas do dente após vários condicionamentos para identificar o efeito da camada híbrida, dos tags de resina e a superfície de dentina mineralizada na resistência ao cisalhamento. Foram utilizados 38 molares humanos extraídos, sendo que cada um foi dividido em duas regiões de dentina, cervical e oclusal. Foram realizados 5 condicionamentos: 1- 0,2\% EDTA; 2- abrasão com partículas de óxido de alumínio e 0,2\% EDTA; 3- ácido fosfórico 10\%; 4- ácido fosfórico 10\% e imersão em solução de colagenase; 5- nenhum tratamento (grupo controle). Foram unidos ao espécime com o sistema adesivo All Bond 2 cilindros de resina composta e então os espécimes foram submetidos ao teste de resistência ao cisalhamento. Outros 12 espécimes de cada grupo foram analisados através de um perfilômetro e um microscópio de força atômica, e 4 foram examinados em MEV. As médias dos valores de resistência ao cisalhamento em MPa, em dentina cervical, dos diferentes grupos foram: 1$8,36 \pm 4,23 ; 2-6,05 \pm 3,62 ; 3-6,87 \pm 3,45 ; 4-13,30 \pm 5,45 ; 5-4,10 \pm 1,54$. Os valores médios da resistência ao cisalhamento em dentina lateral foram: 1$8,77 \pm 3,68 ; 2-8,39 \pm 4,60 ; 3-9,00 \pm 5,62 ; 4-8,44 \pm 4,47 ; 5-6,09 \pm 4,34$. Dentro dos tratamentos realizados não houve diferença significante quando as regiões dos dentes foram comparadas exceto para o grupo 4. Os tratamentos realizados em dentina lateral não apresentaram diferenças quando comparados entre si. Em dentina cervical houve diferença significante na 
resistência adesiva quando os tratamentos foram comparados, onde 1 diferiu de $5 ; 3$ de 5 e 4 de 1,2,3 e 5. Um aumento na rugosidade superficial da dentina foi encontrada no grupo 4. A resistência ao cisalhamento com a dentina não mostrou depender da formação da camada híbrida.

Muitos trabalhos sugerem que restaurações de resina composta aderida em dentina esclerótica ou velha exibem um alto número de falhas clínicas. PRATI et al., em 1999, avaliaram a morfologia dos tags de resina e a camada de dentina infiltrada por resina de cinco sistemas adesivos em dentina humana superficial e profunda de dentes jovens, escleróticos e velhos. A dentina foi obtida após a remoção do esmalte oclusal dos molares extraídos. Os discos de dentina foram condicionados com ácido fosfórico 35 ou 36\% por 25 segundos, usando o ácido gel recomendado pelo fabricante dos sistemas adesivos. Os discos de dentina foram então restaurados com 5 sistemas adesivos (OptiBond FL; Prime\&Bond 2.0; Scotchbond Multi-Purpose Plus; Scotchbond 1; One Step) e secionados em duas metades sendo que cada metade continha camada de dentina superficial e profunda. Metade dos espécimes foi polida usando um procedimento padrão para avaliar a espessura da camada de dentina infiltrada por resina e morfologia pelo MEV. A outra metade foi desmineralizada e desproteinizada para avaliar a presença e a morfologia dos tags de resina. A camada de dentina infiltrada por resina foi mais espessa em dentina profunda que em dentina superficial em todos os 5 grupos de materiais. Prime \& Bond 2.0 teve a camada de resina infiltrada mais espessa em dentina profunda de dentes jovens $(4,0$ a $9,0 \mu \mathrm{m})$, o qual exibiu uma morfologia granular, mas sem irregularidades ou bolhas ao longo da 
interface dentina/resina. Os espécimes de dentina esclerótica e velha mostraram uma camada de dentina infiltrada mais fina, com tags de resina mais curtos e menos ramos laterais que a dentina normal.

FRITZ; FINGER, em 1999, compararam o desempenho do sistema adesivo ETCH \& PRIME 3.0 (EP3) de etapa única com a efetividade de 2 sistemas adesivos comerciais de duas etapas, Clearfil Liner Bond 2 (CL2), um primer auto-condicionante usado em combinação com uma resina adesiva e Gluma One Bond (GL1), uma mistura de primer à base de acetona e resinas adesivas o qual é aplicado em esmalte e dentina condicionados com ácido fosfórico. A resistência de união ao cisalhamento após estocagem em água por $24 \mathrm{~h}$ foi determinada por 10 espécimes cada unidos com os três adesivos. Foram propostas 3 técnicas de utilização do sistema EP3: 1- após a mistura o adesivo foi aplicado em esmalte ou dentina por 30 segundos e polimerizado por 10 segundos; 2- mesma aplicação, mas polimerizado por 20 segundos; 3dupla aplicação e polimerização do EP3. A largura máxima da interface foi registrada ao longo das margens das restaurações de resina composta unidas com cada adesivo em cavidades cilíndricas em dentina. A resistência de união do EP3 foi similar com a dos outros sistemas, mas a resistência de união com a dentina foi aproximadamente $50 \%$ somente da resistência de união dos outros dois adesivos. A margem das restaurações de resina unidas com o sistema EP3 em dentina foi pobre independente da condição de polimerização testada com EP3. CL2 mostrou interfaces significantemente menores ao longo da margem da cavidade e no grupo GL1 7 de 10 restaurações analisadas apresentaram margens perfeitas. Uma investigação por MEV a cada passo de 
aplicação do EP3 confirmou que o produto molha efetivamente o esmalte e dentina e que uma camada híbrida com espessura de aproximadamente $5 \mu \mathrm{m}$ é formada como uma zona de ligação entre dentina (intertubular e peritubular) e resina restauradora.

Em 1999, BENDERLI; YÜCEL compararam quatro ácidos, com dois tempos de aplicação cada e o seu efeito na resistência à tração de uma resina composta. Utilizaram terceiros molares recém extraídos e armazenados em solução salina a $4^{\circ} \mathrm{C}$ por um tempo de três semanas. Os dentes foram seccionados em 3 partes e o terço central foi utilizado para os testes. Este disco de dentina foi ainda dividido em 4 partes iguais e cada parte foi desgastada, até se obter um disco de dentina de $3 \mathrm{~mm}$ de altura e $5 \mathrm{~mm}$ de diâmetro. Quatro diferentes ácidos foram aplicados passivamente em cada porção de dentina exposta (ácido fosfórico/ ácido maleico; Na- EDTA; ácido cítrico ), e dois tempos diferentes (15 e 60 segundos). O adesivo dentinário utilizado foi o Prisma Universal Bond 2 e a resina logo a seguir foi a Heliolux. Depois de prontos os espécimes foram armazenados em água destilada a $37^{\circ} \mathrm{C}$ por uma semana. O grupo controle recebeu os mesmos procedimentos com exceção da aplicação do ácido. Passado o período de estocagem, os espécimes foram levados até a máquina de testes Universal e a resistência a tração foi medida em uma velocidade de $1 \mathrm{~mm} /$ minuto, e o resultado expresso em MPa. O ácido fosfórico aplicado por 15 segundos obteve uma resistência de $129 \mathrm{MPa}$, e com 60 segundos, $63 \mathrm{MPa}$; o ácido maleico com 15 segundos de aplicação $90 \mathrm{MPa}$, com 60 segundos, 149MPa; o Na -EDTA com 15 segundos, $58 \mathrm{MPa}$; com 60 segundos, $69 \mathrm{MPa}$; o ácido cítrico com 15 
segundos obteve uma resistência de $196 \mathrm{MPa}$ e com 60 segundos, $56 \mathrm{MPa} / \mathrm{e}$ o grupo controle $57 \mathrm{MPa}$. Analisando os resultados, os autores concluíram que: a aplicação de ácidos fortes (ácido cítrico ou fosfórico) na superfície de dentina por 15 segundos, originaram valores de união significantemente maiores que com a aplicação de 60 segundos; a utilização de ácidos fracos (maleico ou Na EDTA) na dentina por 15 segundos diminuiu significantemente os valores de adesão comparados com 60 segundos de aplicação; os maiores valores de adesão foram obtidos com a aplicação do ácido maleico por 60 segundos ou ácido fosfórico por 15 segundos ou ácido cítrico por 15 segundos; e que o aumento do tempo de aplicação resultou em um aumento significante de união para os ácidos fracos mas uma diminuição significante para ácidos fortes.

SCHILKE et al., em 1999, determinaram a resistência adesiva ao cisalhamento do sistema resina composta/adesivo dentinário com dentina humana de dentes decíduos, permanentes, dentina de coroas e raízes de dentes bovinos. Além disso, a influência da profundidade da dentina na resistência adesiva. Foram utilizados para este estudo 30 terceiros molares não irrompidos, 30 primeiros e segundos molares decíduos e 30 dentes bovinos. Os dentes bovinos foram seccionados na junção cemento-esmalte. Os dentes humanos e as raízes e coroas dos dentes bovinos foram seccionados no sentido mésio-distal. As raízes dos dentes humanos e a porção lingual foram descartadas. As metades vestibulares de todas as coroas e as raízes dos dentes bovinos foram incluídas em resina acrílica e após a polimerização foram polidas com lixas d'água de granulação 600. A dentina foi então reduzida a uma espessura de $1 \pm 0,01 \mathrm{~mm}$, sendo um disco com a porção vestibular e 
pulpar (dentina profunda). Um adesivo dentinário e uma resina composta foram aplicados seguindo as instruções fornecidas pelo fabricante em cada superfície vestibular e pulpar, exceto para os dentes decíduos onde somente a superfície vestibular foi utilizada. A resistência adesiva ao cisalhamento foi determinada após 24 horas de estocagem em solução aquosa. A resistência adesiva mais baixa foi encontrada em dentes decíduos humanos (média=7,7 $\pm 5,0 \mathrm{MPa}$ ). $\mathrm{O}$ valor mais alto de resistência ao cisalhamento foi encontrado em dentina radicular de dentes bovinos. A média foi 18,0 \pm 8,5MPa para a superfície pulpar e 17,4 $\pm 8,3 \mathrm{MPa}$ para a superfície vestibular. Ainda que a resistência adesiva foi mais baixa em dentina superficial que profunda não houve diferença estatisticamente significante entre superfície vestibular e pulpar dentro de cada grupo. Além disso, nenhuma diferença foi notada quando dentes humanos permanentes foram comparados com dentina coronária de dentes bovinos. Diferenças significantes foram encontradas entre dentina de raiz bovina e dentina de dentes humanos decíduos $(p<0.001)$. A resistência adesiva ao cisalhamento de coroas de dentes bovinos indicou que este substrato pode ser usado como um substituto para dentina permanente humana em estudos utilizando agentes adesivos dentinários. Nem dentina permanente humana, nem raiz ou coroa de dentes bovinos mostraram ser um substituto viável para dentina de dentes decíduos em testes de resistência adesiva ao cisalhamento. Segundo os autores, quando for utilizar dentes bovinos para testes de resistência adesiva é mais provável obter sucesso utilizando a porção coronária ao invés da raiz, pois a dentina radicular pode levar a resultados diferentes estatisticamente. 
O principal objetivo do estudo realizado por TOLEDANO et al., em 1999, foi determinar se a remoção das fibrilas de colágeno resultaria em modificações na molhabilidade e rugosidade da dentina Para determinar as alterações na molhabilidade de superfície de dentina os autores observaram o ângulo de contato. Foram utilizados 20 terceiros molares livres de cárie que foram divididos em 2 grupos. Na superfície de dentina foi medido o ângulo de contato de 10 gotas de água deionizada colocadas com uma micropipeta na dentina. Foi realizado o ataque com ácido fosfórico 35\% por 15 segundos e lavagem por 10 segundos. Outras 10 gotas de água deionizada foram colocadas na dentina condicionada e o ângulo de contato mensurado. Uma gota de primer foi colocada, e novamente medido o ângulo de contato. No grupo 2 foi medido o ângulo de contato da dentina desproteinizada, após a leitura do ângulo de contato do ataque ácido a dentina foi molhada com $\mathrm{NaOCl}$ 5\% por 2 minutos, irrigada por 10 segundos e com 10 gotas de água foram realizadas as medidas. A partir daí foram realizadas as mesmas leituras, mas em dentina profunda após o seccionamento do espécime. As médias da rugosidade foram realizadas em dentina superficial e profunda antes e após o ácido, e após a desproteinização com um perfilômetro. O ataque ácido resultou em um aumento na molhabilidade da dentina devido a um aumento na rugosidade de superfície da dentina e abertura e alargamento dos túbulos dentinários. A desproteinização da dentina atacada aumentou sua molhabilidade, mas não na rugosidade. Para a dentina profunda, a remoção do colágeno não influenciou na média da rugosidade, mas resultou em um aumento significante no grau de molhabilidade. O grau de molhabilidade da 
dentina profunda foi maior que para dentina superficial devido às diferenças morfológicas e químicas.

PERDIGÃo et al,, em 2000, determinaram o efeito de condicionadores com base em ácido fosfórico na resistência ao cisalhamento da dentina com três sistemas adesivos e avaliaram a ultramorfologia interfacial correspondente. A hipótese nula a ser testada foi que nenhuma correlação pode ser estabelecida entre a profundidade de desmineralização e a resistência ao cisalhamento. Os sistemas adesivos utilizados foram OptiBond SOLO, Permaquick PQ1 e Single Bond. Para cada sistema adesivo os espécimes foram divididos em três subgrupos de diferentes ácidos fosfórico em gel comerciais espessados com sílica: 37,5\% (Kerr Gel Etchant), 35\% (Ultraetch) e 35\% (Scotchbond Etching Gel). Após 24 horas em água a $37^{\circ} \mathrm{C}$, os espécimes foram termociclados e levados à máquina de ensaio para o teste de resistência ao cisalhamento. Os dados foram analisados com ANOVA a um e dois critérios. Não houve diferença significante entre as médias de resistência ao cisalhamento. Quando as médias de sistemas adesivos foram combinadas para cada ácido, o número de falhas coesivas foi maior para Permaquick PQ1 e para Ultraetch, respectivamente. Não houve correlação entre espessura da camada híbrida e resistência de união. A análise em TEM mostrou que todos os materiais penetraram a dentina e formaram camada híbrida, independente do ácido gel utilizado. Os autores sugerem que estudos devem ser concentrados no efeito de diferentes condicionadores nas características físicas da camada híbrida. 
Em 2001, RITTER; BERTOLI; SWIFT JR, avaliaram o efeito da inclusão do glutaraldeído na resistência adesiva ao cisalhamento de adesivos à base de etanol (Gluma Comfort Bond \& Desensitizer - GCBD e Gluma Comfort Bond- GCB) e à base de acetona (Gluma One Bond -GOB) e um adesivo convencional de três etapas como controle (Scotchbond Multipurpose- SBMP). 40 incisivos bovinos foram incluídos em resina acrílica, polidos com papel de carbeto de silício \#600 e divididos em 4 grupos. As superfícies de dentina foram condicionadas com ácido fosfórico 35\%, lavados e levemente secos. Após a aplicação e polimerização dos adesivos, as restaurações com a resina composta Charisma foram realizadas com o auxílio de cápsulas de gelatina \#5 e então fotoativadas. Os espécimes foram submetidos ao teste de resistência ao cisalhamento em uma máquina Instron a uma velocidade de deslocamento de $0,5 \mathrm{~mm} /$ minuto. O teste de ANOVA mostrou diferenças estatisticamente significantes $(p<0,01)$, então o teste de Tukey para comparações pareadas. Os valores médios de resistência de união ficaram entre $8 \mathrm{MPa}$ para GOB e 17,7 MPa para SBMP. O mais alto valor de resistência de adesiva foi obtido com SBMP (25MPa), e a média mais alta para os sistemas adesivos Gluma foi obtida com GCBD (14MPa). Todas as falhas ocorreram na interface adesiva (falha adesiva), exceto para o grupo controle SBMP, onde 50\% das falhas foram coesivas em dentina $(n=5), 10 \%$ foram mistas e $40 \%$ foram adesivas. Interessantemente, as cinco falhas coesivas em dentina observadas no sistema SBMP corresponderam aos 5 valores mais altos para este adesivo.

Uma possível técnica para otimizar a infiltração de monômeros resinosos e subseqüentemente criar adesão mais forte e estável é prolongando 
o seu tempo de difusão. El-Din; El-Mohsen, em 2002, testaram a hipótese de que aumentando o tempo de aplicação do primer e do adesivo antes da polimerização poderia aumentar a resistência adesiva da resina composta com a dentina. Foram analisados dois sistemas adesivos de dois frascos (Scotchbond Multi-purpose Plus e OptiBond FL) e um sistema adesivo frasco único( Single Bond). 100 espécimes de discos de dentina foram preparados de molares humanos extraídos. Aproximadamente $1 \mathrm{~mm}$ de estrutura dental foi desgastada para exposição da dentina superficial. Os espécimes foram padronizados e divididos para os três sistemas adesivos e no mínimo 5 espécimes foram usados para cada condição de teste. Para cada adesivo de dois frascos 40 espécimes foram divididos em 4 grupos com tempo de aplicação do primer de 10, 20, 30 e 40 segundos. Cada grupo foi ainda subdividido em dois subgrupos com tempo de aplicação do adesivo de 20 e 40 segundos. Os espécimes que receberam o adesivo de frasco único foram divididos em 4 grupos com um tempo de espera de 10, 20, 30 e 40 segundos antes de secar e polimerizar o sistema adesivo. Os testes de resistência adesiva ao cisalhamento foram realizados usando uma máquina de teste universal Instron numa velocidade de deslocamento de $0,5 \mathrm{~mm} /$ minuto. Os resultados mostraram que para os sistemas adesivos de dois frascos, aumentando o tempo de aplicação do primer superior a 30 ou 40 segundos houve um aumento significante na média da resistência ao cisalhamento $(\mathrm{P}<0,0001)$. $O$ aumento no tempo de aplicação do adesivo antes da polimerização não causou qualquer aumento significante na média da resistência adesiva $(P=0,05)$ a não ser nos grupos que o primer foi aplicado por um tempo superior a 30 segundos. Para o sistema Single Bond, aumentando o 
tempo de aplicação antes de secar e polimerizar para 30 segundos resultou em um aumento estatisticamente significante $(P<0,002)$ na média da resistência ao cisalhamento.

O componente dessensibilizante usado nos novos adesivos é o glutaraldeído. Com o intuito de avaliar se clinicamente a adição de glutaraldeído no adesivo de esmalte e dentina Gluma Comfort Bond (GCB) tem uma função dessensibilizante, como o fornecido pelo fabricante como Gluma Comfort + Desensitizer (GCB+D) DONDI DALL'OROLOGIO D.; LONE, A.; FINGER, W.J., em 2002, realizaram este estudo. Os adesivos GCB e GCB+D foram testados como agentes dessensibilizantes como tratamento tópico de lesões cervicais sensíveis. Dois estudos de dor seguiram o protocolo idêntico sendo o estudo (A) em Abu Dhabi e (B) na Bolonha. Cada um dos 60 e 59 pacientes selecionados, respectivamente, tinham dois dentes com lesões cervicais, caracterizados na escala de dor como grau 3 ou 4. A escala de dor utilizada foi de: 1- (sem dor), 2 (suave), 3 (média), 4 (severa), 5 (muito severa) com relação ao desconforto sob aplicação de ar frio por 2 segundos. Os locais sensíveis vestibulares tratados em A foram geralmente pequenos, em B maiores e em muitos casos estendendo-se para a região proximal do dente. Os pacientes indicaram seu nível de desconforto de acordo com a escala de dor antes e imediatamente após a aplicação tópica de GCB e GCB+D, respectivamente, e então nos retornos após 1 semana, 1 mês para A e 3 meses para B, e 6 meses. O adesivo era aplicado, polimerizado e os dados foram estatisticamente analisados pelo teste $x^{2}(P<0,05)$. Os autores afirmaram que uma fina camada de adesivo aplicado pode não polimerizar e selar a 
superfície de dentina adequadamente devido a inibição de oxigênio. Em particular, os dentes com sensibilidade proximal com pobre acesso para aplicação do adesivo são suspeitos de permanecerem sem selamento adequado e então sensível. Os autores concluíram que o glutaraldeído é um componente ativo viável e efetivo no GCB+D para prevenir a sensibilidade pósoperatória quando, o selamento adequado da dentina com o adesivo, não é obtido.

SOMPHONE et al., em 2002, avaliaram se a resistência adesiva de compômeros com a dentina pode ser aumentada utilizando dois sistemas adesivos sugeridos para compósitos à base de resina. Os autores ainda realizaram uma análise pelo microscópio eletrônico de varredura da micromorfologia da interface entre compômero, sistema adesivo e dentina. Foram utilizados neste estudo 110 dentes bovinos, três compômeros com seus correspondentes sistemas adesivos e duas resinas compostas com dois sistemas adesivos (Clearfil Liner Bond 2V e Single Bond). Como grupo controle foram utilizados os compômeros com os sistemas Clearfil Liner Bond 2V e Single Bond para comparar com a resistência adesiva utilizando o sistema adesivo original que é usualmente recomendado por cada fabricante. A resistência adesiva a tensão foi medida utilizando uma máquina de testes universal com uma velocidade de deslocamento de $2 \mathrm{~mm} / \mathrm{minuto}$. Foram testados 10 espécimes de cada grupo. A espessura da camada híbrida foi medida de um ponto em cada figura e a média calculada a partir de cinco figuras por grupo. Os compômeros unidos à dentina utilizando os sistemas adesivos Single Bond ou Clearfil Liner Bond 2V mostraram uma resistência 
adesiva significantemente maior comparado aos grupos que utilizaram os adesivos originais $(P<0,05)$. A resistência adesiva a tensão do Clearfil Liner Bond $2 \mathrm{~V}$ foi mais alta que do Single Bond $(P<0,05)$. As observações em MEV mostraram boa interação entre os compômeros, sistemas adesivos e dentina com qualquer material restaurador utilizado. A camada híbrida produzida pelo sistema Clearfil Liner Bond $2 \mathrm{~V}$ foi de aproximadamente 0,5 a $1,0 \mu \mathrm{m}$, visto que para o Single Bond foi aproximadamente de 3,1 a $4,1 \mu \mathrm{m}$ de espessura. A espessura da camada híbrida criada em cada espécime dependeu do sistema adesivo utilizado.

O efeito do tipo de condicionamento e do material restaurador na resistência adesiva ao cisalhamento em esmalte e dentina do sistema Prime \& Bond NT foi estudado por SUNICO et al., em 2002. Este estudo também distinguiu a interface dentina-resina formada pelo sistema Prime \& Bond NT em combinação com diferentes condicionadores de superfície e materiais restauradores. A resistência ao cisalhamento foi testada em 60 superfícies vestibulares de dentes bovinos, sendo 30 em esmalte e 30 em dentina. Os espécimes de esmalte e dentina foram divididos em 6 grupos iguais de 5 dentes cada que foram tratados usando diferentes combinações de condicionadores de superfície e materiais restauradores com Prime \& Bond NT. Para avaliação da interface dentina/resina os espécimes foram atacados com íon-argônio e observadas em MEV. Os condicionadores de superfície e os materiais restauradores afetaram significantemente a resistência adesiva em dentina. O condicionamento da dentina antes da aplicação do Prime\& Bond NT aumentou significantemente a resistência adesiva e levou a formação da 
camada híbrida por Spectrum TPH. Para os grupos restaurados com Dyract AP o grupo sem condicionamento $(8,85 \mathrm{MPa})$ mostrou uma resistência adesiva maior que os grupos condicionados (5,12MPa). Os grupos condicionados com ácido fosfórico 36\% formaram camada híbrida intertubular e peritubular de 2,0 a $2,5 \mu \mathrm{m}$ de espessura e tags com aparência de cone invertido indicando que tanto a dentina peritubular quanto intertubular foram descalcificadas. Nos grupos sem condicionamento não houve formação da camada híbrida, mas muitos tags curtos de resina com textura lisa foram observados para os espécimes restaurados com Dyract.

TOLEDANO et al., em 2002, avaliaram o efeito da remoção do colágeno com aplicação de hipoclorito de sódio ( $\mathrm{NaOCl}) 5 \%$ na resistência de união ao cisalhamento de um adesivo à base de acetona em dentina superficial e profunda. Foram utilizados 40 terceiros molares extraídos que, após a limpeza, foram incluídos em resina acrílica mantendo 2/3 da coroa exposta. Um seccionamento na superfície oclusal imediatamente abaixo da junção esmalte/dentina foi realizado para exposição da dentina superficial. A exposição da dentina profunda foi realizada em metade dos espécimes através do seccionamento de mais $1,1 \pm 0,1 \mathrm{~mm}$ abaixo do nível original. Todos os espécimes foram aplainados com papel abrasivo de granulação 600 e então divididos em 2 grupos: 1- tratamento com ácido fosfórico 36\% por 15 segundos; 2- tratamento com ácido fosfórico 36\% por 15 segundos seguido por aplicação de $\mathrm{NaOCl}$ por 2 minutos. O sistema adesivo Prime\&Bond 2.1 foi aplicado após os tratamentos propostos, em dentina úmida, secos por 30 segundos com ar para a evaporação da acetona e fotoativados por 20 segundos. A resina 
composta TPH foi aplicada utilizando uma matriz. Os espécimes foram estocados em água por $24 \mathrm{~h}$, a $37^{\circ} \mathrm{C}$, termociclados 500x e levados a uma máquina universal para testar a resistência de união ao cisalhamento. Para os espécimes condicionados com ácido, a dentina superficial resultou em médias mais altas de resistência de união que em dentina profunda. Não houve diferenças estatisticamente significantes na resistência de união de dentina superficial e profunda após a aplicação de $\mathrm{NaOCl}$. A remoção do colágeno não afetou a média da resistência de união na dentina superficial e aumentou os valores de resistência de união em dentina profunda.

Ainda neste ano, TORII et al., avaliaram a efetividade do condicionamento com ácido fosfórico antes do uso de primers autocondicionantes de dois sistemas adesivos(Unifil Bond- UB; Clearfil SE BondSE). A adesão de resina composta e com esmalte e dentina foi avaliada através de testes de resistência à tensão. Dentes bovinos foram divididos em 4 grupos de 20 espécimes cada. Grupos 1 e 2, os dentes foram lixados com papel de SiC \#600,para obter uma superfície de esmalte plana. Nos grupos 3 e 4 uma superfície de dentina plana foi preparada. Nos grupos 1 e 3 as superfícies de esmalte e dentina foram condicionados com os primers autocondicionantes e secos com um breve jato de ar, os adesivos foram aplicados e fotoativados por 10 s. Nos grupos 2 e 4, as superfícies foram condicionadas com ácido fosfórico gel 35\% por 15 s., lavadas e secas com ar comprimido. A partir daí, os mesmos procedimentos anteriormente citados foram aplicados. Após 24 horas de estocagem, em água destilada, os espécimes foram sujeitos ao teste de tensão para verificar a resistência de união. As interfaces 
dente/resina foram observadas com MEV. Os dados dos testes de tensão foram estatisticamente analisados pelo teste ANOVA a dois critérios para determinar se houve diferença estatisticamente significante $(p<0,05)$ e o teste de Scheffe's para detectar diferenças entre grupos de diferentes produtos e dentro dos grupos. Os resultados mostraram que o condicionamento do esmalte aumentou significantemente os valores de resistência de união por tensão, mas o condicionamento da dentina antes do primer diminuiu significantemente os valores de resistência de união.

A possível contração da camada híbrida durante a metalização dos espécimes em alto vácuo, devido ao teor de água existente, foi pesquisada por ITOU, et al., em 2003. Os autores avaliaram o efeito do método de secagem em ponto crítico na espessura da camada híbrida criada utilizando vários sistemas adesivos. A hipótese nula testada foi que nem os diferentes sistemas adesivos nem o método de secagem afetam a espessura da camada híbrida. Um sistema adesivo de condicionamento total (Photobond), um sistema de três etapas (Scotchbond Multi Purpose), um sistema adesivo de técnica úmida (ALL Bond 2) e um com primer auto-condicionante foram utilizados. Para permitir a mensuração da espessura da camada híbrida, as interfaces dentina/resina foram polidas e levemente condicionadas com ácido fosfórico $40 \%$ por 15 seg. para remover a smear layer do polimento, seguido da imersão em hipoclorito de sódio $10 \%$ por 4 horas. A metade dos espécimes em cada grupo foram sujeitas à fixação em solução de glutaraldeído 4\% (pH 7,4), por 24 horas e secagem, em ponto crítico. A outra metade não foi fixada e a secagem foi em temperatura ambiente. Todos os espécimes foram cobertos com ouro. As 
observações em MEV foram realizadas para determinar a estrutura e espessuras das camadas híbridas. As espessuras das camadas híbridas foram afetadas pelos métodos de secagem, sendo que a secagem, em ponto crítico, produziu camadas híbridas mais espessas $(P<0,05)$. O Photobond criou camadas híbridas mais espessas e os sistemas de Scotchbond Multi Purpose e All Bond 2 produziram camadas híbridas com espessura intermediárias, entre os sistemas de condicionamento total. Entre todos os sistemas adesivos as camadas híbridas de menor espessura foram produzidas pelo sistema com primer auto-condicionante, Mac Bond II o qual apresentavam camadas com uma estrutura mais granular.

TITLEY; CALDWELL; KULKARNI, em 2003, estudaram os efeitos da termociclagem e a integridade da união, em longo prazo, utilizando sistemas adesivos dentinários de frasco único e de múltiplas etapas. Foram utilizados coroas de incisivos bovinos para a realização do estudo. A superfície de dentina foi exposta com lixas \#600 de SiC e incluídos em resina acrílica. Uma área de $4 \mathrm{~mm}$ de diâmetro de dentina foi delimitada para realização dos procedimentos adesivos e um cilindro de resina composta de $4 \mathrm{~mm}$ de diâmetro foi posicionado nesta área e fotoativado. Os sistemas adesivos utilizados neste estudo foram: Scotchbond Multipurpose, Single Bond, All Bond 2, One Step e Prime \& Bond 2.1. Os espécimes foram divididos em 5 grupos contendo 12 espécimes cada um: (1) estocagem em água por 7 dias; (2) termociclados após 24 horas de estocagem e estocados por mais 6 dias antes do teste.; (3) termociclados após 6,5 dias de estocagem e testados após um tempo total de 7 dias; (4) estocagem em água por 24 horas e este grupo serviu como grupo 
controle do período de etocagem; (5) estocagem em água por 270 dias. Todos os espécimes foram submetidos ao teste de resistência ao cisalhamento no final de cada período de estocagem e o modo de fratura foi registrado. Com exceção do One Step, nenhum dos outros adesivos de frasco único, Single Bond e Prime \& Bond 2.1, demonstraram alterações estatisticamente significante nos valores da resistência adesiva após a termociclagem. $\mathrm{O}$ sistema Prime \& Bond 2.1 produziu valores de resistência adesiva mais baixo para todos os parâmetros quando comparado com todos os outros adesivos $(p<0.05)$. Houve um aumento na resistência adesiva do One Step após a termociclagem de 24 horas. O modo de fratura mista (adesiva-coesiva) foi registrado com o Prime \& Bond 2.1 para todos os períodos de estocagem e termociclagem. Estes resultados são provavelmente atribulados ao fato de que os valores de resistência adesiva também foram menores para este adesivo.Os autores concluíram que a termociclagem tem pouco efeito no tipo de falha quando os espécimes foram submetidos ao teste de resistência ao cisalhamento.

Baseados na hipótese que o condicionamento com EDTA pode descalcificar e remover a smear layer sem causar danos severos ao substrato dentinário melhorando a adesão promovida pelos sistemas adesivos simplificados, TORII et al., em 2003, investigaram o efeito do EDTA na resistência adesiva com dentina de dente bovino. Foram utilizados 80 dentes bovinos que foram preparados com lixas para obtenção de discos de dentina. Metade dos espécimes foi condicionada com solução aquosa de EDTA a 0,5 mol $(\mathrm{pH}=7,4)$ por 60 segundos e a outra metade foi tratada com cada um dos 
sistemas adesivos: (One-up Bond F; Reactmer Bond), um sistema autocondicionante (Clearfil SE Bond) e um sistema de frasco único (Single Bond). Para o teste de resistência cisalhamento os adesivos foram aplicados na superfície de dentina condicionada com EDTA. Como grupo controle foi utilizado o sistema Single Bond aplicado sobre a superfície de dentina condicionada com ácido fosfórico 35\%. Após o tratamento da superfície resinas compostas recomendadas pelos fabricantes dos sistemas adesivos foram inseridas e fotoativadas por 40 segundos. A resistência adesiva a tensão foi medida em uma máquina de testes universal, numa velocidade de deslocamento de 2,0 $\mathrm{mm} / \mathrm{minuto}$. As superfícies fraturadas foram preparadas para análise da interface dentina/resina através do MEV e o modo da falha foi registrado. Os espécimes foram incluídos em resina epóxi e seccionados. Após o corte os espécimes foram polidos e condicionados com ácido fosfórico 40\%, por 15 segundos para remover o substrato inorgânico, lavagem sob água abundante e imersão em solução de hipoclorito de sódio 10\% por 4 horas para dissolver o substrato orgânico. Os espécimes foram fixados com glutaraldeído 4\%, desidratados em soluções crescentes de etanol, submetidos à secagem ao ponto crítico e então cobertos com ouro para análise em MEV. Nenhuma diferença no modo de falha foi detectada entre os espécimes condicionados ou não com EDTA usando Clearfill SE Bond. Para o sistema Single Bond os espécimes condicionados com ácido fosfórico mostraram falhas coesivas em dentina mais freqüentemente que os espécimes condicionados com EDTA. Nas interfaces resina/dentina, os espécimes condicionados com EDTA formaram camadas híbridas mais espessas que os não condicionados para todos os sistemas exceto para o Single Bond. 
VELAZQUEZ et al., em 2003, avaliaram a influência de 2 solventes (acetona e etanol) e do método de polimerização (por luz ou dual) na resistência de união e morfologia interfacial. Os adesivos estudados foram formulados a partir de dois monômeros PMGDM (piromellitate de gliceril metacrilato) e HEMA ( 2-hidroxietil metacrilato). 4 grupos de 8 dentes cada foram cortados para expor superfícies planas de dentina e tratar com: (1) sistema fotoativado com acetona como solvente; (2) sistema fotoativado com etanol; (3) sistema dual com acetona; (4) sistema dual com etanol. As superfícies tratadas foram previamente condicionadas com ácido fosfórico 37\% por 20 s. e, lavados por 20 s. Os espécimes foram submetidos ao ensaio de resistência de união ao cisalhamento com discos de resina composta e a morfologia interfacial examinada através do MEV. A morfologia interfacial foi muito similar em todos os grupos indicando que as condições de desmineralização foram mais importantes na determinação da morfologia da camada híbrida e formação dos tags de resina. Houve diferença estatisticamente significante na resistência de união ao cisalhamento quando os métodos de polimerização foram comparados, mas não quando os solventes. A média de resistência de união foi mais alta para os sistemas de polimerização dual estudados. A inibição do oxigênio pode justificar a diferença entre os métodos de polimerização.

O estudo realizado por LOPES et al., em 2003, comparou os valores da resistência de união sobre esmalte e dentina humanos com os valores obtidos em dentes bovinos, utilizando dois sistemas de união com princípios de atuação distintos. Foram utilizados 20 metades de coroas dentais humanas e 
40 coroas bovinas. Os espécimes foram desgastados até obter uma área plana de pelo menos $5 \mathrm{~mm}$ de diâmetro. Os espécimes, num total de 80 , foram divididos em 4 grupos: 1) dente humano em esmalte, 2) dente bovino em esmalte, 3) dente humano em dentina e 4) dente bovino em dentina. Os espécimes de cada grupo foram divididos em 2 subgrupos de 10 espécimes cada, de acordo com o sistema de união utilizado: 1) Scotchbond Multi-Uso (SBMU); e 2) Clearfil Liner Bond 2V (CLBV2). Através de uma matriz bipartida foram confeccionados cilindros com a resina composta Z100 apresentando $4 \mathrm{~mm}$ de diâmetro e $5 \mathrm{~mm}$ de altura. Os ensaios de resistência ao cisalhamento foram realizados em uma máquina Instron a uma velocidade de deslocamento de $0,5 \mathrm{~mm} / \mathrm{min}$. Em esmalte, não se verificou diferença estatística entre os dentes humanos e bovinos para os dois sistemas adesivos utilizados. O SBMU apresentou médias estatisticamente menores em dentina humana (7,01MPa) quando comparada à dentina bovina (11,74 MPa). Para o material CLB2V, não houve diferença estatística entre os substratos humano $(7,43 \mathrm{MPa})$ e bovino $(9,27 \mathrm{MPa})$.

REIS; LOGUERCIO; CARVALHO; GRANDE, em 2004, analisaram os efeitos de diferentes superfícies úmidas na durabilidade da resistência de união com a dentina através de teste de microtração. Os sistemas adesivos estudados foram à base de água e etanol Single Bond (SB); base em acetona One Step (OS) e base de água Syntac Single Component (SC). A dentina superficial de 45 molares humanos extraídos foi utilizada após ser exposta por abrasão. Os adesivos foram aplicados em uma área delimitada $\left(52 \mathrm{~mm}^{2}\right)$ ou em superfície seca com jato de ar por 30 s. ou após molhar novamente com 2,2 ou 
4,0 $\mu$ l de água, seguido pela aplicação de resina composta. Os dentes foram seccionados para obtenção de palitos com uma área de interface dentina resina de $0,8 \mathrm{~mm}^{2}$. O tempo de estocagem foi de $24 \mathrm{~h}$ e 6 meses. O teste de microtração foi realizado e o teste de ANOVA a três critérios mostrou efeito estatisticamente significante no grau de molhamento, tempo de estocagem e dupla interação $(P<0,05)$. Enquanto $S B$ e $S C$ tiveram mais alta resistência a microtração com 0 e 2,5 4 l de água, para OS a resistência foi mais alta com 4,0 $\mu$ l de água. Independente do grau de umidade, reduções na resistência a microtração foram observadas após 6 meses de estocagem para SB e OS $(P<0,05)$, mas não para SC $(P<0,05)$. Nenhuma diferença na resistência entre o período de 24 horas e 6 meses, mas encontrou quando houve diferença quando a umidade foi superior à condição extrema. Significante redução na resistência a microtração foi observada quando a umidade foi superior a 2,5 $\mu$ l. A resistência de união de diferentes sistemas adesivos à base de solventes diminui gradualmente ao longo do tempo, independente do grau de umidade usado no procedimento adesivo.

WANG; SPENCER, em 2004, investigaram como os sistemas adesivos auto-condicionantes se comportaram na desmineralização e formação de camada híbrida em dentina intacta. Os sistemas adesivos utilizados foram: 2 etapas, (Clearfil SE Bond) e dois sistemas de etapa única (One-up Bond e Prompt L-Pop). Foram utilizados três métodos de investigação: técnica de coloração microscópica; espectroscopia Micro Raman; MEV. Os resultados mostraram que a diferença na agressividade dos sistemas adesivos produziu diferentes espessuras de camada híbrida. A técnica de coloração mostrou uma 
distinta linha colorida nas interfaces dentina/adesivo para os três sistemas. A largura da linha variou entre os sistemas. As fibrilas de colágeno nas interfaces não foram totalmente encapsuladas no três sistemas adesivos. Os resultados de Raman mostraram que o Prompt L Pop é o mais agressivo dos sistemas adesivos estudados; desmineralizou quase que totalmente $2 \mu \mathrm{m}$ de profundidade de dentina enquanto Clearfil SE foi $1 \mu \mathrm{m}$ de parcial desmineralização. 


\section{3- PROPOSIÇÃO}

A contínua evolução dos sistemas adesivos tem levado a modificações dos materiais, técnicas e atitudes como o condicionamento da dentina que vem sendo realizado para procedimentos adesivos. Um dos métodos mais comuns para testar os sistemas adesivos é o teste de resistência de união ao cisalhamento. Embora os resultados possam não ser um indicador real da eficiência de união, quando combinado com análise microscópica da interface dente/adesivo pode dar informações úteis do mecanismo de união dos sistemas adesivos. A partir disso, foi proposto um estudo in vitro realizado em substrato bovino, cujos objetivos foram avaliar:

1- a influência do tipo de espessante, usados na composição do ácido fosfórico a $37 \%$, na rugosidade superficial da dentina.

2- a influência dos espessantes na resistência ao cisalhamento quando combinados a 3 sistemas adesivos.

3- a influência dos sistemas adesivos na resistência ao cisalhamento de dois materiais restauradores quando combinados às diferentes formulações do ácido fosfórico 37\%. 


\section{4- MATERIAIS E MÉTODOS}

\section{1- MATERIAIS}

Os materiais testados neste estudo estão relacionados abaixo:

\section{- 3 condicionadores ácidos}

$\checkmark 1$ ácido fosfórico 37\% comercial espessado com sílica coloidal (Dentsply Ind. Com. Ltda, Petrópolis, Rio de Janeiro, Brasil).

$\checkmark 2$ ácidos condicionadores experimentais:

Para a elaboração dos ácidos experimentais, os diferentes espessantes foram adicionados em uma solução de ácido fosfórico 37\% (Fig. 1)(Pharmácia Specífica, manipulação de fórmulas, Bauru, SP-Brasil) até que a forma gel do ácido se formasse. $\mathrm{O}$ peso dos produtos, foram aferidos por uma balança de precisão (Onda Científica Ltda, Campinas São Paulo, Brasil) (Fig. 2).
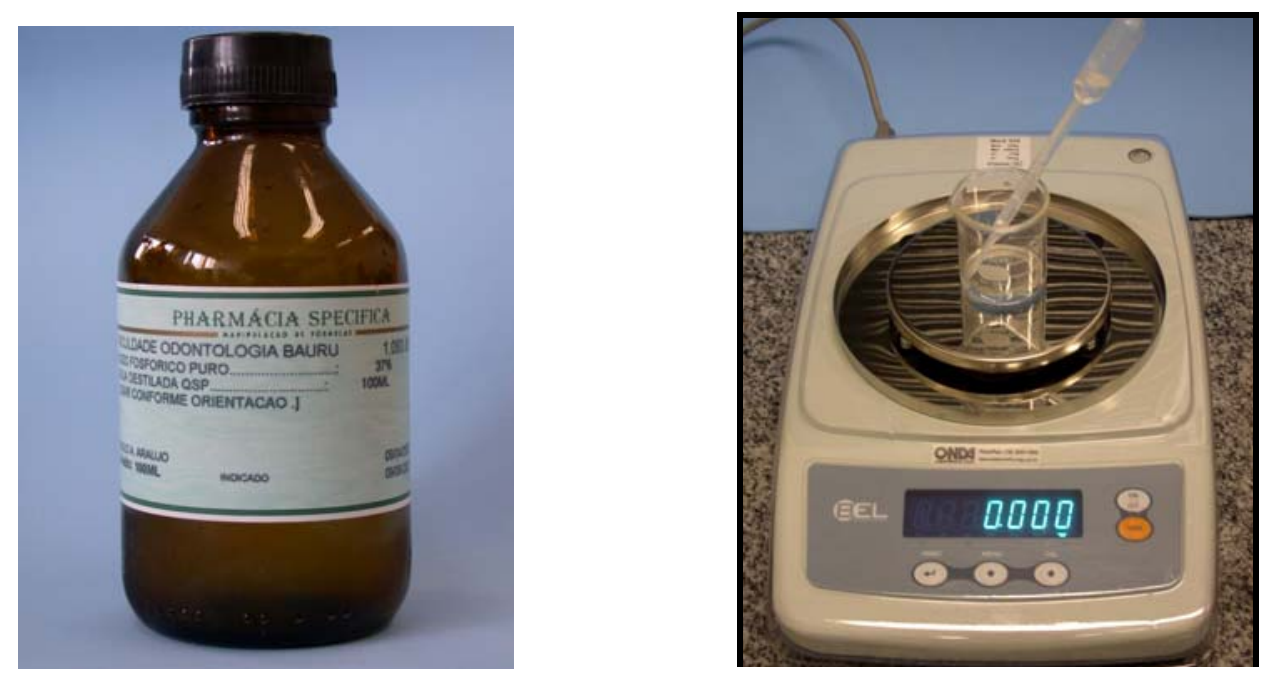

Fig. 1- Ácido fosfórico 37\% líquido, utilizado para formulação dos ácidos experimentais.

Fig. 2- Balança de precisão. 
a) Gel de ácido fosfórico espessado com sílica:

Este gel foi preparado de acordo com a fórmula:

$3 \mathrm{~g}$ de ácido fosfórico $37 \%+0,200 \mathrm{~g}$ de sílica silanizada - 0,04 $\mu \mathrm{m}$ (Aerosil R972- Ch 9-28097-2B, Degussa) + 0,330g de HEMA

\begin{tabular}{|l|c|}
\hline ácido fosfórico 37\% líquido & $3 \mathrm{~g}$ \\
\hline $\begin{array}{l}\text { sílica silanizada - 0,04 } \mu \mathrm{m} \text { (Aerosil - R972- Ch } \\
\text { 9-28097-2B, Degussa) }\end{array}$ & $0,200 \mathrm{~g}$ \\
\hline HEMA & $0,330 \mathrm{~g}$ \\
\hline
\end{tabular}

b) Gel de ácido fosfórico espessado com polímero:

Para a formulação deste gel foi utilizado $10 \mathrm{~g}$ de PMMA (<170 $\mu \mathrm{m})$, (especialmente preparada para este experimento por Clássico, Artigos Odontológicos Ltda, São Paulo, Brasil) para $6 \mathrm{~g}$ de solução de ácido fosfórico a $37 \%$.

\begin{tabular}{|l|c|}
\hline Ácido fosfórico 37\% líquido & $6 \mathrm{~g}$ \\
\hline $\begin{array}{l}\text { PMMA (Artigos Odontológicos Clássico Ltda, } \\
\text { São Paulo, Brasil) }\end{array}$ & $10 \mathrm{~g}$ \\
\hline
\end{tabular}

\section{- 3 sistemas de união}

\section{a) Gluma A (Gluma primer: experimental)}

Este primer seguiu a seguinte fórmula, conforme o estudo realizado por ARAÚJO \& ASMUSSEN, em 1997 (Fig.3):

\begin{tabular}{|c|c|}
\hline Glutaraldeído $20 \%$ & $3,5 \mathrm{ml}$ \\
\hline HEMA & $5,0 \mathrm{ml}$ \\
\hline água. & $1,5 \mathrm{ml}$ \\
\hline
\end{tabular}




\section{b) Gluma B (Gluma resin: experimental)}

Este agente de união de frasco único seguiu uma das formulações utilizadas por ARAÚJO \& ASMUSSEN, em 1989, que segue (Fig.4):

\begin{tabular}{|c|c|}
\hline BisGMA & $0,600 \mathrm{~g}$ \\
\hline HEMA & $2,040 \mathrm{~g}$ \\
\hline Glutaraldeído-50\% & $2,040 \mathrm{~g}$ \\
\hline Água & $0,840 \mathrm{~g}$ \\
\hline Ácido acético & 0,360 \\
\hline Tetrahidrofurano & $5,760 \mathrm{~g}$ \\
\hline Canforoquinona. & $0,012 \mathrm{~g}$ \\
\hline
\end{tabular}
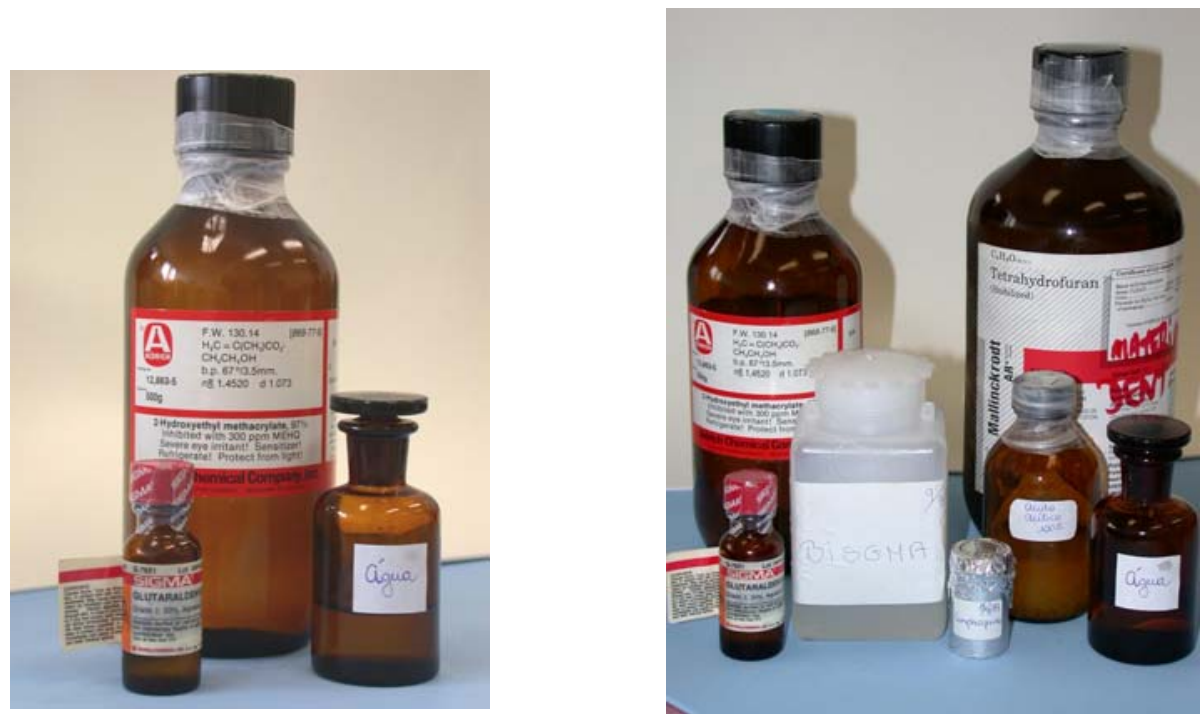

Fig. 3- Materiais utilizados na formulação do Gluma A.

Fig. 4- Materiais utilizados na formulação do Gluma B.

\section{c) Adesivo Comercial (C): Prime \& Bond 2.1}

Prime \& Bond 2.1 (Dentsply Ind. Com. Ltda, Petrópolis, Rio de Janeiro, Brasil, Lote\# 9875) (Fig.5) sendo composto por: 


\begin{tabular}{|c|}
\hline Resinas dimetacrilatos \\
\hline PENTA \\
\hline Fotoiniciadores e estabilizadores \\
\hline hidrofluoreto de cetilamina \\
\hline acetona \\
\hline
\end{tabular}

- 2 materiais restauradores (Fig. 6 )

a) resina composta microhíbrida $(0,01$ a 3,5 $\mu \mathrm{m})$ Filtek - Z $250^{\mathrm{TM}}$ - cor B2 (3M do Brasil Ltda- Produtos Dentários, Sumaré, São Paulo, Brasil, Lote\# 2YM), composta por: BisEMA, UDMA, BisGMA.

b) resina composta microhíbrida, com partículas de ionômero de vidro $(0,01$ a 5,0 $\mu \mathrm{m}$ ) pré-reagidas Beautifil -cor B2 (SHOFU Inc, Kyoto Japan, Lote\# 090140) composta por: TEGDMA, BisGMA e partículas de vidro pré-reagidas (fluroboroaluminosilicato).
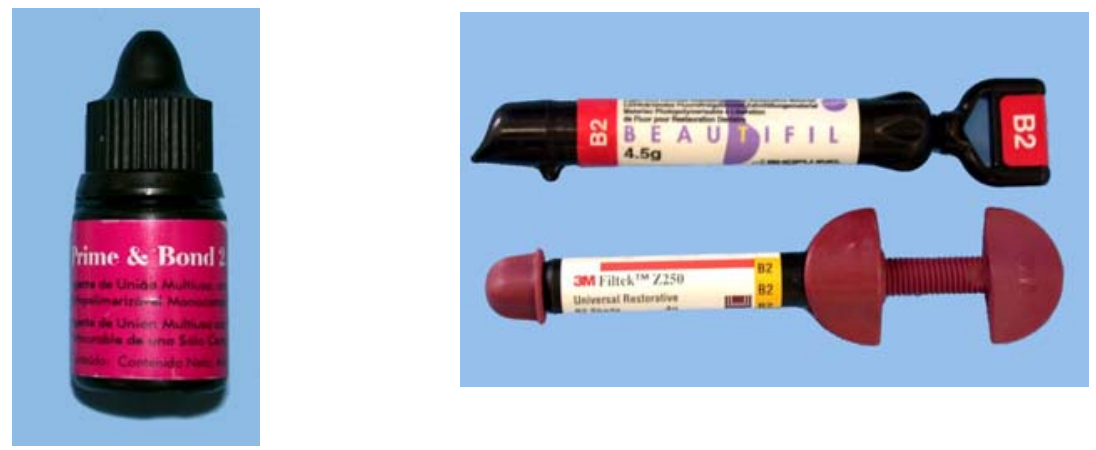

Fig. 5- Sistema adesivo comercial Prime \& Bond 2.1.

Fig. 6- Resinas compostas utilizadas neste estudo. 


\section{2- MÉTODOS}

Para os dois materiais restauradores utilizados foram realizadas combinações entre os ácidos e sistemas de união, totalizando 9 grupos para cada material restaurador. Para cada grupo foram preparados 8 espécimes (TABELA 5).

TABELA 5- Grupos testados.

\begin{tabular}{|l|c|c|}
\hline \multirow{2}{*}{ Filtek $Z 250^{\mathrm{TM}}$ ou Beautifil } & \multirow{2}{*}{ Gluma 1 (A) } & Ácido comercial \\
\cline { 3 - 3 } & \multirow{2}{*}{ Filtek $Z 250^{\mathrm{TM}}$ ou Beautifil } & Ácido com sílica \\
\cline { 3 - 3 } & \multirow{2}{*}{ Gluma 2 (B) } & Ácido com polímero \\
\cline { 3 - 3 } & & Ácido comercial \\
\hline \multirow{2}{*}{ Filtek Z $250^{\mathrm{TM}}$ ou Beautifil } & \multirow{2}{*}{ Prime \& Bond 2.1 (C) } & Ácido com sílica \\
\cline { 3 - 3 } & & Ácido com polímero \\
\cline { 3 - 3 } & & Ácido com sílica \\
\hline
\end{tabular}

\subsection{1- Obtenção do substrato dentinário:}

O substrato dentinário de dentes bovinos foi eleito para este estudo como alternativa viável à utilização de dentes humanos (SCHILKE et al 1999; TORIl et al 2003) Foram utilizados 144 incisivos bovinos, provenientes de animais de dois a três anos de idade que foram abatidos em frigorífico. Imediatamente após a extração, os dentes foram acondicionados em uma solução de cloramina-T a $0,5 \%$, a uma temperatura de $4^{\circ} \mathrm{C}$. Tecidos remanescentes e debris foram removidos dos dentes e estes permaneceram 
em uma nova solução de cloramina-T a 0,5\% à mesma temperatura, por não mais que três meses.

\subsection{2- Preparo dos espécimes:}

a) Inclusão:

Primeiramente, a porção radicular e $2 \mathrm{~mm}$ da borda incisal dos dentes foram removidas, com um disco de diamante, em baixa velocidade sob refrigeração constante, e desprezadas. Os condutos radiculares e a câmara pulpar quando exposta foram obliterados com cera utilidade (Wilson, Polidental, Ind. \& Com. LTDA, Brasil) com o intuito de evitar a penetração de resina epóxi no interior dos dentes. As coroas dos dentes foram inseridas individualmente, em formas cilíndricas de silicone de condensação, obtidas a partir de uma matriz metálica (Fig. 7a), com a região cervical vestibular voltada para baixo, de modo que esta região ficasse em íntimo contato com o fundo da forma (Fig. 7b). Para a inclusão, uma resina epóxi (Redelease, São Paulo, SP, Brasil) com baixa liberação de calor durante a polimerização foi utilizada. A proporção da resina foi de $10 \mathrm{~g}$ da base para $1 \mathrm{~g}$ do catalisador, aferido por uma balança de precisão (Onda Científica Ltda, Campinas São Paulo, Brasil) e após a manipulação, o material foi vertido no interior da formas (Fig.7c). Após 24 horas, que é o tempo necessário para a completa polimerização da resina epóxi de inclusão, os espécimes foram retirados das formas e levados para uma máquina lixadeira (APL-4, Arotec - SP, Brasil)(Fig. 7d). Lixas d' água com granulação 80 foram utilizadas, sob refrigeração de água corrente, a fim de expor aproximadamente uma superfície de dentina com $5 \mathrm{~mm}$ de diâmetro, correspondente à região cervical dos dentes, que era a primeira região a ser 
exposta. A dentina foi polida com lixas de carbeto de silício (Norton -SP, Brasil), de numerações crescentes de 600 e 1200, e para promover uma padronização na camada de detritos ou smear layer, estabeleceu-se o tempo de 30 segundos em cada lixa.

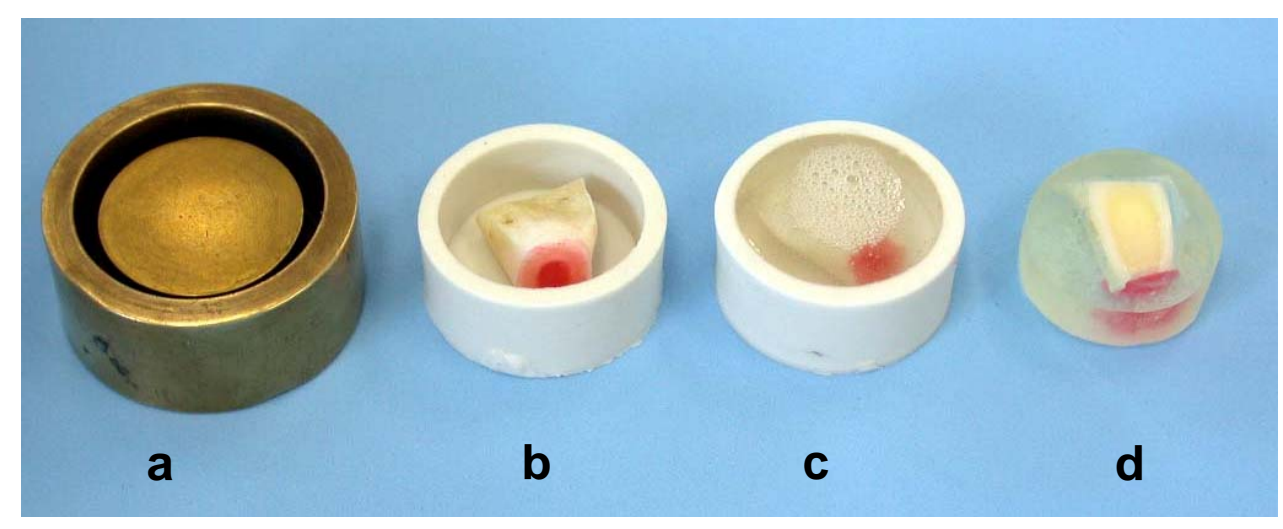

Fig. 7- Seqüência de inclusão. Através de uma matriz metálica (a) foi confeccionada uma matriz de silicone (b) e com resina epóxi foi realizada a inclusão da porção coronária (c), e após a exposição da dentina em lixadeira, obtivemos o espécime para os testes.

\subsection{3- Determinação da rugosidade superficial}

Para realização das leituras de rugosidade superficial (antes e após os condicionamentos ácidos) foi utilizado o rugosímetro Hommel Tester T1000 basic (Hommelwerke GmbH ref: \#240851- Schwenningem- Germany) que constitui um aparelho de alta sensibilidade com ponta ativa de diamante, utilizado para medir rugosidade superficial quantitativamente (Figura 8). Foram realizadas 3 leituras aleatórias passando sempre pelo centro da superfície de dentina e o valor de rugosidade foi obtido através de sua média aritmética (Anexo 4). As leituras nas superfícies de dentina foram realizadas antes e após o condicionamento com ácido fosfórico, comercial e experimentais, espessados com sílica e polímero, utilizando-se 8 espécimes para cada grupo. 
O estudo da rugosidade leva em consideração o valor da média aritmética de todas as distâncias absolutas do perfil de rugosidade traçado, ou seja, da área percorrida pelo sensor de varredura de superfície. Toda superfície apresenta um certo grau de rugosidade, de imperfeições, ou ainda de depressões e elevações, que podem ser aqui denominadas de picos e vales. Através da varredura ou escaneamento e leitura sobre os espécimes, por meio de um sensor, obtém-se valores numéricos da rugosidade, em termos da rugosidade aritmética $(\mathrm{Ra})$.

A média da rugosidade $(\mathrm{Ra})$ de cada leitura realizada é definida como o valor médio percorrido pelo sensor do aparelho sobre a superfície da amostra. A ponta do sensor percorre a superfície e seus movimentos verticais são convertidos em um sinal elétrico e registrados pelo aparelho. Diferentes geometrias de superfície podem produzir valores de rugosidade média idênticos, prejudicando uma análise mais apurada dos resultados. Para diminuir esta possibilidade, deve-se utilizar um filtro elétrico cut-off que elimine a detecção de irregularidades acima de seu limiar; neste estudo foi utilizado um cut-off de $0,25 \mu \mathrm{m}$, indicado para a medição de superfícies polidas e ou levemente abrasionadas. A ponta do rugosímetro percorreu $1,25 \mathrm{~mm}$, em cada leitura efetuada e no mesmo sentido (mésio-distal) para as três leituras, antes e após o condicionamento ácido.

As diferenças dos valores entre as médias, antes e após os condicionamentos ácidos, foram reportadas como a rugosidade provocada pelo ácido. 


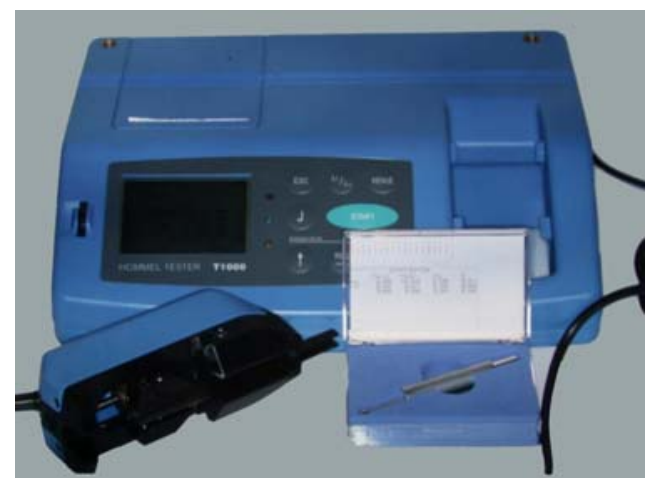

Fig. 8- Rugosímetro utilizado para análise da rugosidade superficial da dentina.

\subsection{4- Procedimento adesivo}

Foram feitas combinações entre tipo de ácido condicionador e tipo de agente de união, formando os grupos citados. Nos grupos controle foi utilizado o adesivo comercial Prime \& Bond 2.1 (Dentsply Ind. Com. Ltda, Petrópolis, Rio de Janeiro, Brasil) combinado com os três diferentes ácidos, totalizando 18 grupos. Uma fita adesiva foi perfurada com perfurador de papel, criando um orifício de $4 \mathrm{~mm}$ de diâmetro e foi posicionada na superfície de dentina exposta para demarcar a região adesiva (Fig. 8). Este método garantiu que a área na qual os ácidos condicionadores (Fig. 9) e agentes adesivos foram aplicados, fosse padronizada para obter precisão nos valores de resistência adesiva (HOLTAN, NYSTROM, OLIN, 1994). Os espécimes utilizados para o teste de rugosidade superficial foram aproveitados e antes da aplicação dos sistemas adesivos, foi aplicado $1 \mathrm{ml}$ de água na superfície. 

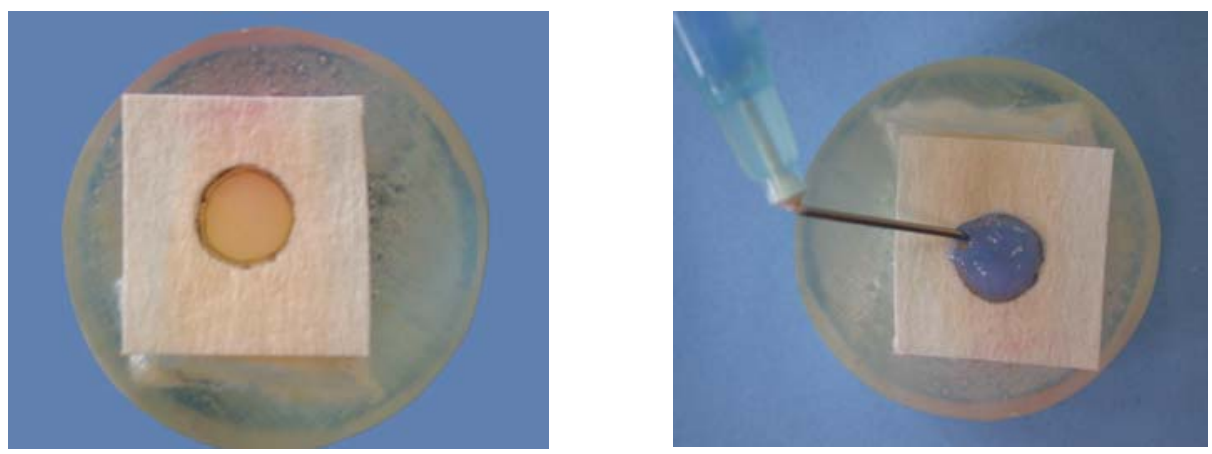

Fig. 9- Demarcação da área a ser condicionada e restaurada.

Fig. 10- Condicionamento com ácido fosfórico 37\% comercial.

Gluma A- (Gluma primer)- Grupos 4, 5, 6, 7, 13 e 14

A seqüência deste procedimento adesivo envolveu: Condicionamento da dentina com os ácidos descritos por 20 segundos; lavagem com água deionizada por 40 segundos; secagem com jato de ar por 5 segundos para obtenção de uma dentina úmida; aplicação ativa do primer por 10 segundos e permanecendo por mais 15 segundos na superfície; aplicação uniforme de uma camada de resina fluida sendo 1 gota do ARM bonding Agent- catalisador + 1 gota do bonding agent Universal (ARM, Dentsply, Ind Com. Ltda, Petrópolis, Rio de Janeiro, Brasil) e aplicação de um leve jato de ar.

Gluma B- (Gluma resin)- Grupos 1, 2, 3, 10, 11, 12,

Para estes grupos a seqüência do procedimento adesivo foi a seguinte: aplicação dos ácidos por 20 segundos; lavagem com água deionizada por 40 segundos; secagem com jato de ar por 5 segundos para obtenção de uma superfície de dentina úmida; aplicação ativa do Gluma resin por 10 segundos e permanecendo por mais 15 segundos na superfície; aplicação de um leve jato de ar para evaporação dos solventes e fotoativação por 20 segundos. 
Prime \& Bond 2.1 (C)- Grupos 8, 9,15,16,17 e18.

Como controle dos adesivos experimentais foi utilizado um sistema adesivo comercial cuja seqüência envolve: Condicionamento do dente com os diferentes ácidos por 20 segundos, lavagem com água deionizada por 40 segundos; secagem com papel absorvente, de acordo com as instruções do fabricante, para obtenção de uma superfície úmida; aplicação do Prime \& Bond 2.1 por 15 segundos, leve jato de ar e fotoativação por 20 segundos.

Para a condensação do material restaurador os dentes incluídos nos cilindros de resina epóxi foram fixados em um dispositivo idêntico ao utilizado por ARAÚJO \& ASMUSSEN, em 1989 (Figs 11 e 12). O dispositivo é constituído de uma base circular com a qual se apóia sobre a bancada. Dela se eleva uma haste cilíndrica que apóia no centro um parafuso que movimenta uma pequena plataforma elevadora. Na extremidade superior a haste sustenta uma plataforma também circular a qual é perfurada no centro para a fixação da matriz de teflon bipartida. Esta matriz tem um orifício central com 3,6 mm de diâmetro, no qual será condensada a resina restauradora (Fig. 13). Na parte inferior desta matriz o espécime é comprimido pela plataforma elevadora de forma que a superfície de dentina já tratada se coloque em contato com a abertura inferior do orifício central da matriz de teflon. Através deste orifício a resina composta foi condensada sobre a dentina e fotoativada através de um aparelho fotopolimerizador de lâmpada halógena, (Optilux, Demetron Research Co. - Danbury, EUA) com cerca de $600 \mathrm{~mW} / \mathrm{cm}^{2}$ de densidade de potência, aferida periodicamente com um radiômetro (modelo 100, Demetron Research 
Co.) (Fig. 14). O orifício apresenta $3,6 \mathrm{~mm}$ de diâmetro por $2 \mathrm{~mm}$ de altura, de modo que cilindros de resina composta de mesma medida foram confeccionados (Fig.15).

O trabalho foi realizado em um laboratório com temperatura controlada em $23 \pm 1^{\circ} \mathrm{C}$ e umidade relativa de $50 \pm 5 \%$
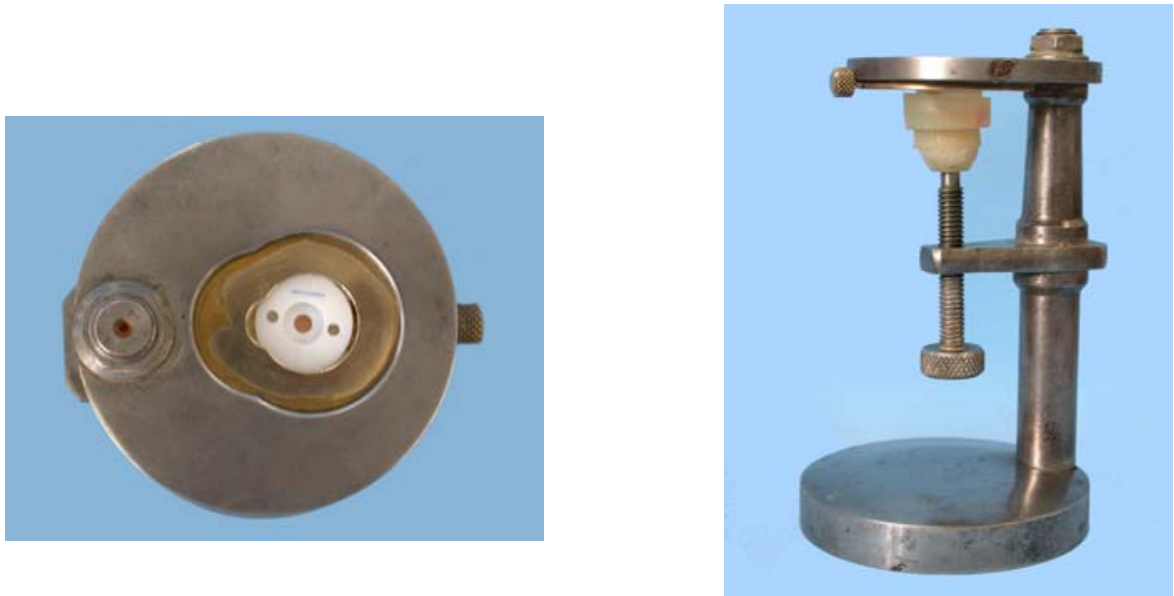

Figs. 11 e 12- Dispositivo utilizado para condensação do material restaurador, numa vista superior e lateral.
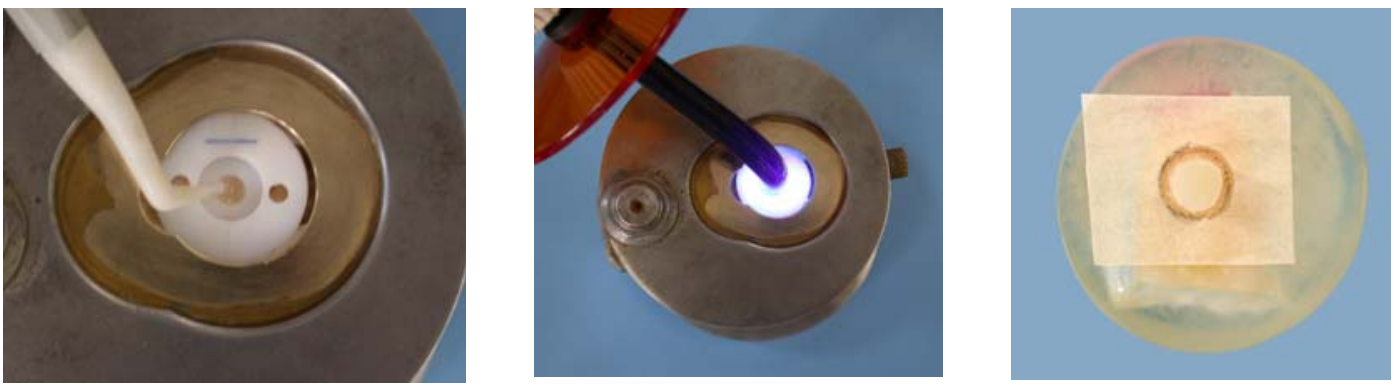

Fig. 13- Condensação da resina composta no interior da matriz.

Fig. 14- Fotoativação da resina composta.

Fig. 15- Espécime pronto para o teste de resistência ao cisalhamento.

\subsection{5- Ensaios de resistência ao cisalhamento}

Após 24 horas de armazenagem dos espécimes já restaurados, em água deionizada à $37^{\circ} \mathrm{C}$, foram executados os ensaios de resistência de união 
ao cisalhamento. Cada espécime foi acoplado ao dispositivo para ensaios de cisalhamento pela técnica do laço de fio ortodôntico, com diâmetro de $0,7 \mathrm{~mm}$ e 32cm de comprimento, em uma Máquina de Ensaio Universal (Kratos - SP, Brasil) (Fig.16). O laço foi realizado pela soldagem das duas pontas do fio ortodôntico e adaptado ao dispositivo. Ele tem uma dobra feita na extremidade que abraça o espécime, a fim de ser mantido sempre em contato com a união dentina/resina (Fig. 17). Era então tracionado, com uma célula de carga de $2000 \mathrm{Kgf}$, a uma velocidade de deslocamento de 0,5mm/minuto, até a ruptura do conjunto material restaurador/dente. Após o teste os valores foram registrados em Newtons e convertidos para megaPascal (MPa) sendo esses valores divididos pela área da superfície de união (3,6mm de diâmetro). Os espécimes fraturados foram observados sob um Estereoscópio (Citoval 2, Carl Zeiss, Jena, Alemanha) com um aumento de 40x. O tipo de falha foi considerado como adesiva, uma vez localizada na interface adesiva, coesiva quando a fratura ocorreu em um dos materiais ou mista (SUDSANGIAM, VAN NOORT, 1999).
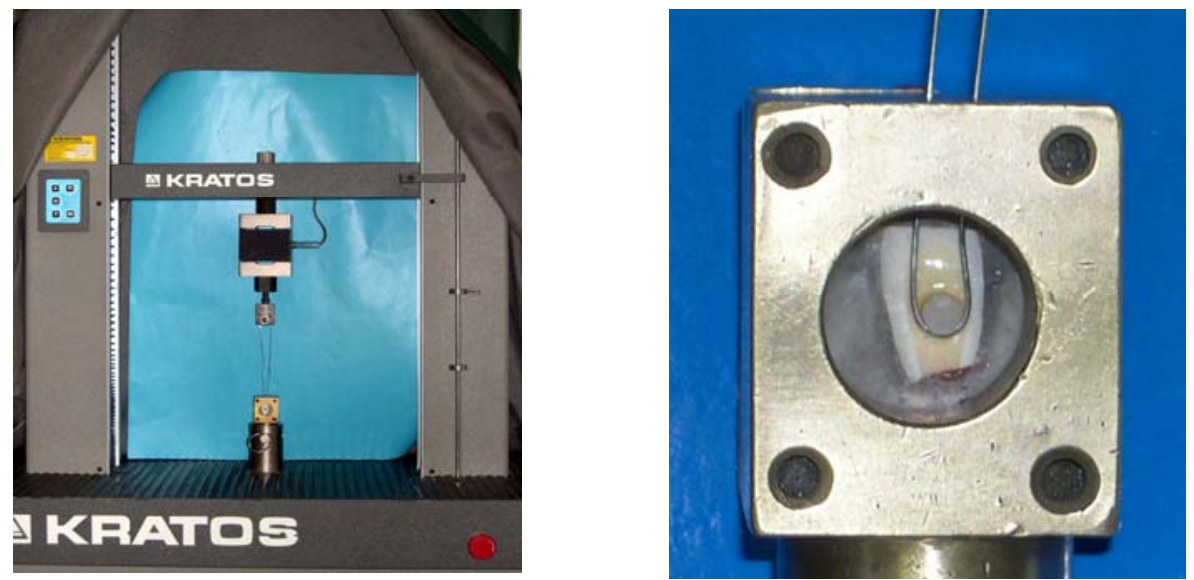

Fig. 16- Máquina de Ensaio Universal Kratos.

Fig. 17- Espécime acoplado no dispositivo para o teste de resistência ao cisalhamento. 


\subsection{6- Preparo dos espécimes para exame em microscópico eletrônico de varredura (MEV).}

$\mathrm{Na}$ análise do tipo de condicionamento, foram confeccionados 2 espécimes de cada formulação de ácido fosfórico 37\%. Para a análise da camada híbrida foram confeccionados 12 espécimes que não foram submetidos ao teste de cisalhamento. Para cada um dos materiais restauradores foram realizados dois espécimes de cada sistema adesivo, sendo que o condicionamento, para esta análise, foi realizado somente com o ácido fosfórico 37\% comercial (Dentsply Ind. Com Ltda, Petrópolis, Rio de Janeiro, Brasil). Após as restaurações, os dentes incluídos nos cilindros de resina epóxi, foram fixados na máquina de corte (Dressing Stick Holder- model 65012- South Bay Technology Inc. San Clemente Califórnia, EUA) (Fig. 18) e através de um disco de diamante ( Diamond Wheel - Part\# DWH4123, San Clement, Califórnia, EUA) , em baixa velocidade sob refrigeração constante, foram realizados três cortes longitudinais e três cortes transversais (Fig. 19). O corte perpendicular central foi realizado no meio do cilindro do material restaurador. Com esta configuração obtivemos duas superfícies para exame da zona de interdifusão ou camada híbrida e dos tags de resina no MEV.
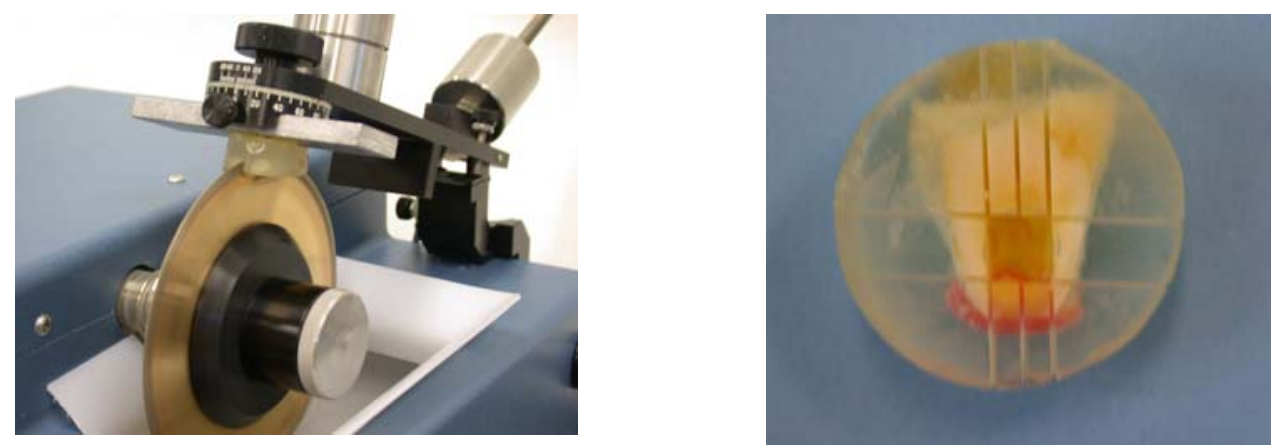

Fig. 18- Máquina de corte

Fig. 19- Espécime após o seccionamento. 
As interfaces observadas receberam um acabamento da superfície sob refrigeração constante com lixas de carbeto de silício (Norton - São Paulo, Brasil) nas granulações decrescentes de 100, 500, 600, 1200 e 2000 com um tempo de 1 minuto em cada lixa sob pressão manual. No intervalo de cada lixa os espécimes foram levados ao ultra-som (Ultrasonic Cleaner 1440DOdontobrás Ind. Com. de Equipamentos Odontológicos Ltda, Ribeirão Preto, São Paulo, Brasil) por 5 minutos sendo que a interface a ser observada ficou voltada para baixo para que os resíduos removidos não precipitassem novamente. O polimento das interfaces foi realizado em uma polidora (Struers, DANMARK) com pastas abrasivas de alumina (Arotec, São Paulo, SP, Brasil) em ordem decrescente de tamanho de partículas, sendo $1 \mu \mathrm{m}, 0,3 \mu \mathrm{m}$ e $0,05 \mu \mathrm{m}$, respectivamente, por um tempo de 1 minuto. Após o polimento com cada uma das pastas, os espécimes foram lavados com água deionizada e levados ao ultra-som por um tempo de 5 minutos, totalizando um tempo de 40 minutos em ultra-som sempre com o cuidado de colocar para baixo a interface a ser analisada. Os espécimes foram condicionados com ácido clorídrico 0,6M por 30 segundos e lavados com água deionizada por um minuto para dissolver o componente mineral da dentina e uma das interfaces de cada espécime foi também imersa em solução de hipoclorito de sódio 2,5\% por 2 minutos e lavados novamente com água deionizada por um minuto para remoção do colágeno que não estava protegido por resina e assim sendo possível analisarmos os tags de resina formados.

Todas as interfaces foram fixadas através da imersão em solução tampão de fosfato de sódio a 0,1 M com 2,5 \% de glutaraldeído, com pH de 7.4, por 12 horas a $4^{0} \mathrm{C}$. Após essa fixação, os espécimes foram lavados em 20 
ml de uma solução tampão de fosfato de sódio a $0,2 \mathrm{M}$, com pH de 7,4 por uma hora, sendo que, a cada vinte minutos, foi substituída por uma nova solução. Decorrido este tempo os espécimes foram lavados com água deionizada por um minuto (PERDIGÃO, J; LAMBRECHTS, P; VAN MEERBEEK, B, et al, 1995).

Os espécimes passaram por um processo de desidratação em concentrações progressivas de etanol (25, 50 e 75\%, por 20 minutos, 95\%, por 30 minutos e 100\%, por 60 minutos)(TAY, 1994; VAN DER GRAAF \& BOSCH, 1993).

A secagem dos espécimes foi realizada em uma capela com remoção de ar em razão da toxicidade das soluções utilizadas. Os espécimes foram imersos inicialmente em uma solução de etanol 100\% e hexametildisilizane (HMDS- Sigma Chemicals, EUA) 100\%, numa proporção de 1:1 por 30 minutos e depois imersos em uma solução de hexametildisilizane (HMDS) 100\% por 30 minutos. Decorrido este tempo os espécimes foram removidos desta última solução e colocados individualmente sobre um filtro de papel, secos com ar em temperatura ambiente, e armazenados em um dissecador, contendo sílica gel desidratada até o momento da metalização para o exame em MEV (LEO 435 VP).

Foram então montados em stubs de alumínio com fita de carbono e recobertos com ouro através de um metalizador (MED 010- Balzers UNION). Em seguida, os espécimes foram observados em várias magnitudes pelo MEV. 


\subsection{ANÁLISE ESTATÍSTICA}

Os resultados obtidos neste estudo foram submetidos à Análise de Variância (ANOVA) e posteriormente ao Teste de Tukey para comparações individuais entre os grupos (UNO, FINGER, 1996). 


\section{5- RESULTADOS}

\section{A- Rugosidade Superficial}

Para verificar se após o condicionamento, com as diferentes formulações de ácido, houve um aumento significante na rugosidade da superfície de dentina, foi aplicado o teste "T" de Student, nas médias dos valores obtidos para cada formulação, antes e após o condicionamento. Houve diferença estatisticamente significante $(P<0,05)$ somente para 0 ácido experimental espessado com sílica ( $p=0,0013)$, já para os ácidos comercial e espessado por polímero não houve diferença significante na rugosidade da superfície de dentina antes e após o condicionamento ( $P>0,05)$ (TABELA 6).

TABELA 6: Teste "T "de Student- Amostras pareadas antes e após o condicionamento ácido.

\begin{tabular}{c|c|c|c|c}
\hline ÁCIDO & $\begin{array}{c}\text { DIF. das } \\
\text { Médias }\end{array}$ & VALOR DE T & $\begin{array}{c}\text { Grau de } \\
\text { Liberdade }\end{array}$ & $p$ \\
\hline Polímero & $-0,0185$ & $-1,1430$ & 7 & 0,2906 \\
\hline Comercial & $-0,0001$ & $-0,2991$ & 7 & 0,9769 \\
\hline Sílica & $-0,0028$ & $-5,1268$ & 7 & 0,0013 * \\
\hline
\end{tabular}

* Houve um aumento significante na rugosidade superficial da dentina após o condicionamento sendo o $\mathrm{P}<0,05$.

Para verificar se houve diferença estatisticamente significante entre as três formulações de ácido na rugosidade superficial após o condicionamento, as médias das diferenças obtidas, antes e após o condicionamento, de cada 
formulação foram submetidas ao teste de ANOVA a um critério de classificação, com nível de significância de 5\%. Na TABELA 7, podemos observar as médias e desvio padrões dos 3 ácidos na rugosidade superficial, após o condicionamento. Não houve diferença estatisticamente significante quando os ácidos foram comparados entre si sendo o $p=0,604$.

TABELA 7: Média e Desvio padrão das três formulações do ácido na rugosidade superficial, após o condicionamento.

\begin{tabular}{c|c|c|c}
\hline GRUPO & MÉDIA & DESVIO PADRÃO & N $^{\circ}$ VALORES \\
\hline comercial & 0,0110 & 0,0010 & 8 \\
\hline polímero & 0,0138 & 0,0008 & 8 \\
\hline sílica & 0,00275 & 0,0015 & 8 \\
\hline
\end{tabular}

\section{B- Resistência ao cisalhamento}

Os resultados das médias de resistência ao cisalhamento dos dois materiais restauradores podem ser visualizadas nos GRÁFICOS 1 e 2. 


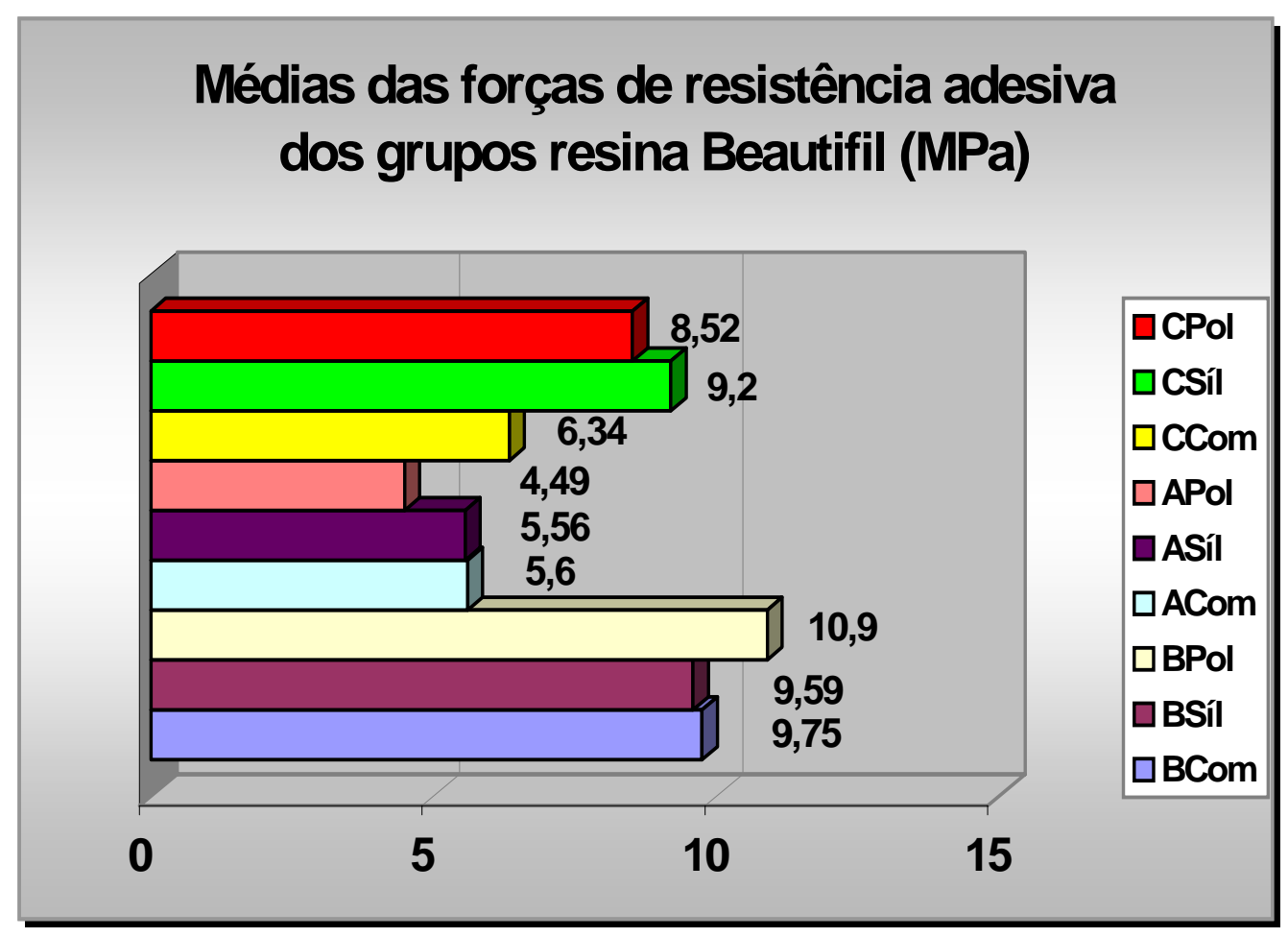

Gráfico 1: Médias das forças de resistência adesiva ao cisalhamento dos grupos realizados com a resina composta Beautifil, através dos 3 sistemas adesivos e combinados aos 3 ácidos (polímero, sílica e comercial), sendo que na legenda a primeira letra corresponde aos sistemas:Gluma A, Gluma B, e adesivo comercial (C).

Nos grupos restaurados com a resina Beautifil quando verificamos a influência dos espessantes na resistência ao cisalhamento através do teste de ANOVA a um critério de classificação, observamos que não houve diferença significante entre os tipos de espessantes utilizados $(P<0,01)$. As médias e desvio padrão dos grupos restaurados com a resina composta Beautifil estão na TABELA 8 . 
TABELA 8: Média e Desvio padrão dos grupos realizados com a resina Beautifil.

\begin{tabular}{|c|c|c|c|}
\hline & Ácido comercial-F & Ácido sílica- S & Ácido polímero-P \\
\hline Gluma A & $5,600 \pm 2,995$ & $5,563 \pm 2,397$ & $4,488 \pm 2,579$ \\
\hline Gluma B & $9,750 \pm 3,303$ & $9,588 \pm 3,252$ & $10,900 \pm 3,374$ \\
\hline Adesivo C & $6,338 \pm 2,492$ & $9,200 \pm 2,403$ & $8,525 \pm 2,732$ \\
\hline
\end{tabular}

Quando comparamos individualmente pelo teste de Tukey, verificamos as diferenças entre as formulações de ácido em relação a cada sistema adesivo. Não houve diferença estatisticamente significante quando as diferentes formulações de ácido foram comparadas entre si, independente do sistema adesivo utilizado, com nível de significância de 1\% (TABELA 9).

TABELA 9: Comparação individual pelo teste de Tukey entre as formulações dos ácidos em relação a cada sistema adesivo na resistência ao cisalhamento, dos grupos restaurados com a resina Beautifil.

\begin{tabular}{|c|c|c|c|}
\hline & GLUMA A & GLUMA B & Adesivo C \\
\hline Com. x sílica & 3,675 & $-1,388$ & $-2,588$ \\
\hline Com. x polímero & 3,813 & 1,713 & $-3,263$ \\
\hline Polímero x sílica & $-0,138$ & $-3,100$ & 0,675 \\
\hline
\end{tabular}

Quando aplicamos os testes de ANOVA a um critério de classificação nos grupos realizados com a resina Beautifil condicionados com ácido fosfórico a 37\% espessado com sílica e comparamos a resistência adesiva entre os 
sistemas adesivos utilizados verificamos que houve diferença estatisticamente significante entre os sistemas adesivos, com nível de significância de $5 \%$. Através do teste de Tukey verificamos que o sistema adesivo Gluma B apresentou os melhores resultados, com diferença estatisticamente significante $(\mathrm{P}<0,05)$ somente quando comparado com o Gluma $A$. O sistema adesivo comercial (C) apresentou diferença estatisticamente significante $(P<0,05)$ quando comparado com o Gluma A.

Quando utilizamos a resina Beautifil e condicionamos os espécimes com ácido fosfórico a 37\% espessado com polímero e comparamos os 3 sistemas adesivos, verificamos que houve diferenças estatisticamente significantes entre os sistemas $(P<0,05)$. Diante disso, o teste de Tukey foi aplicado e resultou que o sistema adesivo Gluma B e o sistema comercial apresentaram melhores resultados quando comparado ao Gluma $A(P<0,05)$. Quando o sistema Gluma B foi comparado com o sistema comercial (C) não houve diferenças estatisticamente significantes.

Os grupos condicionados com ácido fosfórico comercial a 37\% e restaurados com a resina Beautifil quando submetidos ao teste de ANOVA a um critério para comparar os resultados obtidos com os 3 sistemas adesivos mostrou que houve diferenças estatisticamente significante $(P<0,05)$ entre os sistemas. O teste de Tukey mostrou que o sistema adesivo Gluma B apresentou resultados significantemente melhores que o sistema Gluma A. Entre os sistemas adesivos Gluma A e comercial (C) e entre o sistema Gluma B e comercial $(C)$, não houve diferenças estatisticamente significantes $(P<0,05)$ (TABELA 10). 
TABELA 10: Comparação individual pelo teste de Tukey entre os sistemas adesivos em relação a cada formulação de ácido empregado nos grupos restaurados com a resina Beautifil.

\begin{tabular}{|c|c|c|c|}
\hline & Ácido comercial & Ácido sílica & Ácido polímero \\
\hline A $\times$ B & $-4,150 *$ & $-4,025 *$ & $-6,413$ * \\
\hline A $\times$ C & $-0,738$ & $-3,638 *$ & $-4,038$ * \\
\hline B $\times$ C & 3,413 & 0,388 & 2,375 \\
\hline
\end{tabular}

* diferença estatisticamente significante $(\mathrm{P}<0,05)$.

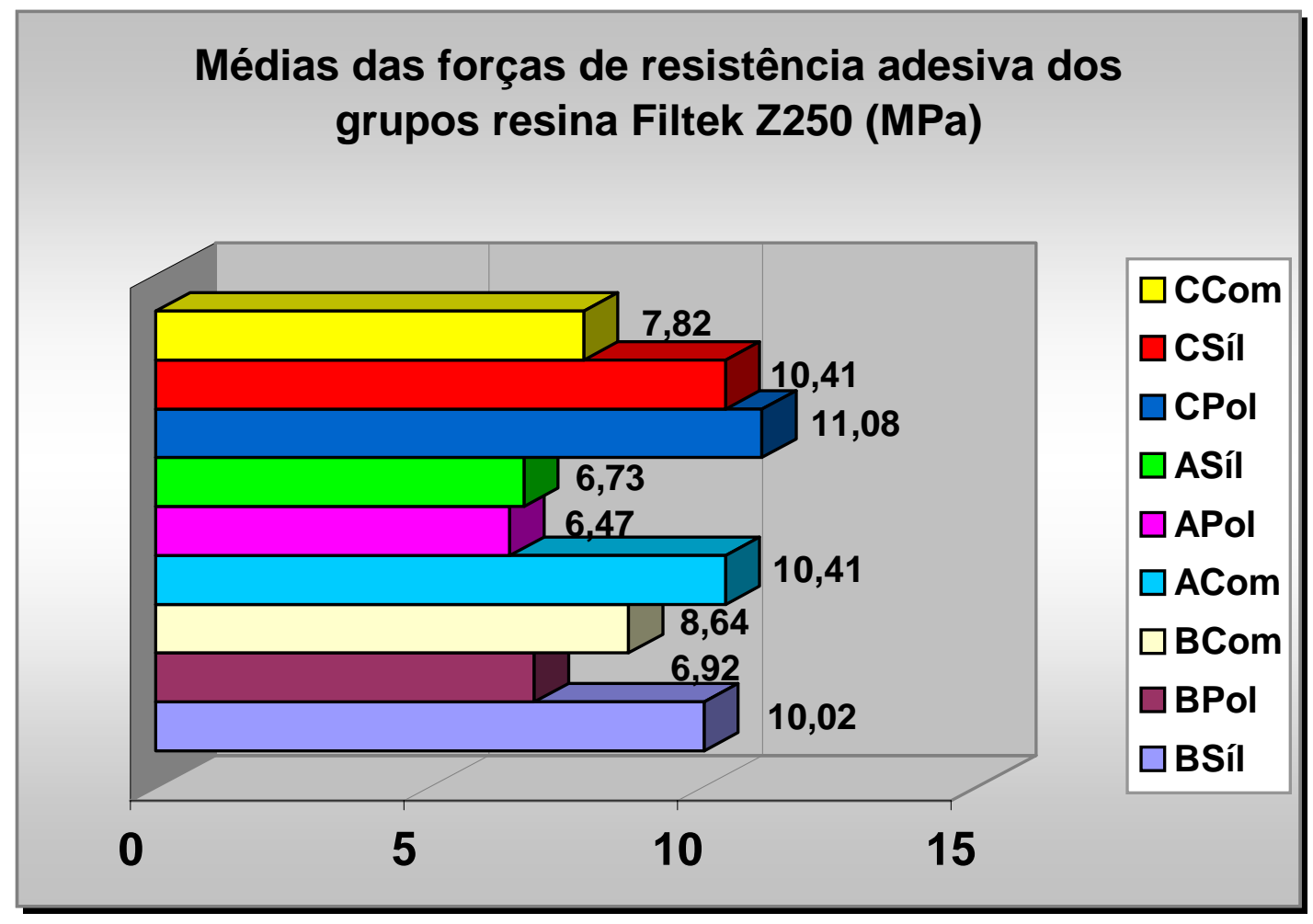

Gráfico 2: Médias das forças de resistência adesiva ao cisalhamento dos grupos realizados com a resina composta Filtek $Z 250^{\mathrm{TM}}$, através dos 3 sistemas adesivos combinados a três formulações de ácido (polímero, sílica e comercial), sendo que na legenda a primeira letra corresponde aos sistemas:Gluma A, Gluma B, e adesivo comercial (C). 
Nos grupos restaurados com a resina Filtek $\mathrm{Z} 250^{\mathrm{TM}}$ quando verificamos a influência dos espessantes na resistência ao cisalhamento utilizando os diferentes sistemas adesivos através do teste de ANOVA, observamos que não houve diferença significante entre os tipos de espessantes utilizados $(P<0,01)$. As médias e desvio padrão dos grupos restaurados com a resina composta Filtek Z 250 ${ }^{\text {TM }}$ estão na TABELA 11.

TABELA 11: Média e Desvio padrão dos grupos realizados com a resina Filtek $\mathrm{Z} 250^{\mathrm{TM}}$ e teste de Tukey.

\begin{tabular}{|c|c|c|c|}
\hline & Ácido comercial & Ácido sílica & Ácido polímero \\
\hline Gluma A & $10,413 \pm 3,663$ & $6,738 \pm 1,757$ & $6,600 \pm 2,785$ \\
\hline Gluma B & $8,638 \pm 2,755$ & $10,025 \pm 3,273$ & $6,925 \pm 2,605$ \\
\hline Adesivo C & $7,825 \pm 3,565$ & $10,413 \pm 3,663$ & $11,088 \pm 3,478$ \\
\hline
\end{tabular}

Quando comparamos individualmente pelo teste de Tukey, verificamos as diferenças entre as formulações de ácido em relação a cada sistema adesivo. Não houve diferença estatisticamente significante quando as diferentes formulações de ácido foram comparadas entre si, independente do sistema adesivo utilizado, com nível de significância de 1\% (TABELA 12). 
TABELA 12: Comparação individual pelo teste de Tukey entre as formulações dos ácidos em relação a cada sistema adesivo na resistência ao cisalhamento, dos grupos restaurados com a resina Filtek $\mathrm{Z} 250^{\mathrm{TM}}$.

\begin{tabular}{|c|c|c|c|}
\hline & GLUMA A & GLUMA B & Adesivo C \\
\hline Com. x sílica & 3,675 & $-1,388$ & $-2,588$ \\
\hline Com. x polímero & 3,813 & 1,713 & $-3,263$ \\
\hline Polímero x sílica & $-0,138$ & $-3,100$ & 0,675 \\
\hline
\end{tabular}

Quando aplicamos os testes de ANOVA a um critério nos grupos restaurados com a resina Filtek $\mathrm{Z} 250^{\mathrm{TM}}$, condicionados com ácido fosfórico a 37\% espessado com sílica coloidal e comparamos os 3 sistemas adesivos, verificamos que não houve diferenças estatisticamente significantes entre os sistemas adesivos estudados $(P>0,05)$.

Os grupos condicionados com ácido fosfórico comercial a 37\% e restaurados com a resina Filtek $\mathrm{Z} 250^{\mathrm{TM}}$ quando submetidos ao teste de ANOVA a um critério mostrou que não houve diferenças estatisticamente significantes $(P>0,05)$ nos resultados obtidos com os 3 sistemas adesivos.

Quando comparamos os sistemas adesivos nos grupos restaurados com a resina Filtek $\mathrm{Z} 250^{\mathrm{TM}}$ e condicionados com ácido fosfórico a $37 \%$ e espessado com polímero, verificamos que houve diferenças estatisticamente significantes entre os sistemas $(P<0,05)$. O teste de Tukey mostrou que o sistema comercial (C) apresentou resultados estatisticamente melhores $(P<0,05)$ que os sistemas Gluma A e Gluma B. Quando os resultados obtidos 
com os sistemas Glumas A e B foram comparados entre si, não houve diferenças estatisticamente significantes ( $P>0,05)$ (TABELA 13).

TABELA 13: Comparação individual pelo teste de Tukey entre os sistemas adesivos em relação a cada formulação de ácido empregado, nos grupos restaurados com a resina Filtek $\mathrm{Z} 250^{\mathrm{TM}}$

\begin{tabular}{|c|c|c|c|}
\hline & Ácido comercial & Ácido sílica & Ácido polímero \\
\hline A $\times$ B & 1,775 & $-3,288$ & $-0,450$ \\
\hline A $\times$ C & 2,588 & $-3,675$ & $-4,613$ * \\
\hline B $\times$ C & 0,813 & $-0,388$ & $-4,163$ * \\
\hline
\end{tabular}

* diferença estatisticamente significante $(P<0,05)$.

Em todos os grupos, nenhuma falha do tipo coesiva foi observada em dentina, a grande maioria falhou na interface dentina/resina ou mista com falha coesiva em resina. As quantificações dos tipos de falhas obtidas durante o teste estão representadas nas TABELAS 14 e 15.

TABELA 14 - Quantificação dos tipos de falhas apresentadas pelos espécimes, considerando o sistema adesivo utilizado.

\begin{tabular}{c|c|c|c}
\hline & \multicolumn{3}{|c}{ TIPOS DE FALHAS } \\
\hline BEAUTIFIL & Adesiva & Mista & Coesiva \\
\hline Gluma A & $54,17 \%$ & $45,83 \%$ & $0 \%$ \\
\hline Gluma B & $33,33 \%$ & $66,67 \%$ & $0 \%$ \\
\hline Adesivo C & $37,5 \%$ & $62,5 \%$ & $0 \%$ \\
\hline Filtek Z 250 $^{\text {TM }}$ & Adesiva & Mista & Coesiva \\
\hline Gluma A & $58,33 \%$ & $41,67 \%$ & $0 \%$ \\
\hline Gluma B & $50 \%$ & $50 \%$ & $0 \%$ \\
\hline Adesivo C & $37,5 \%$ & $62,5 \%$ & $0 \%$ \\
\hline
\end{tabular}


TABELA 15- Quantificação dos tipos de falhas apresentadas pelos espécimes, considerando a formulação de ácido utilizado.

\begin{tabular}{|c|c|c|c|}
\hline \multirow[b]{2}{*}{ BEAUTIFIL } & \multicolumn{3}{|c|}{ TIPOS DE FALHAS } \\
\hline & Adesiva & Mista & Coesiva \\
\hline Ácido comercial & $37,5 \%$ & $62,5 \%$ & $0 \%$ \\
\hline Ácido sílica & $58,33 \%$ & $41,67 \%$ & $0 \%$ \\
\hline Ácido polímero & $41,67 \%$ & $58,33 \%$ & $0 \%$ \\
\hline Filtek Z $250^{\mathrm{TM}}$ & Adesiva & Mista & Coesiva \\
\hline Ácido comercial & $33,33 \%$ & $66,67 \%$ & $0 \%$ \\
\hline Ácido sílica & $37,5 \%$ & $62,5 \%$ & $0 \%$ \\
\hline Ácido polímero & $41,67 \%$ & $58,33 \%$ & $0 \%$ \\
\hline
\end{tabular}

\section{C- Análise da morfologia Interfacial em MEV}

O condicionamento da dentina com ácido fosfórico 37\%, independente do espessante, removeu a smear layer, abriu e aumentou o diâmetro dos túbulos dentinários (Figs 20, 21 e 22). As fotomicrografias das superfícies de dentina tratadas com ácido fosfórico 37\% comercial e experimental espessados por sílica mostraram que partículas residuais de sílica permaneciam na superfície de dentina mesmo após a lavagem (Figs. 23 e 24). Quando a superfície da dentina foi condicionada com o ácido fosfórico 37\% experimental espessado com polímero os túbulos dentinários estavam abertos e a superfície apresentava-se limpa e descontaminada (Fig. 25). 

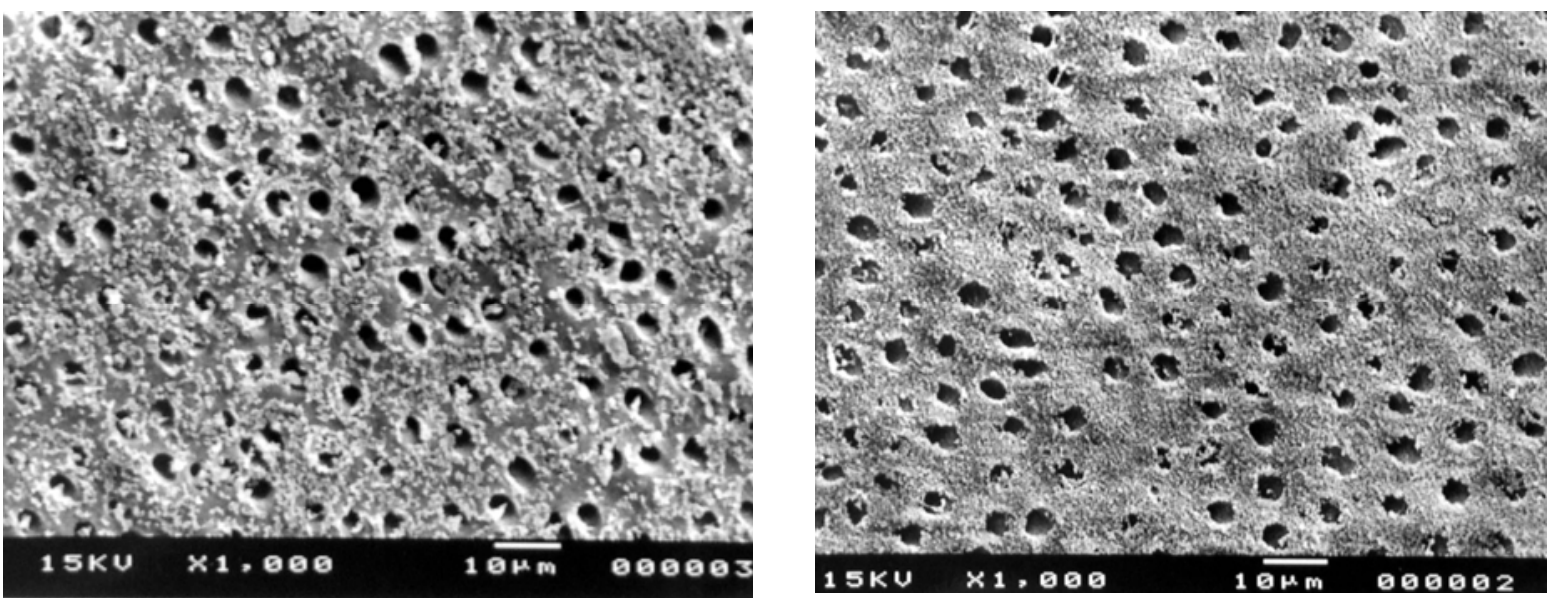

Fig. 20- Superfície condicionada com ácido fosfórico 37\% gel espessado com sílica. Smear layer foi removida e os túbulos dentinários abertos. Resíduos de sílica podem ser observados.(1000x)

Fig. 21- Superfície condicionada com ácido fosfórico 37\% gel comercial. Smear layer foi removida e os túbulos dentinários abertos.(1000x)
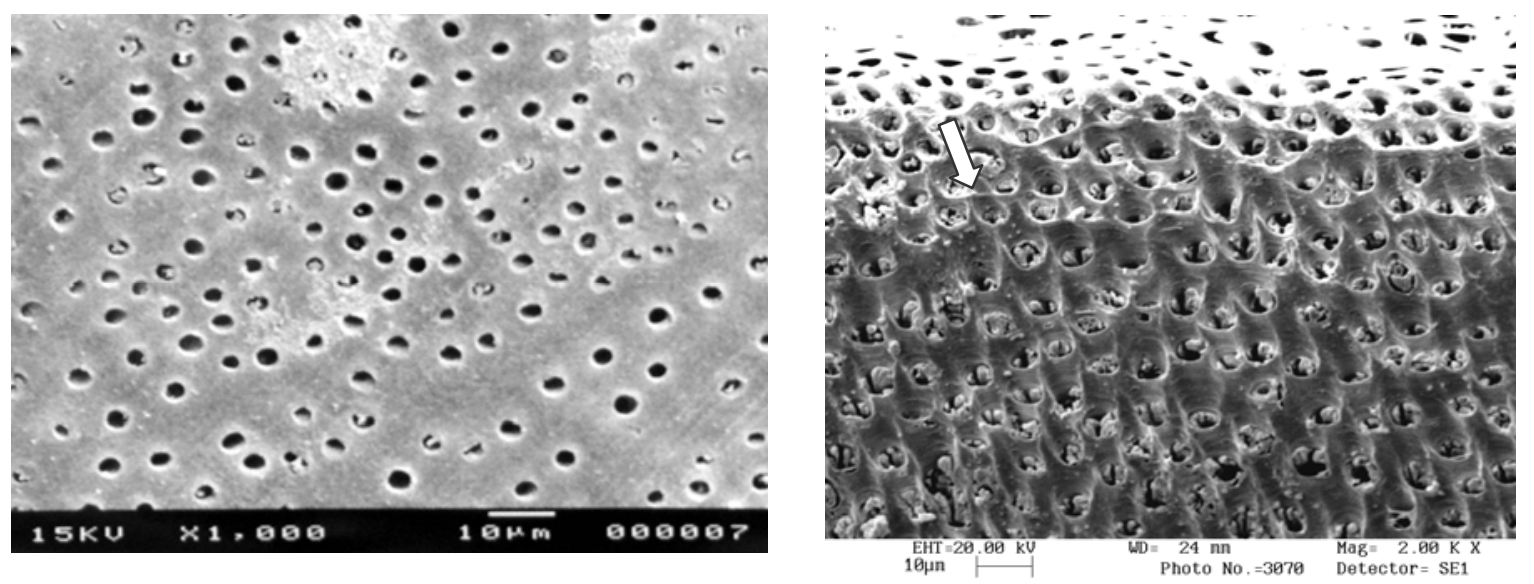

Fig. 22- Superfície condicionada com ácido fosfórico 37\% gel espessado com polímero. Smear layer foi removida e os túbulos dentinários abertos.(1000x)

Fig. 23- Fotomicrografia ilustrando a superfície da dentina tratada com ácido fosfórico comercial vista em uma secção longitudinal. Note a abertura dos túbulos dentinários, mas mesmo após a lavagem ficaram resíduos de sílica na superfície dentinária (seta). (2000 x) 

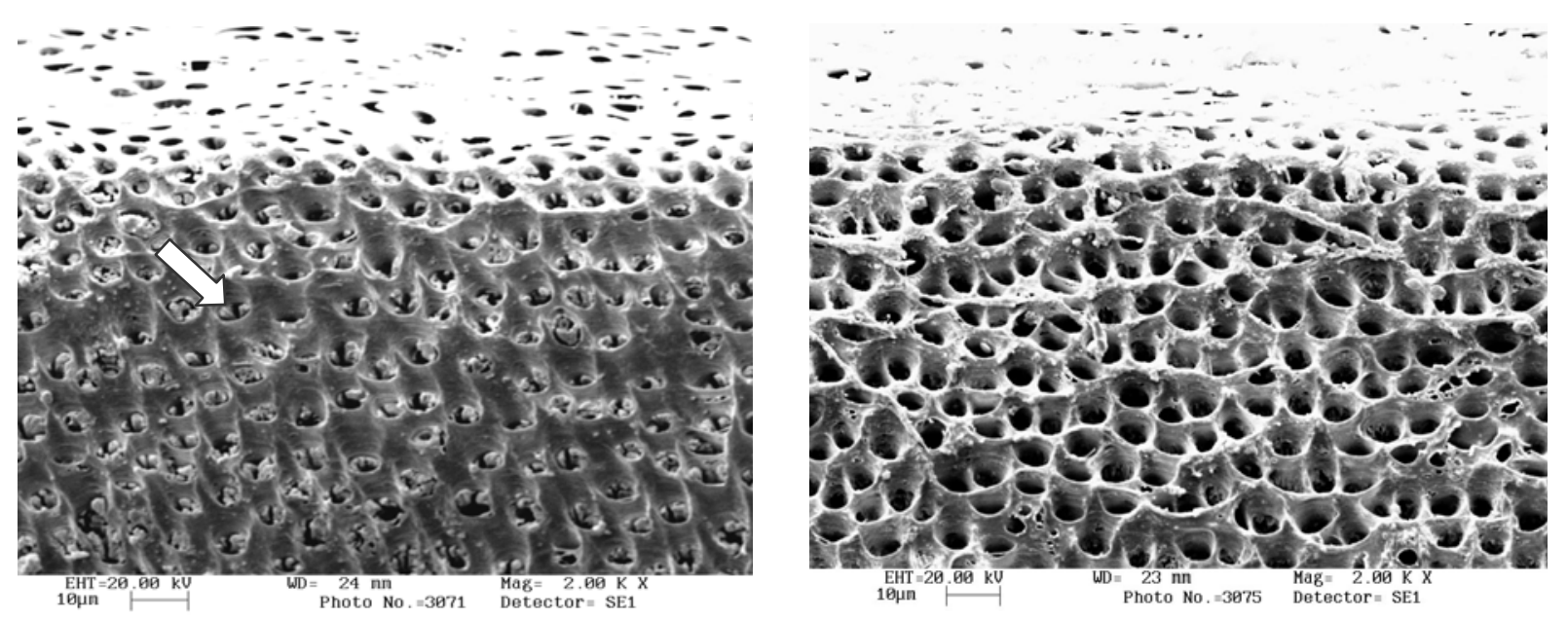

Fig. 24- Fotomicrografia ilustrando a superfície dentinária após o condicionamento com ácido experimental espessado com sílica vista em uma secção longitudinal. Note a abertura dos túbulos dentinários, mas mesmo após a lavagem ficaram resíduos de sílica na superfície dentinária (seta). (2000 x)

Fig. 25- Fotomicrografia ilustrando a superfície da dentina após o condicionamento com ácido experimental espessado com polímero. Os túbulos dentinários apresentavam-se abertos, porém sem resíduos do agente condicionante. $(2000 \mathrm{x})$

Após a dentina ter sido desmineralizada e desproteinizada numerosos tags de resina se tornaram evidentes, independente de qual sistema adesivo tenha sido utilizado (Figs 26 e 27). Quando os dentes não foram parcialmente desproteinizados, ou seja, submetidos à imersão em hipoclorito de sódio, os tags pareceram estar cobertos com uma matriz orgânica e observamos somente a camada híbrida (Figs. 28 e 29). 

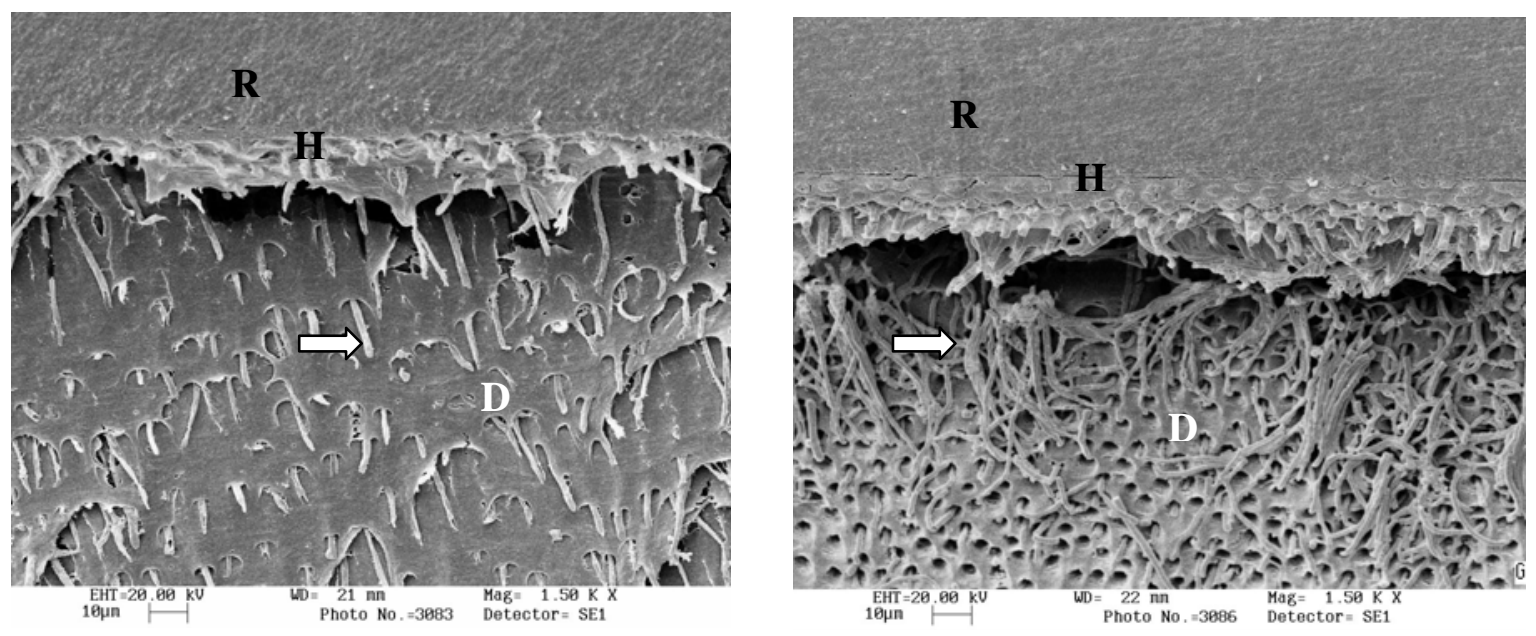

Fig. 26- Fotomicrografia ilustrando a interface dentina/resina composta Filtek $Z$ $250^{\mathrm{TM}}$ produzida pelo Gluma A, após o tratamento com $\mathrm{HCl}$ e $\mathrm{NaOCl}$. A formação dos tags de resina pode ser observada (seta). (1500 x)

Fig. 27- Fotomicrografia ilustrando a interface dentina/resina composta Filtek Z $250^{\mathrm{TM}}$ produzida pelo Gluma $\mathrm{B}$, após o tratamento com $\mathrm{HCl}$ e $\mathrm{NaOCl}$. Os tags de resina são mais longos (seta) e a camada híbrida mais espessa (H).(1500 x)
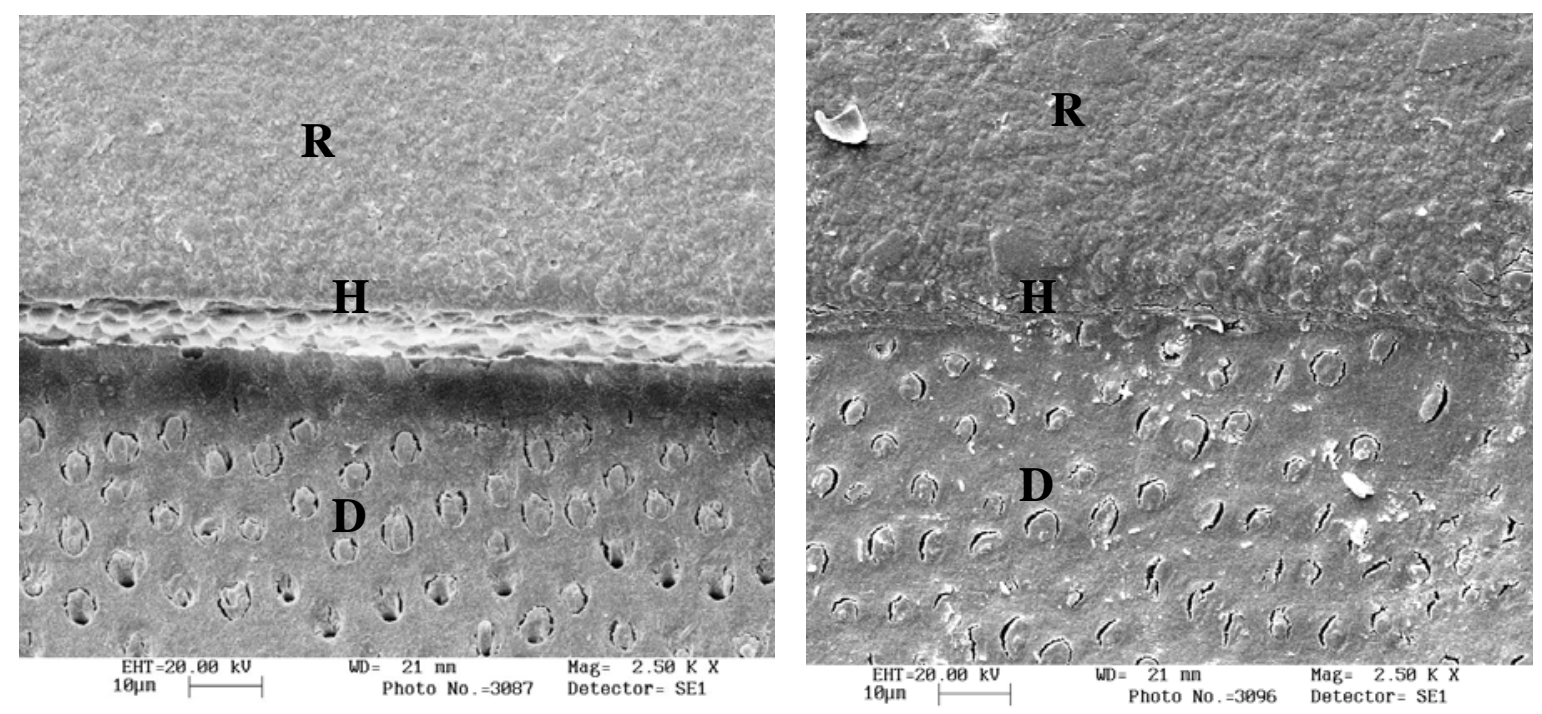

Fig. 28- Fotomicrografia ilustrando a intertace dentına/resına composta Filtek $Z$ $250^{\mathrm{TM}}$ produzida pelo Gluma 2 (B), não submetida a desproteinização com $\mathrm{NaOCl}$ (2500 x)

Fig.29- Fotomicrografia ilustrando a interface dentina/resina composta Beautifil produzida pelo sistema comercial (C), não submetida a desproteinização com $\mathrm{NaOCl} .(2500 \mathrm{x})$ 
A penetração da resina no interior dos túbulos dentinários e a formação da zona de interdifusão dentina/resina ou camada híbrida pôde ser visualizada em todos os sistemas adesivos utilizados neste estudo (Gluma A, B e adesivo comercial). Nos grupos que o sistema adesivo Gluma A foi utilizado, observamos uma camada híbrida fina, tags de resina mais curtos embora em algumas fotomicrografias apresentaram-se longos (Fig. 30). Para os sistemas Gluma B e adesivo comercial podemos observar uma camada híbrida mais espessa e tags de resina mais longos que os formados com o sistema de Gluma A (Figs. 31 e 32). Nos sistemas Gluma B e adesivo comercial, a presença de ramificações laterais nos tags de resina. Muitos dos tags de resina, especialmente nos espécimes dos sistemas Gluma B e comercial (C), observados em secção sagital mostraram um núcleo de resina, circundados por uma camada de dentina, infiltrada por resina (Fig. 31). Nas figuras 31 e 32, verificamos ramificações laterais dos tags de resina. Nenhuma correlação significante foi verificada entre a espessura da camada híbrida e a resistência ao cisalhamento. 

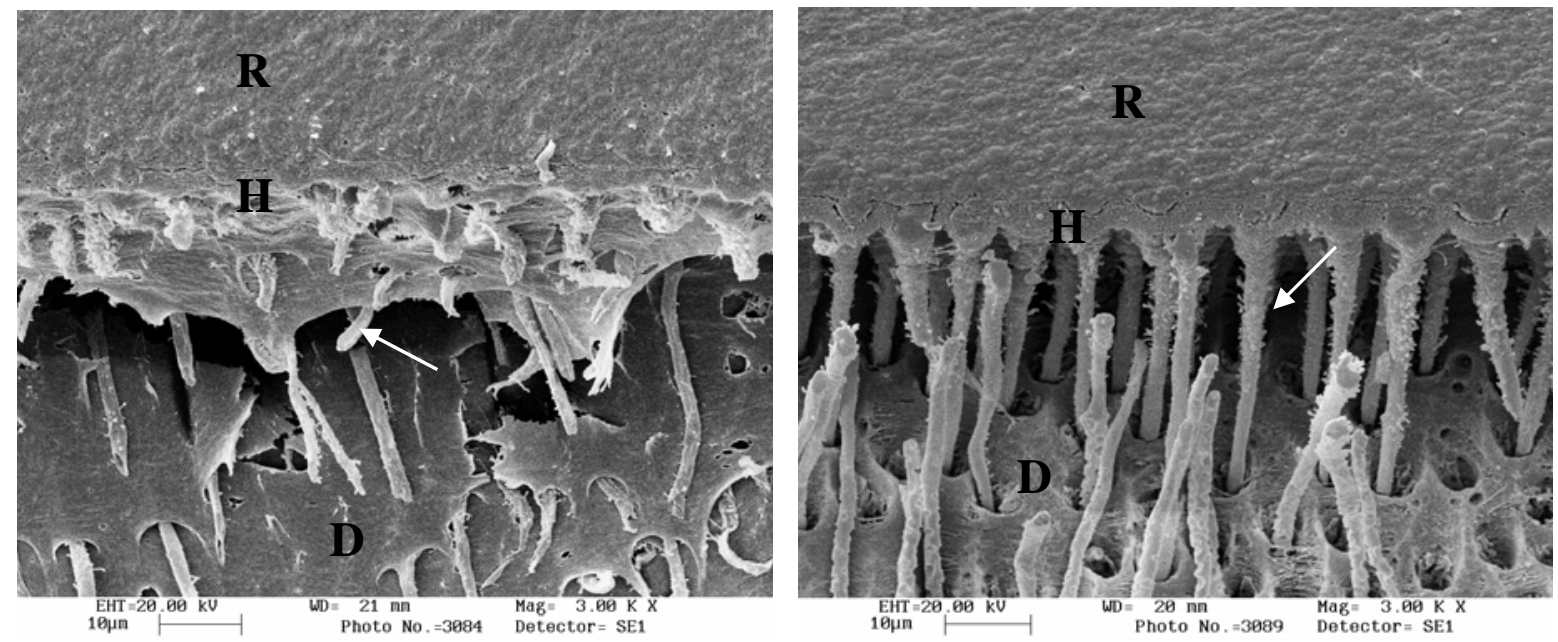

Fig. 30- Fotomicrografia da interface unida com Gluma A restaurada com a resina composta Filtek $Z$ 250. Camada híbrida, ácido resistente, é fina e com muitos tags de resina curtos. (3000 x)

Fig. 31- Fotomicrografia da interface unida com Gluma B restaurada com a resina composta Filtek $Z$ 250. Camada híbrida, ácido resistente, é mais espessa e com muitos tags de resina longos. Há presença de ramificações laterais. $(3000 \mathrm{x})$

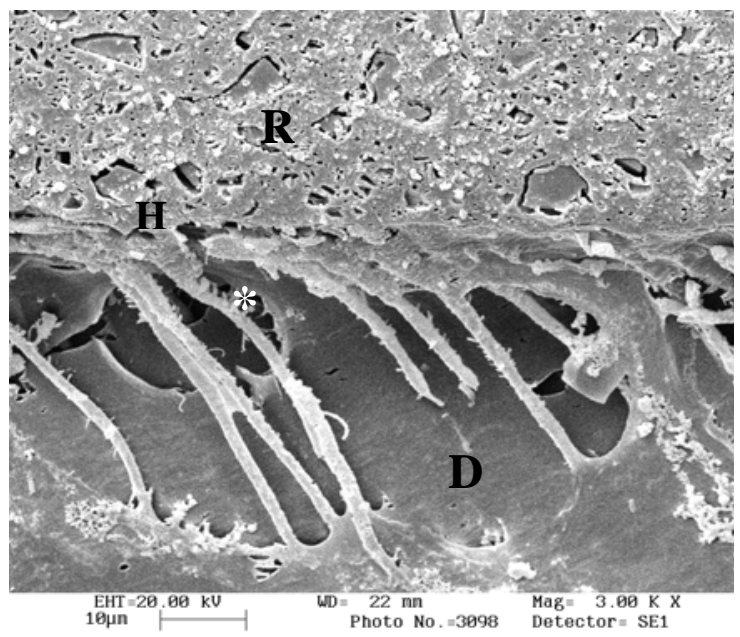

Fig. 32- Fotomicrografia da interface unida com adesivo comercial restaurada com a resina composta Beautifil. Camada híbrida, ácido resistente, é mais espessa e os tags de resina são longos. Há presença de ramificações laterais $\left({ }^{*}\right) \cdot(3000 \mathrm{x})$ 


\section{6- DISCUSSÃO}

No presente estudo, foram utilizados dentes bovinos, em razão da dificuldade na obtenção de um grande número de dentes humanos extraídos e livres de cárie, assim sendo, optamos pelo substrato dental bovino durante a execução do teste de resistência de união através do ensaio de cisalhamento, descrita nos estudos prévios de NAKAMICHI; IWAKU; FUSAYAMA, 1983, RETIEF et al., 1990, FOWLER et al., 1992, SCHILKE et al., 1999, LOPES et al., 2003, TORII et al., 2003. O estudo de SCHILKE et al., em 1999, demonstrou que a resistência adesiva com a dentina superficial, humana e bovina, não apresentou diferença significante, sendo que a resistência adesiva em dentina profunda diminuiu de acordo com o aumento desta profundidade, devido à redução progressiva na densidade da dentina (dentina intertubular). Os valores de resistência de união dependeram de vários fatores, como sistema adesivo, local e estrutura dentária e ainda das diversas situações clínicas de acordo com o que foi verificado por ISHIOKA; CAPUTO; 1989, EICK et al., 1991, SANO et al., 1998, FINGER; BALKENHOL, 1999, MIYASAKI; IWASAKI; ONOSE, 2002. Estudos em condições laboratoriais podem ser divergentes dos obtidos em situações clínicas. No trabalho realizado por SCHILKE et al., em 1999, nenhuma diferença significante foi constatada quando a dentina humana coronária foi comparada com a dentina coronária dos dentes bovinos. Os testes de resistência adesiva ao cisalhamento, em dentina de dentes bovinos, demonstraram que esse substrato pode ser usado como substituto para dentina permanente humana. Entretanto devemos utilizar a porção coronária e não a radicular, pois os ensaios de resistência adesiva 
sobre o substrato radicular bovino podem apresentar resultados diferentes (NAKAMICHI et al., 1983, LOPES et al., 2003).

Os diferentes testes de adesão foram estudados por PASHLEY et al., em 1995b, e concluíram que o ensaio de resistência ao cisalhamento pode apresentar tendência à flexão, porém foi o método considerado como o de maior facilidade de execução. AL-SALEHI; BURKE, em 1997, concluíram que os testes de cisalhamento predominaram em $80 \%$ dos trabalhos analisados sobre resistência adesiva analisados. Sendo assim, no presente estudo o ensaio de resistência ao cisalhamento foi realizado com a finalidade de avaliar a adesão dos sistemas adesivos experimentais (Gluma A e B) e comercial (Prime \& Bond 2.1) à estrutura dentinária bovina. O sistema Gluma A foi preparado seguindo uma formulação do trabalho de ARAÚJO; ASMUSSEN, em 1997, e o sistema Gluma B, seguindo uma formulação do trabalho de ARAÚJO; ASMUSSEN, realizado em 1989.

Nos ensaios de microtração, a resistência de união do material adesivo é analisada sobre pequenas regiões da interface adesiva e, como a área submetida ao teste é menor, em torno de $1 \mathrm{~mm}^{2}$, há uma melhor distribuição da tensão sobre o espécime, ocorrendo maior incidência de falhas adesivas (SANO, 1994; PASHLEY, 1999) permitindo uma análise real da resistência de união entre os materiais envolvidos. Nos testes de tração e cisalhamento, a alta incidência de falhas coesivas pode distorcer os resultados da resistência de união adesiva (PASHLEY et al., em 1995b). No presente estudo, apesar de executado o tradicional teste de resistência ao cisalhamento, as análises das regiões de fratura não registraram falhas coesivas, tanto em relação aos 
diferentes sistemas adesivos quanto aos diferentes condicionamentos ácidos utilizados. Então, podemos afirmar que mesmo em ensaios tradicionais, uma execução a rigor do método, pode minimizar as dificuldades postuladas e até mesmo as inerentes ao ensaio.

Segundo a literatura consultada, não há consenso até o momento entre os pesquisadores quanto à classificação do tipo de falha e método de análise; se através de lupa estereoscópica (NAKAJIMA et al., 1995, SANO et al., 1994) ou por MEV (KWONG et al., 2002, NAKAJIMA et al., 2000, RETIEF et al., 1990). No presente estudo, a análise do tipo de falha foi realizada através do método estereoscópico, e utilizamos o MEV para analisarmos a morfologia da camada híbrida e da dentina condicionada. A estereoscopia permitiu a constatação da ligação fraca, localizada no topo da camada híbrida, demonstrando alta resistência da matriz desmineralizada, o que também foi relatado por SANO et al.. (1994).

As regiões onde ocorreram as falhas adesivas encontradas no presente estudo (adesiva ou mista com falha coesiva em resina), não indicaram haver relação com a espessura da camada híbrida, concordando com UNO; FINGER, em 1995a, PRATI et al., em 1999.

A microscopia eletrônica de varredura tem sido utilizada extensivamente para caracterizar o substrato e os mecanismos de união dos sistemas adesivos. Durante o preparo dos espécimes para microscopia eletrônica de varredura, a secagem dos mesmos é necessária para se obter alto vácuo, com o prejuízo de induzir certa contração dos espécimes, afetando suas dimensões originais. ITOU et al., em 2003, estudaram a possível 
contração da camada híbrida durante a metalização dos espécimes em alto vácuo, em relação ao teor de água existente e concluíram que a secagem, em ponto crítico, produziu camadas híbridas mais espessas que a secagem em temperatura ambiente. CARVALHO et al., em 1996b, compararam três métodos de secagem durante o preparo dos espécimes para análise em MEV. A secagem em HMDS mostrou ser mais efetiva do que a secagem em ponto crítico. Já os espécimes fixados em formalina obtiveram a maior contração após a secagem, independente do método estudado. No presente estudo, os espécimes foram fixados em solução tampão de fosfato de sódio a 0,1 M com 2,5 \% de glutaraldeído, com desidratação em soluções crescentes de etanol e secagem em solução de HMDS. Observamos, em alguns espécimes, que houve a contração da camada híbrida e do material restaurador, formando uma fenda na interface dentina/restauração, podendo ser atribuído ao método de fixação e secagem dos espécimes (PASHLEY, 1993, CARVALHO et al., 1996b) (Fig. 33).

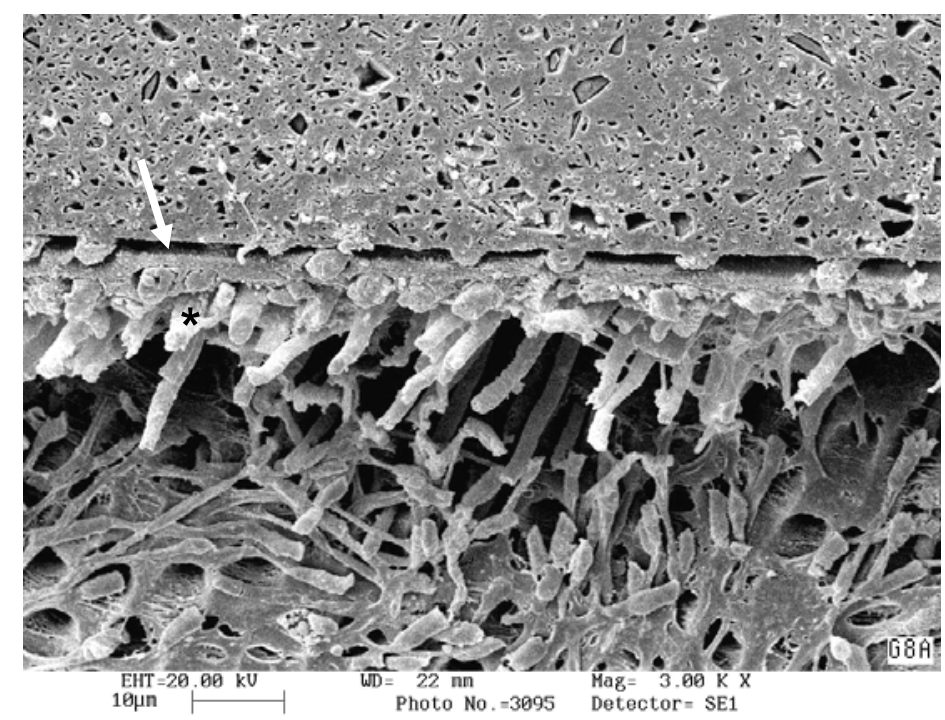

Fig. 33- Fotomicrografia da interface dentina/resina do sistema Gluma A, restaurado com resina composta Beautifil. Observamos uma fenda (seta) na interface adesiva, mas há formação de tags de resina $\left(^{*}\right) .(3000 x)$ 
O mecanismo tradicional de união da resina composta com dentina consiste de três etapas: condicionamento ácido dentinário, aplicação do primer e do agente adesivo (VAN MEERBEEK et al., 1998). O condicionamento ácido remove a smear layer, desobstrui os túbulos dentinários, resultando em uma matriz de colágeno separada por microporos dentro da dentina intertubular. (VANMEERBEEK, 1992a, PASHLEY et al., 1993, SANO et al., 1994) Um dos objetivos deste estudo foi observar o efeito de cada uma das três etapas do mecanismo de união sobre a resistência ao cisalhamento. Então, baseados nos resultados de COLLI et al., 1999, VAN MEERBEEK et al., 1992b, foi proposto o condicionamento ácido da dentina com três formulações de ácido fosfórico à 37\%, variando o espessante, na tentativa de estabelecer parâmetros para rugosidade superficial da dentina e a possível influência sobre a resistência adesiva. Os ácidos experimentais foram espessados com sílica silanizada ou polímero (PMMA) e o ácido comercial (controle) espessado com sílica coloidal. Os resultados do condicionamento, com os ácidos com polímero e comercial, não demonstraram diferença significante sobre a rugosidade da superfície dentinária, somente o ácido experimental espessado com sílica. Os diferentes espessantes não influenciaram a resistência ao cisalhamento, tanto para o grupo restaurado com resina composta Filtek $\mathrm{Z} 250^{\mathrm{TM}}$ quanto para o grupo restaurado com resina composta Beautifil.

COLLI et al., em 1999, compararam a rugosidade superficial da dentina frente à diferentes métodos de condicionamento ácido, ora desmineralizando parcialmente a dentina através de ácido fosfórico 37\%, ora removendo as fibrilas de colágeno com hipoclorito a 2,5\% (após o condicionamento ácido) e 
ora preservando a smear layer. Obtiveram um grau de rugosidade significantemente menor no grupo em que a smear layer foi preservada. GWINNETT et al., em 1994, COLLI et al., em 1999, encontraram correlação entre rugosidade superficial da dentina e resistência ao cisalhamento. Nos resultados obtidos por COLLI et al., em 1999, houve um aumento na rugosidade superficial e na área de superfície dos espécimes quando condicionados com ácido fosfórico seguido pela remoção das fibrilas de colágeno. Houve um aumento na resistência ao cisalhamento na dentina cervical, mas a correlação foi limitada. No presente trabalho, a rugosidade superficial da dentina, antes e após o condicionamento ácido, aumentou somente nos espécimes condicionados com ácido experimental espessado com sílica, não estabelecendo uma relação entre rugosidade superficial e resistência ao cisalhamento. As diferentes formulações de ácido não influenciaram a resistência ao cisalhamento dos grupos restaurados com as resinas compostas Filtek $\mathrm{Z} 250^{\mathrm{TM}}$ e Beautifil. Através da análise das fotomicrografias verificamos que o condicionamento ácido da dentina, independente da formulação, removeu a smear layer, abriu e aumentou o diâmetro dos túbulos e criou porosidades na região intertubular, na qual ficou evidente a exposição da matriz de dentina, concordando com os trabalhos de GWINNETT, em 1993, PASHLEY et al., em 1993. (Fig. 34)

O espessante à base de polímero foi totalmente removido pela lavagem com água. Já para os ácidos onde a sílica foi utilizada como espessante, mesmo após a lavagem por 40s, verificamos a presença de resíduos de sílica na superfície de dentina, tanto para o ácido comercial como para o 
experimental (Fig 34). O depósito de vários minerais ou sais dos condicionadores na superfície de dentina pode influenciar a resistência de união, pois KANCA, em 1993, constatou que em todos sistemas adesivos testados em seu trabalho a menor resistência de união foi obtida após o uso de condicionador ácido contendo oxalato e a maior resistência de união foi observada na dentina condicionada com ácido fosfórico sem sílica ou oxalato. O trabalho de UNO, FINGER, em 1995a mostrou que a concentração do ácido fosfórico, a quantidade de sílica (espessante) e o tempo de condicionamento apresentaram diferentes efeitos na resistência de união com a dentina e no selamento marginal da resina composta, aderida por Gluma. Entretanto, no presente trabalho, não houve influência das diferentes formulações de ácido sobre a resistência ao cisalhamento.

UNO, FINGER, em 1995a, analisaram a resistência de união e a superfície dentinária com fotomicrografias (MEV), afirmando que o pirogênico óxido de sílica, adicionado aos ácidos líquidos como agente espessante, não teve efeito adverso na eficiência de união do sistema Gluma, embora resíduos não tenham sido facilmente removidos da dentina pela lavagem. Fotomicrografias semelhantes foram obtidas, no presente estudo (Fig.34). O agente espessante alternativo, o polímero em pó, utilizado também em ácidos comerciais, não deixou resíduos após a lavagem da superfície condicionada. 


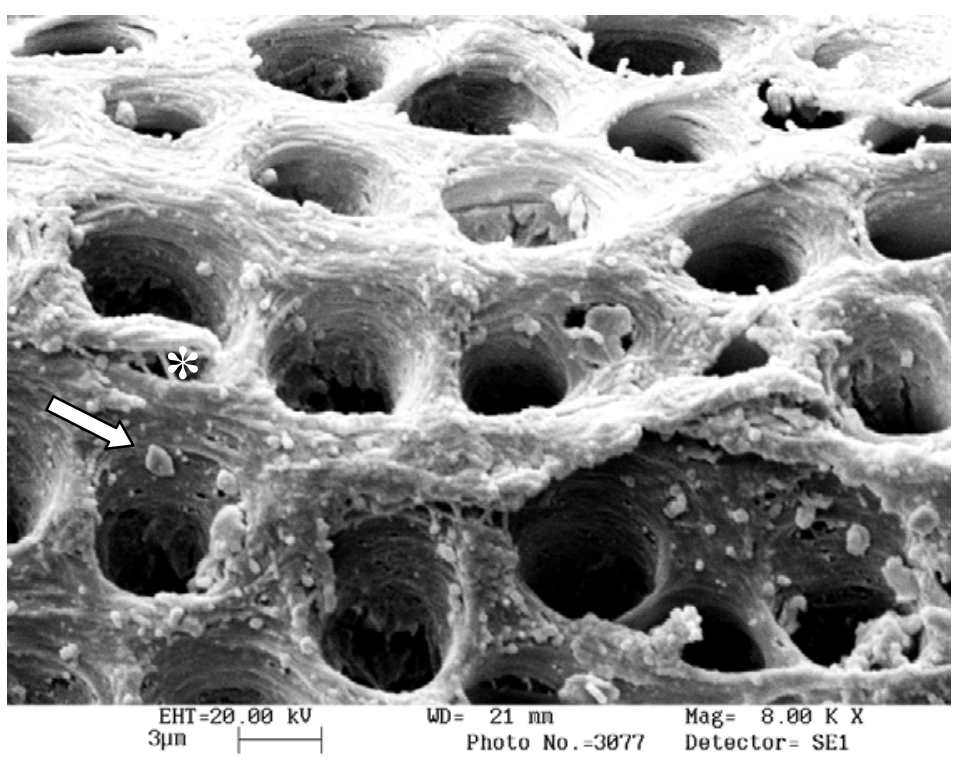

Fig. 34 - Fotomicrografia da superfície tratada com ácido fosfórico 37\% experimental espessado com sílica. A dentina intertubular esta porosa e rugosa na embocadura dos túbulos. Nota-se a presença de resíduos de sílica após a lavagem (seta), (*) rede de fibras de colágeno exposta. (8000 x)

Foi aceito que a smear layer, formada no assoalho da cavidade dentinária deve ser removida ou alterada por condicionadores ácidos, sendo considerada uma importante etapa para obter união adequada entre o substrato de dentina e o sistema adesivo (PASHLEY, 1992, COLLI et al., 1999). Quando os condicionadores ácidos removem a fase mineral da dentina ocorre uma alteração radical em sua composição, a água substitui os cristais de apatita, formando uma matriz composta por $30 \%$ de colágeno e $70 \%$ de água (CARVALHO et al., 1996c). Entretanto, a água não oferece o mesmo suporte às fibrilas de colágeno como com os sólidos cristais de apatita, causando o colapso do colágeno desmineralizado após sua remoção com a secagem, alterando a dimensão dos espaços em torno das fibrilas de colágeno, 
tornando a dentina impenetrável pelo agente adesivo (PASHLEY et al., 1993). Caso permaneça alguma água dentro dos espaços interfibrilares, a qualidade de matriz de colágeno é mantida e os espaços interfibrilares também permaneceram abertos (KANCA, 1992b; PERDIGÃO, 1995).

WATANABE; NAKABAYASHI, em 1993, GWINNETT, 1993, afirmaram que a completa remoção da smear layer e a desmineralização do substrato dentinário, facilitou a impregnação do monômero e formação da camada híbrida.

A técnica de adesão úmida pode garantir eficiente interdifusão da resina somente se todo o remanescente de água na superfície da dentina for completamente eliminado e substituído pelos monômeros durante a etapa de aplicação do primer. Em alguns dos sistemas adesivos atuais, o primer hidrofílico é dissolvido em solventes voláteis, tais como acetona e etanol, que podem auxiliar no deslocamento da água remanescente, como também carregar os monômeros polimerizáveis para dentro dos túbulos dentinários abertos e nos espaços da matriz de colágeno (TAY et al., 1996). Os solventes dos primers são então evaporados por um leve jato de ar, levando também parte dos monômeros ativos do primer. As moléculas desses monômeros apresentam um radical hidrofílico, com afinidade pelas fibrilas de colágeno expostas, e um radical hidrofóbico, com afinidade ao adesivo, co-polimerizando com a resina adesiva. Quando a água dentro da matriz de colágeno não é completamente deslocada, a polimerização da resina dentro da camada híbrida pode ser comprometida, pois a água remanescente compete pelo espaço com 
a resina adesiva dentro da dentina desmineralizada (JACOBSEN, SÖDERHOLM, 1995).

Quando a dentina se apresenta com excesso de umidade, tem sido relatado a ocorrência de um fenômeno, denominado de over wetting ou sobremolhamento. Quando a água na superfície de dentina não é completamente substituída pelos primers hidrofílicos tem sido documentado ultramorfologicamente como o fenômeno de sobremolhamento (TAY et al., 1996). Em condições de excesso de umidade, a água que não foi removida durante a aplicação do primer parece causar uma separação dos componentes hidrofóbicos e hidrofílicos, resultando na formação de bolhas e glóbulos na interface dentina/resina. Esta deficiência na interface, indubitavelmente, quebra a união e resulta em selamento incompleto dos túbulos (TAY et al., 1996).

O HEMA é um derivado do metacrilato e componente hidrofílico de muitos sistemas adesivos devido a sua habilidade de permeação pela dentina desmineralizada e em promover adesão dentinária (RITTER; BERTOLLI; SWIFT JR., 2001). Embora sua função na adesão dentária não seja completamente conhecida, o HEMA se infiltra dentro da dentina intertubular durante a adsorção facilitando a difusão dos monômeros resinosos e a formação da camada híbrida (NAKABAYASHI; WATANABE; GENDUSA, 1992). O grupo hidroxila no HEMA se liga com o colágeno exposto devido a sua polaridade de natureza hidrofílica e o grupo metacrilato do HEMA tem alta afinidade com monômeros hidrofóbicos (RITTER; BERTOLLI; SWIFT JR., 2001). O HEMA é um componente conveniente nos sistemas adesivos por sua natureza anfótera, já que esses materiais atuam como um elo de ligação entre 
a superfície de dentina úmida e a resina restauradora hidrofóbica. PAUL et al, em 1999, constataram que a aplicação de um jato de ar intenso pode não remover efetivamente a água, da mistura HEMA e água. A água dentro das fibrilas de colágeno pode localizar-se em áreas mais profundas da matriz, onde sua remoção por jatos de ar é mais difícil. Sob estas condições, a difusão do monômero deve ser mais difícil. Um estudo espectroscópico com Micro Raman demonstrou diminuição na concentração de monômeros no topo da camada híbrida formada pelos adesivos aplicados sob a técnica de adesão úmida (KITASAKO et al., 2001, WANG; SPENCER, 2004). Nas partes mais profundas da camada híbrida, a alta concentração de água pode comprometer a polimerização do adesivo. Pobremente polimerizadas, as cadeias poliméricas ficam frágeis e menos estáveis quando comparadas com aquelas formadas em regiões livres de água (REIS et al., 2004).

A ausência ou baixa concentração de água foi o principal fator que permitiu a polimerização dos adesivos de forma mais efetiva, tornando a ligação mais estável ao longo do tempo (REIS et al., 2004). A direta correlação entre resistência adesiva e a polimerização da resina composta foi demonstrada por YANAGAWA; FINGER, em 1994. No presente trabalho, o sistema Gluma A foi utilizado juntamente com o sistema de união ARM polimerizado quimicamente, já o sistema experimental Gluma B e o sistema comercial (C) são sistemas polimerizados por luz. Diferenças na polimerização entre sistemas adesivos podem ter contribuído para os altos valores de resistência de união dos materiais ativados por luz, concordando com o trabalho de MOTA et al., em 2003. No trabalho realizado por REIS et al., em 
2004, o efeito da sorção da água foi menos evidente nos adesivos polimerizados sob condições de pouca umidade (por $30 \mathrm{~s}$ ). A secagem dos sistemas Gluma A e B, neste trabalho, foi de 5 segundos, mas o sistema Gluma B apresentou valores de resistência de união significantemente mais altos em quase todos os grupos estudados com a resina Beautifil. É interessante saber que a degradação das interfaces unidas pode ser minimizada pelo uso de resinas adesivas mais hidrofóbicas embora estas resinas sejam incompatíveis com o substrato dentinário úmido (REIS et al., 2004). Por mais de 10 anos, a técnica adesiva úmida tem sido recomendada para união dentinária (KANCA, 1992b). Enquanto a dentina está totalmente hidratada, a matriz de colágeno não colapsa e espaços livres estão disponíveis para infiltração dos monômeros resinosos dos sistemas adesivos. (PASHLEY et al., 1993) Baseado neste raciocínio e nos altos valores de resistência ao cisalhamento, em superfícies úmidas, monômeros mais hidrofílicos foram incluídos na composição de sistemas adesivos disponíveis no mercado.

No presente trabalho, o sistema comercial apresenta a acetona em sua composição, o sistema experimental Gluma A foi formulado à base de água e 0 Gluma B, além da água apresentava em sua fórmula o tetrahidrofurano, um solvente bastante volátil. Os maiores valores de resistência ao cisalhamento foram obtidos pelo sistema Gluma $B$, nos grupos restaurados com a resina composta Beautifil, quando comparado ao Gluma A. Na maioria dos grupos desta resina, não houve diferença estatística em relação ao sistema comercial. Os valores de resistência ao cisalhamento, dos espécimes restaurados com a resina composta Filtek $\mathrm{Z} 250^{\mathrm{TM}}$, mostraram diferenças estatísticas somente nos 
grupos condicionados com ácido espessado com polímero. O sistema adesivo comercial apresentou maiores valores que os sistemas Gluma A e B. A razão para estes resultados não está clara, mas pode ser devida à composição do adesivo. Acreditamos que o solvente utilizado no sistema Gluma B, o tetrahidrofurano, comportou-se como a acetona, carregando o excesso de água concomitantemente com a sua evaporação devido à maior pressão de vapor, permitindo uma maior penetração do sistema adesivo na matriz de colágeno (TAY; GWINNETT; WEI, 1996). O tetrahidrofurano provou ser um solvente com propriedades desejáveis: 1- solvente conveniente para os componentes do sistema Gluma; 2- evapora facilmente; 3- deixando um bom filme na superfície do dente. Os resultados com o tetrahidrofurano confirmaram os obtidos por ARAÚJO; ASMUSSEN, em 1989. O sistema Gluma A foi formulado seguindo a composição do sistema adesivo que apresentou maiores valores de resistência ao cisalhamento no trabalho de ARAÚJO; ASMUSSEN, em 1997. Os valores obtidos com o sistema Gluma A, no presente trabalho foram similares aos de VARGAS; COBB; DENEHY, em 1997, sendo que o sistema à base de água resultou em valores mais baixos, de resistência de união, quando aplicado em dentina úmida e isso pode ser explicado pela ausência de solventes voláteis resultando em excesso de água na matriz de colágeno desmineralizada que não foi eliminada junto a evaporação dos solventes.

PASHLEY, em 1993 afirmou que a dentina úmida propiciou uma rede de fibrilas de colágeno mais porosa, permitindo uma maior infiltração dos monômeros adesivos, quando comparada à superfície seca (jatos de ar) que colapsou a rede de fibrilas de colágeno. Essa ocorrência pode explicar os altos 
valores de resistência de união obtidos com a técnica úmida, estudada por KANCA, em 1992a; KANCA, em 1992b. No presente estudo, todos os sistemas adesivos foram aplicados sobre superfície dentinária relativamente úmida. A ausência da camada híbrida pode resultar em uma interface mais rígida, livre de colágeno, com conseqüente concentração de tensão na área e um alto risco de desunião. A penetração de resina dentro dos túbulos dentinários e a formação da camada híbrida foram observadas em todos os grupos do presente estudo, concordando com o trabalho de PERDIGÃO et al., em 2000.

No presente estudo foram observadas variações na espessura da camada híbrida entre os espécimes como ocorrido também em vários estudos (UNO; FINGER, 1996, VARGAS, COBB; DENEHY, 1997). A camada híbrida formada pelos sistemas Gluma B e comercial (C) apresentou-se aparentemente mais espessa que no sistema Gluma A. Os tags de resina formados com o sistema Gluma B e comercial (C) apresentaram-se mais longos e em maior número que os do sistema Gluma A. Este achado pode ser resultado da diferente formulação nos 3 sistemas adesivos. No sistema comercial (C), à base de acetona, e experimental Gluma B, contendo tetrahidrofurano, examinados no presente estudo, a capacidade de carregar a água dos solventes voláteis pareceu deslocar a água efetivamente da matriz intertubular. Houve uma boa infiltração da resina através da matriz de colágeno até mesmo em condições de sobremolhamento, onde o sistema Gluma B, contendo água foi aplicado em dentina úmida, concordando com os resultados de TAY; GWINNETT; WEI, em 1996, quando examinou sistemas à base de acetona. Segundo PERDIGÃO et al., em 2000, as variações da espessura da 
camada híbrida podem ser resultado de dois fatores:1- profundidade de desmineralização obtida de acordo com o ácido utilizado; 2- a camada híbrida pode ser observada em MEV, sendo possível a visualização somente após o seccionamento da interface dentina/resina. Se o seccionamento não for realizado perpendicularmente à interface, a espessura da camada híbrida pode parecer maior, devido à angulação das secções. No presente estudo, embora diferentes espessuras de camada híbrida tenham sido observadas, nenhuma correlação com a resistência de união à dentina foi encontrada, concordando com YOSHIYAMA et al., 1995, SUNICO et al., 2002, KWONG et al., 2002, MIYASAKI; IWASAKI; ONOSE, 2002, SOMPHONE; PEREIRA; TAGAMI, 2002, TORIl et al., 2003.

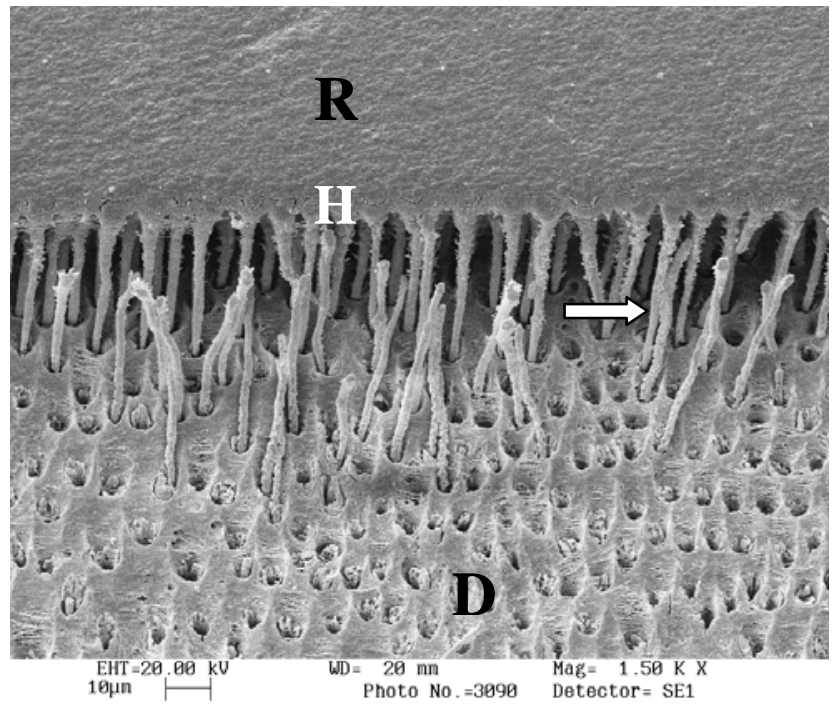

Fig. 35 - Secção transversal da interface unida com o sistema comercial (C) e restaurada com a resina Filtek $Z 250^{\mathrm{TM}}$. Formação dos tags de resina (seta). $\mathrm{R}$ (resina), H (camada híbrida), D (dentina). (1500 x)

Apesar de não encontrarmos uma relação entre a espessura da camada híbrida e a resistência ao cisalhamento, podemos observar que houve 
um menor número de tags formados pelo sistema Gluma A (Fig. 36) quando comparado com os sistemas Gluma B (Fig. 37) e comercial (C) (Fig. 38). No sistema Gluma A observamos tags mais curtos e com até $40 \mu \mathrm{m}$ de comprimento (Fig. 39), o que se assemelhou com os valores obtidos por SUNICO et al., 2002, nos espécimes condicionados com ácido fosfórico 36\% (35 $\mu \mathrm{m}$, em média). Nos sistemas Gluma B e comercial (C) os tags de resina ocorreram em maior número e de maior comprimento; no sistema Gluma 2 (B) tags com até $96,69 \mu \mathrm{m}$ de comprimento e $100,43 \mu \mathrm{m}$ de comprimento no sistema comercial como observado nas Figs. 40 e 41.
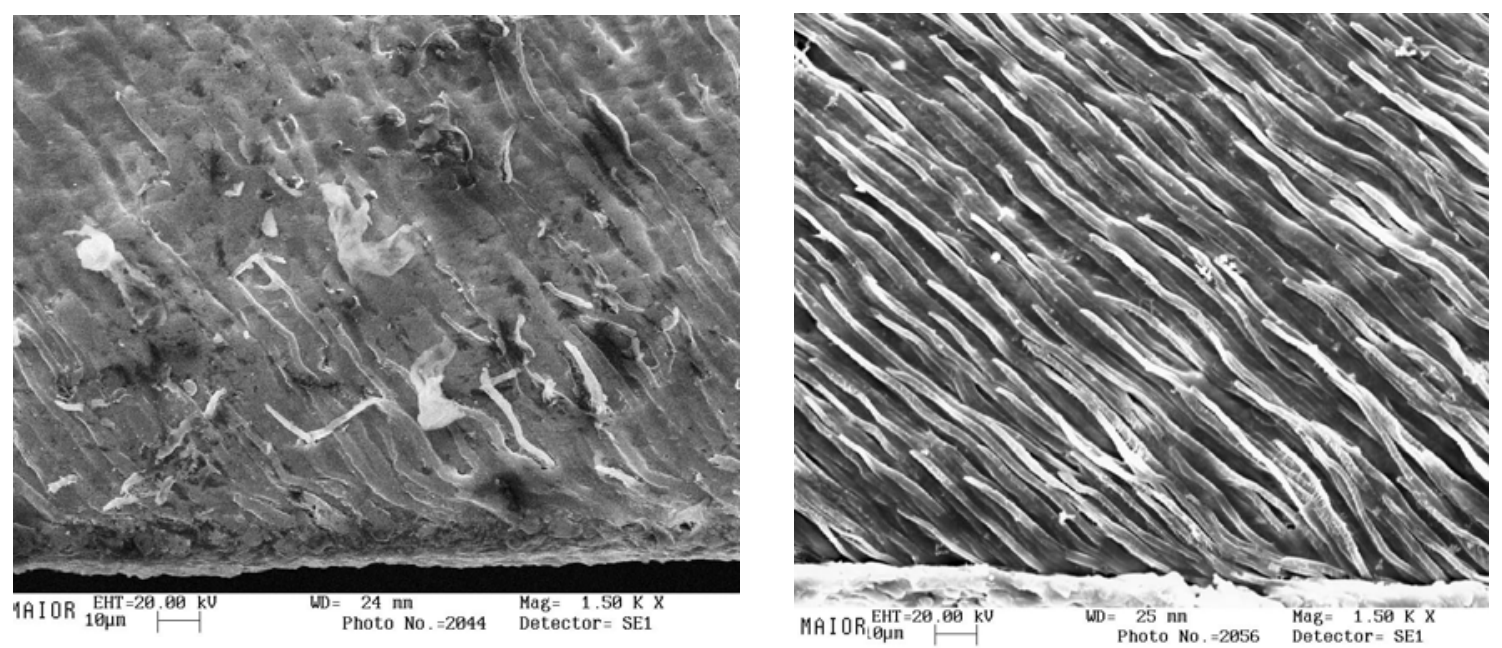

Fig. 36- Fotomicrografia da interface dentina/resina no sistema Gluma A restaurada com a resina Beautifil. Os tags são em menor número, mais curtos e desorganizados. $(1500 \mathrm{x})$

Fig. 37- Fotomicrografia da interface dentina/resina no sistema Gluma B restaurada com a resina Beautifil. Os tags de resina estão em maior número e se apresentam mais longos. (1500 x) 

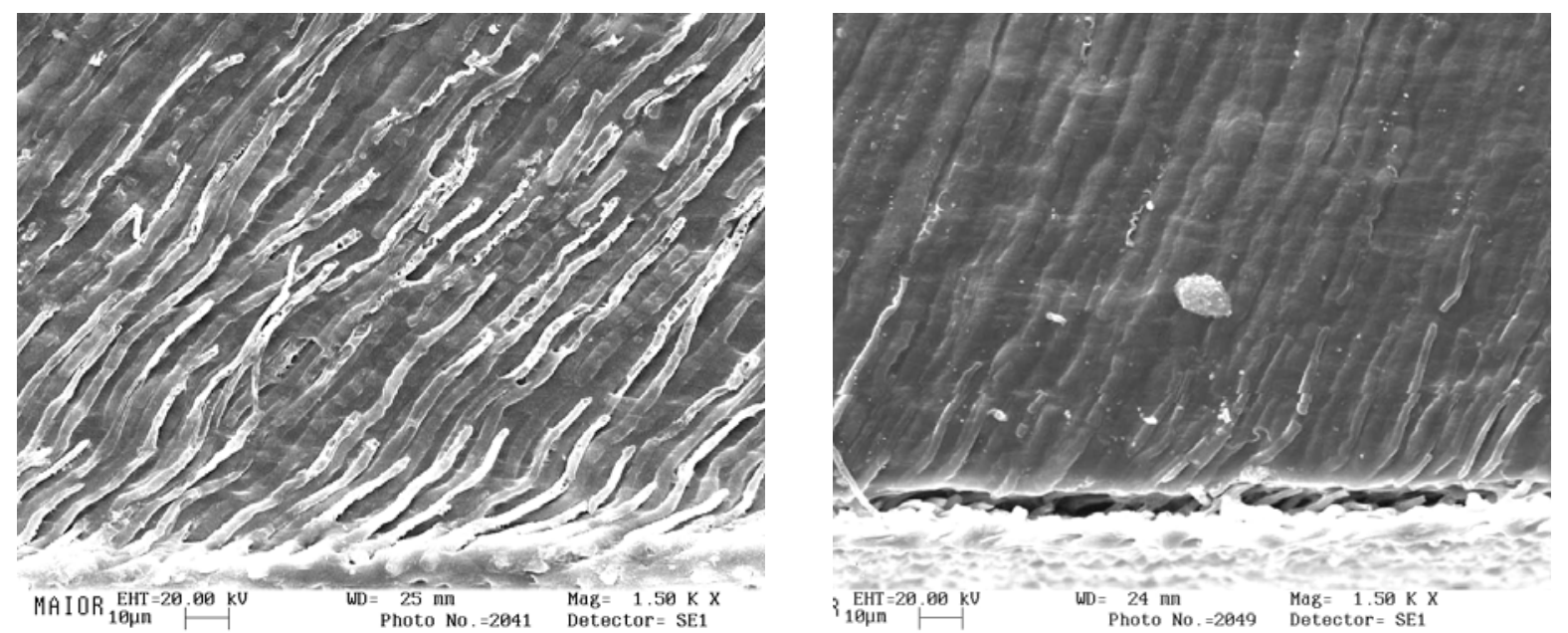

Fig. 38- Fotomicrografia da interface dentina/resina no sistema comercial (C) restaurada com a resina Beautifil. Os tags de resina estão em maior número. $(1500 x)$

Fig. 39- Fotomicrografia da interface dentina/resina no sistema Gluma A restaurada com a resina Beautifil. Houve a formação dos tags de resina, onde a média dos comprimentos foi de $38 \mu \mathrm{m} .(1500 x)$
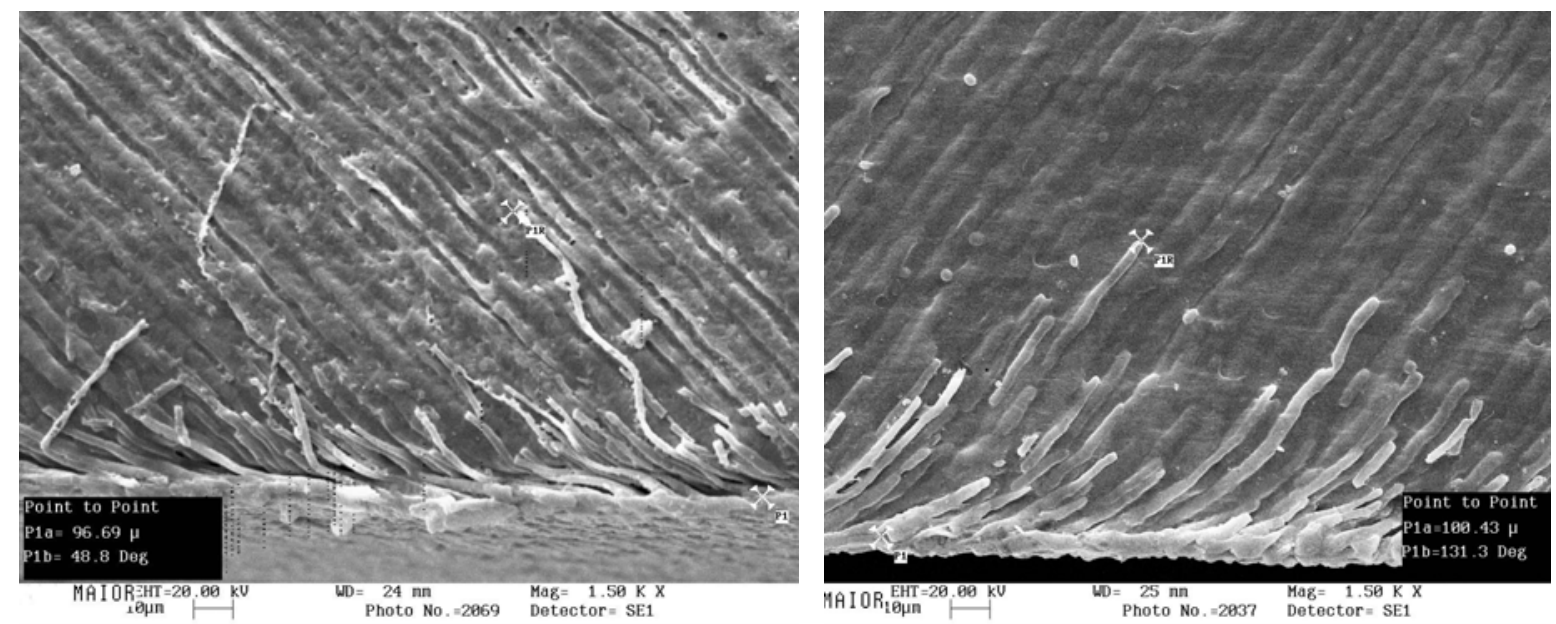

Fig. 40 - Fotomicrografia da interface dentina/resina no sistema Gluma B. A maioria dos tags formados eram longos e com comprimento de até 96,69um de comprimento (distância P1a-P1b). (1500 x).

Fig. 41 - Fotomicrografia da interface dentina/resina no sistema comercial (C). Formação de tags de resina sendo que o tag mais longo apresentou-se com

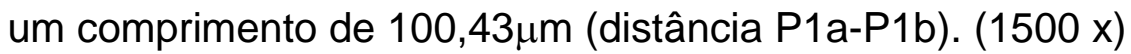


Além da formação dos tags de resina, observamos uma maior ocorrência de ramificações laterais nos sistemas Gluma B e comercial (C), quando comparados ao sistema Gluma A, mesmo não sendo estabelecida uma relação entre a espessura da camada híbrida e resistência ao cisalhamento, houve evidências de relação entre a quantidade e comprimento dos tags com a resistência ao cisalhamento (Figs 42, 43 e 44).
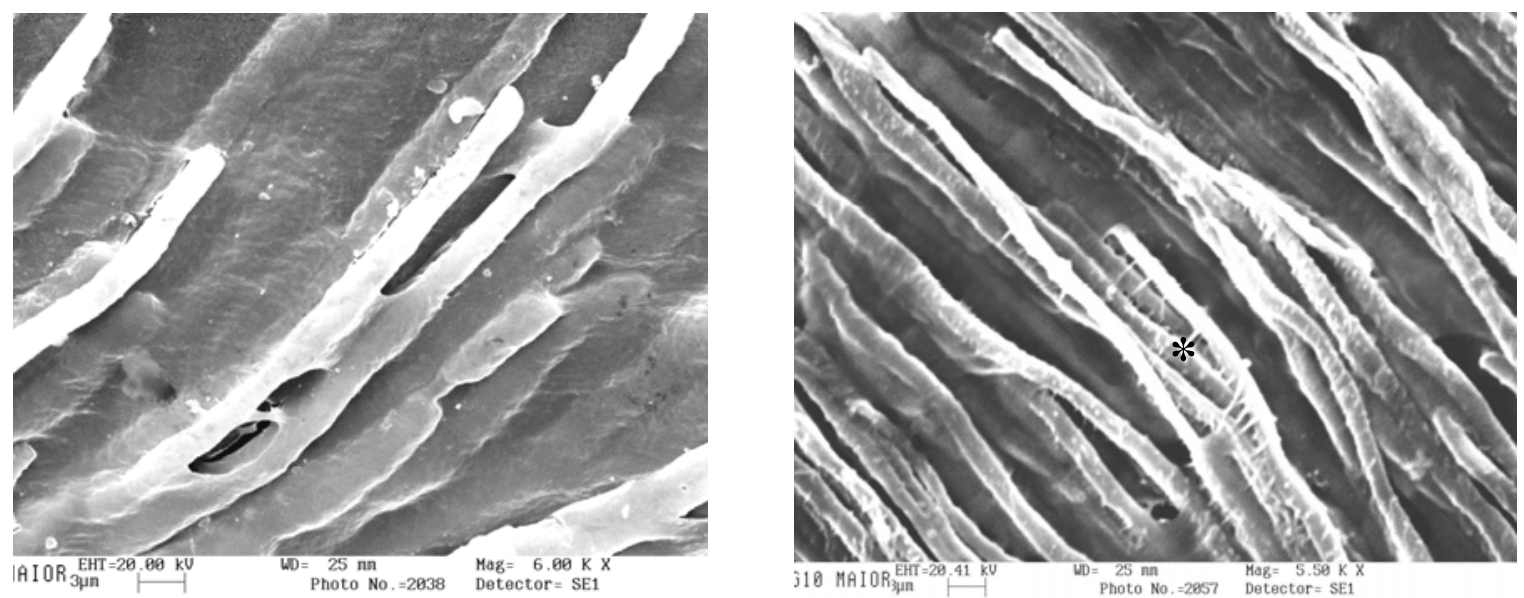

Fig. 42- Fotomicrografia da interface unida com o sistema Gluma A em que poucas ramificações laterais são visualizadas. (6000 x)

Fig. 43- Secção transversal da interface unida com o sistema Gluma B. Tags de resina presentes com várias ramificações laterais $\left(^{*}\right) \cdot(5500$ x)

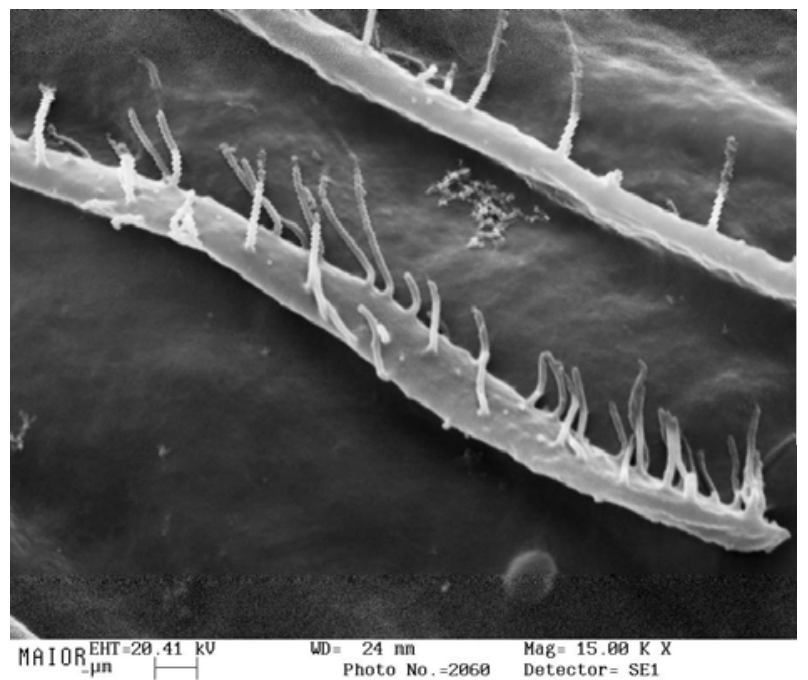

Fig.44. Gluma B: Formação de tags com muitas ramificações laterais. $(15000 x)$ 
Os materiais adesivos apresentam um desempenho diferente nas várias regiões dos dentes (LOPES et al., 2003). Como resultado, pode haver uma ampla variedade de resistências de união para o mesmo adesivo em diferentes regiões do esmalte e dentina. A dentina tem uma microestrutura altamente orientada com túbulos arranjados de forma radial estendendo-se da câmara pulpar externa para a junção dentina esmalte na coroa. 0 condicionamento ácido, molhamento da superfície e a permeabilidade dentinária não são uniformes na superfície oclusal plana da dentina. Diferenças na resistência de união ao cisalhamento podem ser causadas pela natureza heterogênea do substrato dentinário. (WATANABE; MARSHALL, 1996) Os valores de resistência ao cisalhamento encontrados no presente estudo apresentaram-se menores que os valores de PERDIGÃO; DENEHY; SWIFT JR, em 1994, YOSHIYAMA et al., em 1995, UNO; FINGER, em 1995a, RITTER; BERTOLI; SWIFT JR, em 2001, MIYASAKI; IWASAKI; ONOSE, em 2002, REIS et al., em 2004, porém similares aos estudos realizados por FOWLER et al., em 1992, SUNICO et al., em 2002. Os valores de resistência ao cisalhamento obtidos no presente estudo foram maiores que os obtidos por RETIEF et al., 1990 e KANCA, em 1992a, quando utilizou a mistura HEMA e água em superfície de dentina úmida. VAN NOORT et al. (1989) investigou as configurações da resistência de união pela análise da tensão por elemento finito. Constatou que a resistência de união variou de acordo com a geometria do espécime, configuração da carga, do módulo de elasticidade e a técnica de aplicação do sistema adesivo. Existe uma distribuição da tensão não uniforme na interface adesiva e essas tensões são sensíveis à geometria da carga, a forma e tamanho das partículas de carga das resinas compostas, além da 
dureza dos materiais envolvidos (VAN NOORT, 1989, VAN MEERBEEK, et al., 1992a).

Com base na literatura e nos resultados obtidos no presente estudo, foi observado que os sistemas adesivos hidrofílicos aplicados com a técnica úmida apresentaram resultados laboratoriais adequados podendo ser previsto sua viabilidade clínica com um desempenho confiável. O uso de sistemas adesivos com grande quantidade de água deve ser reconsiderado para obtenção de uniões mais estáveis com a dentina. Recentemente, outros estudos estão tentando substituir a água por solventes não aquosos, capazes de expandir novamente a matriz de dentina desmineralizada (PASHLEY et al., 2002; CARVALHO et al., 2003). A existência do solvente tetrahidrofurano, na formulação de sistemas adesivos no mercado atual, é pouco conhecida, portanto seria interessante que outros experimentos fossem realizados utilizando este solvente, para que estes resultados sejam confrontados e outras propriedades sejam estudadas. Pequenas alterações, na formulação dos sistemas adesivos e nos procedimentos técnicos têm aumentado a conveniência e a qualidade desses sistemas adesivos, portanto deve-se seguir com a incessante busca por sistemas menos sensíveis à técnica de aplicação e com altos valores de resistência adesiva. 


\section{7- CONCLUSÕES}

A análise dos dados, de acordo com os critérios estabelecidos neste trabalho, possibilitou as seguintes conclusões:

1. A rugosidade superficial da dentina aumentou significantemente após o condicionamento com ácido experimental espessado com sílica.

2. A resistência ao cisalhamento não foi influenciada pelos espessantes, tanto

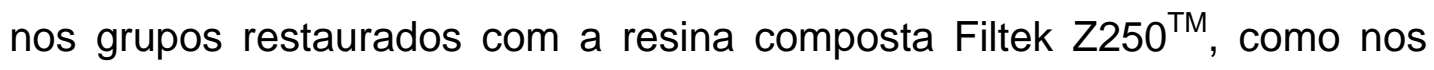
grupos restaurados com a resina composta Beautifil.

3. Para os grupos restaurados com a resina composta Filtek $Z 250 T M$, quando condicionados com ácido comercial e ácido experimental espessado com sílica, não houve diferença significante entre os sistemas adesivos na resistência ao cisalhamento.

4. Para os grupos restaurados com a resina composta Beautifil, independente da formulação do agente condicionante, o sistema adesivo Gluma B apresentou maiores valores de resistência ao cisalhamento quando comparado ao Gluma A e, quando comparado ao sistema comercial, não mostrou diferenças significantes.

5. A resistência ao cisalhamento do sistema comercial empregado com a resina Beautifil, mostrou diferença significante somente quando comparado ao Gluma A, utilizando os ácidos experimentais, espessados com sílica e polímero. 


\section{ANEXOS}

ANEXO 1- GRUPOS TESTADOS

\begin{tabular}{|c|c|c|c|}
\hline GRUPOS & MATERIAL & ÁCIDO & ADESIVO \\
\hline 1. & Z 250 & sílica & Gluma B \\
\hline 2. & Z 250 & comercial & Gluma B \\
\hline 3. & Z 250 & polímero & Gluma B \\
\hline 4. & Z 250 & sílica & Gluma A \\
\hline 5. & Beautifil & comercial & Gluma A \\
\hline 6. & Beautifil & sílica & Gluma A \\
\hline 7. & Beautifil & polímero & Gluma A \\
\hline 8. & Z 250 & polímero & comercial \\
\hline 9. & Z 250 & sílica & comercial \\
\hline 10. & Beautifil & comercial & Gluma B \\
\hline 11. & Beautifil & sílica & Gluma B \\
\hline 12. & Beautifil & polímero & Gluma B \\
\hline 13. & Z 250 & comercial & Gluma A \\
\hline 14. & Z 250 & polímero & Gluma A \\
\hline 15. & Z 250 & comercial & comercial \\
\hline 16. & Beautifil & sílica & comercial \\
\hline 17. & Beautifil & polímero & comercial \\
\hline 18. & Beautifil & comercial & comercial \\
\hline
\end{tabular}


ANEXO 2: Resistência ao cisalhamento de cada espécime dos diferentes

grupos.

\section{Grupos Beautifil}

\begin{tabular}{|l|l|l|r|}
\hline beautifil & Gluma B & comercial & 11,7 \\
\hline beautifil & Gluma B & comercial & 5,4 \\
\hline beautifil & Gluma B & comercial & 10,3 \\
\hline beautifil & Gluma B & comercial & 5,6 \\
\hline beautifil & Gluma B & comercial & 14,6 \\
\hline beautifil & Gluma B & comercial & 7,3 \\
\hline beautifil & Gluma B & comercial & 11,3 \\
\hline beautifil & Gluma B & comercial & 11,8 \\
\hline média & & & 9,75 \\
\hline DP & & & 3,303245 \\
\hline beautifil & Gluma B & sílica & 10,7 \\
\hline beautifil & Gluma B & sílica & 12,4 \\
\hline beautifil & Gluma B & sílica & 4,4 \\
\hline beautifil & Gluma B & sílica & 14,3 \\
\hline beautifil & Gluma B & sílica & 6,8 \\
\hline beautifil & Gluma B & sílica & 9,8 \\
\hline beautifil & Gluma B & sílica & 11,1 \\
\hline beautifil & Gluma B & sílica & 7,2 \\
\hline média & & & 9,5875 \\
\hline DP & & & 3,252883 \\
\hline beautifil & Gluma B & polímero & 8 \\
\hline beautifil & Gluma B & polímero & 9,5 \\
\hline beautifil & Gluma B & polímero & 10,5 \\
\hline beautifil & Gluma B & polímero & 12,5 \\
\hline beautifil & Gluma B & polímero & 16,9 \\
\hline beautifil & Gluma B & polímero & 7,3 \\
\hline beautifil & Gluma B & polímero & 14,2 \\
\hline beautifil & Gluma B & polímero & 8,3 \\
\hline média & & & 10,9 \\
\hline DP & & & 3,374272 \\
\hline beautifil & Gluma A & comercial & 4,8 \\
\hline beautifil & Gluma A & comercial & 2,1 \\
\hline beautifil & Gluma A & comercial & 3,8 \\
\hline beautifil & Gluma A & comercial & 11,1 \\
\hline beautifil & Gluma A & comercial & 6,9 \\
\hline beautifil & Gluma A & comercial & 5,3 \\
\hline beautifil & Gluma A & comercial & 8,1 \\
\hline beautifil & Gluma A & comercial & 2,7 \\
\hline média & & & 5,6 \\
\hline DP & & & 2,995711 \\
\hline beautifil & Gluma A & sílica & 3,5 \\
\hline beautifil & Gluma A & sílica & 2,1 \\
\hline
\end{tabular}

\section{Grupos Filtek Z250}

\begin{tabular}{|l|l|l|r|}
\hline Z 250 & Gluma B & sílica & 12,2 \\
\hline Z 250 & Gluma B & sílica & 8,7 \\
\hline Z 250 & Gluma B & sílica & 13,9 \\
\hline Z 250 & Gluma B & sílica & 8,7 \\
\hline Z 250 & Gluma B & sílica & 6,3 \\
\hline Z 250 & Gluma B & sílica & 5,8 \\
\hline Z 250 & Gluma B & sílica & 14,5 \\
\hline Z 250 & Gluma B & sílica & 10,1 \\
\hline média & & & 10,025 \\
\hline DP & & & 3,273596 \\
\hline Z 250 & Gluma B & polímero & 8,5 \\
\hline Z 250 & Gluma B & polímero & 9,6 \\
\hline Z 250 & Gluma B & polímero & 2,9 \\
\hline Z 250 & Gluma B & polímero & 6 \\
\hline Z 250 & Gluma B & polímero & 8,9 \\
\hline Z 250 & Gluma B & polímero & 8,3 \\
\hline Z 250 & Gluma B & polímero & 8 \\
\hline Z 250 & Gluma B & polímero & 3,2 \\
\hline média & & & 6,925 \\
\hline DP & & & 2,605352 \\
\hline Z 250 & Gluma B & comercial & 2,6 \\
\hline Z 250 & Gluma B & comercial & 10,5 \\
\hline Z 250 & Gluma B & comercial & 8,6 \\
\hline Z 250 & Gluma B & comercial & 10,3 \\
\hline Z 250 & Gluma B & comercial & 7,8 \\
\hline Z 250 & Gluma B & comercial & 11,3 \\
\hline Z 250 & Gluma B & comercial & 7,9 \\
\hline Z 250 & Gluma B & comercial & 10,1 \\
\hline média & & & 8,6375 \\
\hline DP & & & 2,755741 \\
\hline Z 250 & Gluma A & comercial & 11,3 \\
\hline Z 250 & Gluma A & comercial & 7,9 \\
\hline Z 250 & Gluma A & comercial & 9 \\
\hline Z 250 & Gluma A & comercial & 11,8 \\
\hline Z 250 & Gluma A & comercial & 14,5 \\
\hline Z 250 & Gluma A & comercial & 16,1 \\
\hline Z 250 & Gluma A & comercial & 5,7 \\
\hline Z 250 & Gluma A & comercial & 7 \\
\hline média & & & 10,4125 \\
\hline DP & & & \\
\hline Z 250 & Gluma A & polímero & 12,3 \\
\hline Z 250 & Gluma A & polímero & 7,3 \\
\hline
\end{tabular}




\begin{tabular}{|l|l|l|r|}
\hline beautifil & Gluma A & sílica & 6,5 \\
\hline beautifil & Gluma A & sílica & 9,2 \\
\hline beautifil & Gluma A & sílica & 4,1 \\
\hline beautifil & Gluma A & sílica & 4,6 \\
\hline beautifil & Gluma A & ślica & 8 \\
\hline beautifil & Gluma A & sílica & 6,5 \\
\hline média & & & 5,5625 \\
\hline DP & & & 2,397581 \\
\hline beautifil & Gluma A & polímero & 5 \\
\hline beautifil & Gluma A & polímero & 9,8 \\
\hline beautifil & Gluma A & polímero & 2,6 \\
\hline beautifil & Gluma A & polímero & 2,1 \\
\hline beautifil & Gluma A & polímero & 6,5 \\
\hline beautifil & Gluma A & polímero & 3,9 \\
\hline beautifil & Gluma A & polímero & 3 \\
\hline beautifil & Gluma A & polímero & 3 \\
\hline média & & & 4,4875 \\
\hline DP & & & 2,579279 \\
\hline beautifil & comercial & comercial & 6,5 \\
\hline beautifil & comercial & comercial & 4 \\
\hline beautifil & comercial & comercial & 3,5 \\
\hline beautifil & comercial & comercial & 5,1 \\
\hline beautifil & comercial & comercial & 8,7 \\
\hline beautifil & comercial & comercial & 9,1 \\
\hline beautifil & comercial & comercial & 9,6 \\
\hline beautifil & comercial & comercial & 4,2 \\
\hline média & & & 6,3375 \\
\hline DP & & & 2,492811 \\
\hline beautifil & comercial & sílica & 6 \\
\hline beautifil & comercial & sílica & 11,7 \\
\hline beautifil & comercial & sílica & 7,3 \\
\hline beautifil & comercial & sílica & 10,8 \\
\hline beautifil & comercial & sílica & 7,9 \\
\hline beautifil & comercial & sílica & 12,4 \\
\hline beautifil & comercial & sílica & 10,4 \\
\hline beautifil & comercial & sílica & 7,1 \\
\hline média & & & 9,2 \\
\hline DP & & & 2,403569 \\
\hline beautifil & comercial & polímero & 7,9 \\
\hline beautifil & comercial & polímero & 10,7 \\
\hline beautifil & comercial & polímero & 8,2 \\
\hline beautifil & comercial & polímero & 3,4 \\
\hline beautifil & comercial & polímero & 8,7 \\
\hline beautifil & comercial & polímero & 10,3 \\
\hline beautifil & comercial & polímero & 12,3 \\
\hline beautifil & comercial & polímero & 6,7 \\
\hline média & & & 2,732215 \\
\hline DP & & & \\
\hline
\end{tabular}

\begin{tabular}{|l|l|l|r|}
\hline Z 250 & Gluma A & polímero & 8,3 \\
\hline Z 250 & Gluma A & polímero & 4,4 \\
\hline Z 250 & Gluma A & polímero & 6,1 \\
\hline Z 250 & Gluma A & polímero & 6,3 \\
\hline Z 250 & Gluma A & polímero & 3,7 \\
\hline Z 250 & Gluma A & polímero & 3,4 \\
\hline média & & & 6,475 \\
\hline DP & & & 2,917313 \\
\hline Z 250 & Gluma A & sílica & 6,5 \\
\hline Z 250 & Gluma A & sílica & 5,7 \\
\hline Z 250 & Gluma A & sílica & 6,4 \\
\hline Z 250 & Gluma A & sílica & 5,2 \\
\hline Z 250 & Gluma A & sílica & 7,2 \\
\hline Z 250 & Gluma A & sílica & 5,3 \\
\hline Z 250 & Gluma A & sílica & 6,9 \\
\hline Z 250 & Gluma A & sílica & 10,7 \\
\hline média & & & 6,7375 \\
\hline DP & & & 1,757382 \\
\hline Z 250 & comercial & polímero & 9,4 \\
\hline Z 250 & comercial & polímero & 16,6 \\
\hline Z 250 & comercial & polímero & 10,2 \\
\hline Z 250 & comercial & polímero & 6,7 \\
\hline Z 250 & comercial & polímero & 8,3 \\
\hline Z 250 & comercial & polímero & 11,2 \\
\hline Z 250 & comercial & polímero & 15,9 \\
\hline Z 250 & comercial & polímero & 10,4 \\
\hline média & & & 11,0875 \\
\hline DP & & & 3,478274 \\
\hline Z 250 & comercial & sílica & 10,4 \\
\hline Z 250 & comercial & sílica & 17,5 \\
\hline Z 250 & comercial & sílica & 11 \\
\hline Z 250 & comercial & sílica & 13,4 \\
\hline Z 250 & comercial & sílica & 10,1 \\
\hline Z 250 & comercial & sílica & 6,2 \\
\hline Z 250 & comercial & sílica & 8,9 \\
\hline Z 250 & comercial & sílica & 5,8 \\
\hline média & & & 10,4125 \\
\hline DP & & & 3,79678 \\
\hline Z 250 & comercial & comercial & 11,6 \\
\hline Z 250 & comercial & comercial & 12,7 \\
\hline Z 250 & comercial & comercial & 10,9 \\
\hline Z 250 & comercial & comercial & 7,4 \\
\hline Z 250 & comercial & comercial & 6,7 \\
\hline Z 250 & comercial & comercial & 6,3 \\
\hline Z 250 & comercial & comercial & 3,9 \\
\hline comercial & comercial & 3,1 \\
\hline DP & & & 7,825 \\
\hline
\end{tabular}


ANEXO 3: Médias da resistência ao cisalhamento dos grupos das resina compostas FilteK Z $250^{\mathrm{TM}}$ e Beautifil unidas ao dente (B ou Z) através dos 3 sistemas adesivos, Gluma A (G1), Gluma B (G2), sistema comercial (Gcom), condicionados por ácido fosfórico $37 \%$ espessado com sílica, polímero ou comercial.

\section{Médias das forças de resistência adesiva ao cisalhamento (MPa)}

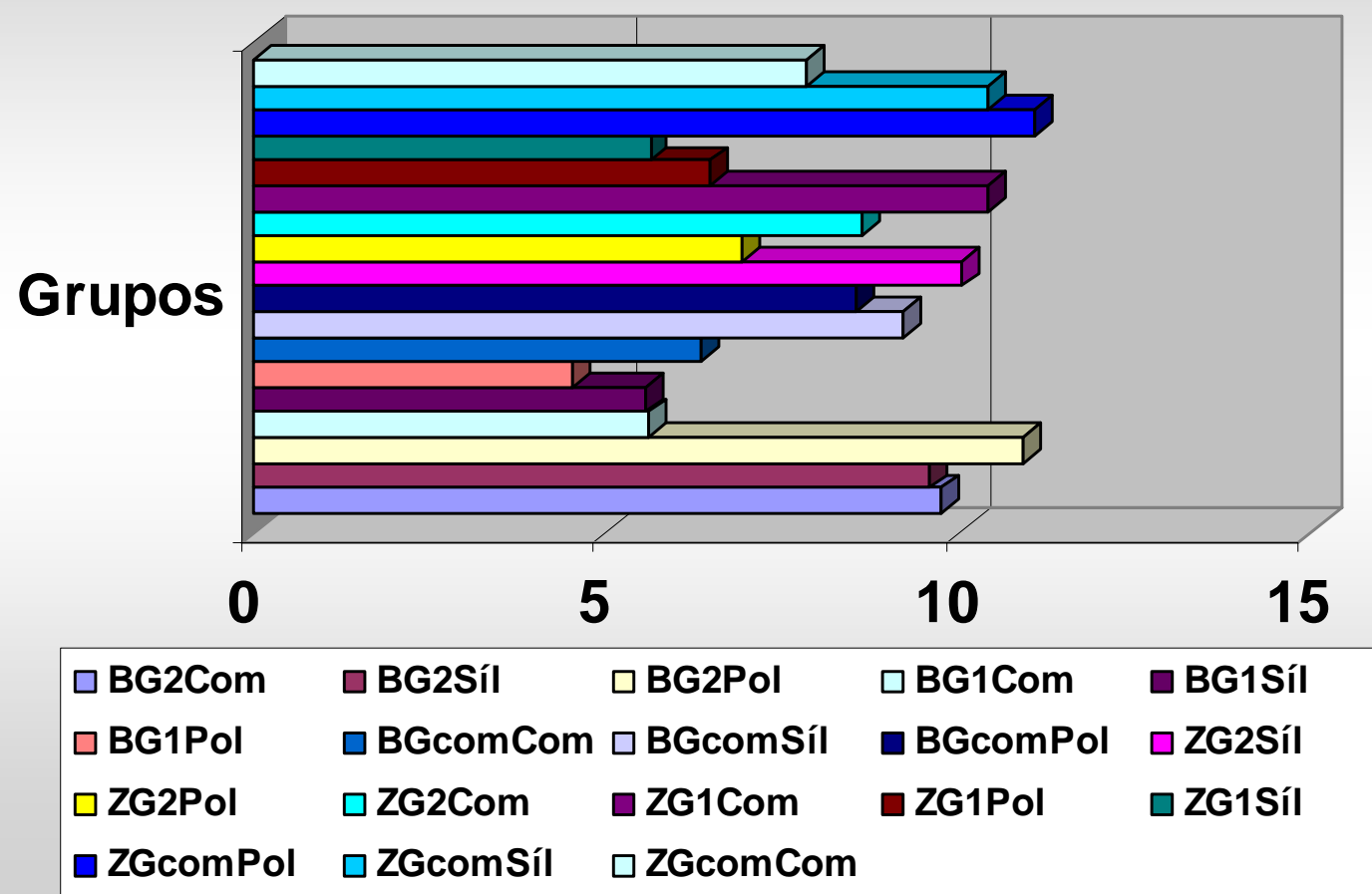

ANEXO 4: Médias da Rugosidade superficial da dentina antes e após condicionamento ácido.

\begin{tabular}{|c|c|c|}
\hline \multicolumn{3}{|c|}{ Ácido Comercial } \\
\hline Antes & Após & diferença \\
\hline 0,01 & 0,013 & 0,003 \\
\hline 0,0115 & 0,0155 & 0,004 \\
\hline 0,0105 & 0,0155 & 0,005 \\
\hline 0,012 & 0,0125 & 0,0005 \\
\hline 0,0135 & 0,0135 & 0 \\
\hline 0,0125 & 0,014 & 0,0015 \\
\hline 0,014 & 0,016 & 0,002 \\
\hline 0,0125 & 0,0125 & 0 \\
\hline
\end{tabular}




\begin{tabular}{|c|c|c|}
\hline \multicolumn{3}{|c|}{ Ácido espessado com sílica } \\
\hline Antes & Após & diferença \\
\hline 0,011 & 0,013 & 0,002 \\
\hline 0,01 & 0,0135 & 0,0035 \\
\hline 0,01 & 0,0155 & 0,0055 \\
\hline 0,01 & 0,014 & 0,004 \\
\hline 0,011 & 0,0125 & 0,0015 \\
\hline 0,012 & 0,0135 & 0,0015 \\
\hline 0,013 & 0,014 & 0,001 \\
\hline 0,011 & 0,014 & 0,003 \\
\hline
\end{tabular}

\begin{tabular}{|r|r|r|}
\hline \multicolumn{3}{|c|}{ Ácido espessado com polímero } \\
\hline \multicolumn{2}{|c|}{ Antes } & \multicolumn{2}{|c|}{ Após } & \multicolumn{1}{c|}{ diferença } \\
\hline 0,009 & 0,012 & 0,003 \\
\hline 0,01 & 0,014 & 0,004 \\
\hline 0,012 & 0,013 & 0,001 \\
\hline 0,014 & 0,016 & 0,002 \\
\hline 0,013 & 0,015 & 0,002 \\
\hline 0,012 & 0,0155 & 0,0035 \\
\hline 0,014 & 0,016 & 0,002 \\
\hline 0,013 & 0,0155 & 0,0025 \\
\hline
\end{tabular}




\section{REFERÊNCIAS BIBLIOGRÁFICAS}

1. AL-SALEHI, S.K.; BURKE, F.J.T. Methods used in dentin bonding tests: an analysis of 50 investigations on bond strength. Quint. Int., v. 28, n. 11, p. 717-23, Nov. 1997.

2. ARAÚJO, P.A.; ASMUSSEN, E. Bonding to dentin with a simplified Gluma system. Int. Dent. J, v. 39, n. 4, p. 253-7, Dec. 1989.

3. ARAÚJO, P.A., ASMUSSEN, E. The gluma system for bonding to dentin: effect of acidic pretreatment and surface wetness on bond strength. Rev. FOB, v. 5, n. 1/2, p. 59-63, Jan./Jun. 1997.

4. ASMUSSEN, E. UNO, S. Adhesion of restorative resins to dentin: chemical and physicochemical aspects. Oper. Dent., v. 17, supl. 5, p. 68-74, 1992.

5. BARKMEIER, W.W.; COOLEY, R.L. Laboratory evaluation of adhesive systems. Oper. Dent., v. 17, supl. 5, p. 50-61, 1992.

6. BARKMEIER, W.W.; ERICKSON, R.L. Shear bond strength of composite to enamel and dentin using Scotchbond Multi-Purpose. Amer.J.Dent., v.7, n.3, p.175-9, June 1994.

7. BECK, M.D.; SWIFT, E.J.; DENEHY, G.E. Use of phosphoric acid etchants with Scotchbond Multi-Purpose. J. dent.Res., v.72, p.133, 1993. Special Issue. /Abstract n.240/

Normas recomendadas para o uso em âmbito da Universidade de São Paulo, com base no documento "Referências Bibliográficas: exemplos", emanado do Conselho Superior do Sistema Integrado de Bibliotecas da USP, em reunião de 20 de setembro de 1990. 
8. BENDERLI, Y; YUCEL, T. The effect of surface treatment on the bond strength of resin composite to dentin. Oper.Dent., v. 24, n.2, p.96-102, Mar/Apr. 1999.

9. BUONOCORE, M.G. A simple method of increasing the adhesion of acrylic filling materials to enamel surfaces. J. dent. Res., v.34, n.6, p.849-53, Dec.1955.

10. CAGIDIACO, M.C.; FERRARI, M.; DAVIDSON, C.L. Comparison of in vivo and in vitro demineralized dentin with phosphoric and maleic acid. J. Dent._Child., v.64, n.1, p.17-21, Jan./Feb. 1997.

11. CARVALHO, R.M. et al. A review of polimerization contraction: the influence of stress development versus stress relief. Oper.Dent., v.21, n.1, p. 1724, Jan./Feb. 1996a.

12. CARVALHO, R.M.; YOSHIYAMA, M.; BREWER, P.D.; PASHLEY, D.H. Dimensional changes of demineralized human dentine during preparation for scanning electron microscopy. Arch. Oral Biol., v. 41, n. 4, p. 379-86, Apr. 1996b.

13. CARVALHO, YOSHIYAMA, M; PASHLEY, E.L.; PASHLEY, D.H. In vitro study on the dimensional changes of human dentine after demineralization. Arch. Oral Biol., v. 41, n. 4, p. 369-77, April, 1996c.

14. CARVALHO, R.M. et al. Effects of HEMA/solvent combinations on bond strength to dentin. J dent. Res., v. 82, n. 8, p. 597-601, Aug. 2003.

15. CHAN, A. R. et al. A short-and long-term shear bond strength study using acids of varying dilutions on bovine dentin. J.Dent., v.25, n.2, p.145-52, Mar. 1997.

16. CHRISTENSEN, G. J. Clinical factors affecting adhesion. Oper. Dent., v.17, Supl. 5, p.24-31, 1992. 
17. COLI, P. et al. In vitro dentin pretreatment: surface roughness and adhesive shear bond strength. Eur. J. Oral Sci., v. 107, n. 5, p. 400-13, Oct. 1999.

18. DAVIS E. L. et al. Adhesion of dentin bonding agents after smear layer treatments. Amer.J.Dent., v.5, n.1, p.29-32, Feb. 1992.

19. DONDI DALL'OROLOGIO, G. LONE, A.; FINGER, W.J. Clinical evaluation of the role of glutardialdehyde in a one-bottle adhesive. Amer. J. Dent., v. 15 , n. 5 , p. $330-4$, Oct. 2002.

20. DUKE, E.S. Cinical studies of adhesive systems. Oper. Dent., v. 17, supl. 5, p.103-10, 1992.

21. DUKE, E.S. Adhesion and its application with restorative materials. Dent.Clin.N.Amer., v.37, n.3, p.329-40, Jul. 1993.

22. EICK, J.D. et al. The dentinal surface: its influence on dentinal adhesion. Part I. Quint. Int, v. 22, n. 12, p. 967-77, Dec. 1991.

23. EL-DIN, A.K.N.; EL-MOHSEN, M.M.A. Effect of changing application times on adhesive systems bond strengths. Amer. J. Dent, v. 15, n. 5, p. 3214, Oct. 2002.

24. ERICKSON, R.L. Surface interactions of dentin adhesive materials. Oper. Dent., v. 17, supl. 5, p. 81-94, 1992.

25. FINGER, W.J.; UNO, S. Bond strength of gluma cps using the moist dentin bonding technique. Amer. J. Dent., v. 9, n. 1, p. 27-30, Feb. 1996.

26. FINGER, W.J.; BALKENHOL, M. Practitioner variability effects on dentin bonding with an acetone-based one-bottle adhesive. J. Adhes. Dent., v. 1, n. 4, p. 311-4, Winter 1999.

27. FOWLER,C.S. et al. Influence of selected variables on adhesion testing. Dent. Mater., v. 8, n. 4, p. 265-9, July 1992. 
28. FRITZ, U.B.; FINGER, W.J. Bonding efficiency of single-bottle enamel/dentin adhesives. Amer. J. Dent., v. 12, n. 6, p. 277-82, Dec. 1999.

29. GOES, M.F. et al. Morphological effect of the type, concentration and etching time of acid solutions on enamel and dentin surfaces. Braz.dent.J., v.9, n.1, p.3-10, 1998.

30. GWINNETT, A.J. Quantitative contribution of resin infiltration/hybridization to dentin bonding. Amer.J.Dent., v. 6, n. 1, p.7-9, Feb. 1993.

31. GWINNETT, A.J. Altered tissue contribution to interfacial bond strength with acid conditioned dentin. Amer. J. Dent., v. 7, n. 5, p. 243-6, Oct. 1994.

32. HALLER, B. Recent developments in dentin bonding. Amer. J. Dent, v. 13, n. 1, p. 44-50, Feb. 2000.

33. HOLTAN, J.R.; NYSTROM, G.P.; OLIN, P.S., et al. Bond strength of six dentinal adhesives. J Dent. V. 22, n. 2, p. 92-6, Apr. 1994.

34. ISHIOKA, S.; CAPUTO, A.A. Interaction between the dentinal smear layer and composite bond strength. J prosth. Dent., v. 61, n. 2, p. 180-5, Feb. 1989.

35. ITOU, K. et al. Effect of drying methods on hybrid layer thickness. Amer. J. Dent., v. 16, n. 5, p. 335-9, Oct. 2003.

36. JACOBSEN, T.; SODERHÖLM, K.J. Some effects of water on dentin bonding. Dent. Mater., v. 11, n. 2, p. 132-6, Mar. 1995.

37. JOHNSON, G.H. et al. Dentin bonding systems: a review of current products and techniques. J. Amer. Dent. Assoc., v. 122, n. 7, p. 34-41, July 1991.

38. KANCA III, J. Effect of resin primer solvents and surface wetness on resin composite bond strength to dentin. Amer. J. Dent., v. 5, n. 4, p. 213-5, Aug. 1992a. 
39. KANCA III, J. Resin bonding to wet substrate. I- Bonding to dentin. Quint. Int., v. 23, n. 1, p. 39-41, Sept. 1992b.

40. KANCA III, J. Etchant composition and bond strength to dentin. Amer. J. Dent., v. 6, n. 6, p. 287-90, Dec. 1993.

41. KITASAKO Y. et al. Shear bond strengths of three resin cements to dentin over 3 years in vitro. J Dent., v. 29, n. 2, p. 139-44, Feb. 2001.

42. KWONG, S.M. Micro-tensile bond strengths to sclerotic dentin using a selfetching and a total-etching technique. Dent Mater, v. 18, n. 5, p. 359-69, Jul. 2002.

43. LOPES, M.B. et al. Comparative study of the dental substrate used in shear bond strength tests. Pesq. Odontol. Bras., v. 17, n. 2, p. 171-5, 2003.

44. MACIEL, K.T. et al. The effects of acetone, etanol, HEMA, and air on the stiffness of human decalcified dentin matriz. J. dent. Res., v. 75, n. 11, p. 1851-8, Nov. 1996.

45. MATOS, A.B. et al. Effects of acid etching on dentin surface: SEM morphological study. Braz. dent. J., v.8, n.1, p.35-41, 1997.

46. MIEARS, J.R.; CHARLTON, D.G.; HERMESCH, C.B. Effect of dentin moisture and storage time on resin bonding. Amer. J. Dent., v.8, n.2, p.80-2, Apr.1995.

47. MIYASAKI, M.; IWASAKI, K.; ONOSE, H. Adhesion of single application bonding systems to bovine enamel and dentin. Oper. Dent., v. 27, n. 1, p. 88-94, Jan./Feb. 2002.

48. MOTA, C.S. et al. Tensile bond strength of four resin luting agents bonded to bovine enamel and dentin. J. prosth. Dent., v. 89, n. 6, p. 558-64, Jun. 2003. 
49. NAKABAYASHI, N.; KOJIMA, K.; MASUHARA, E. The promotion of adhesion by the infiltration of monomers into tooth substrates. J.Biomed. Mater. Res., v.16, n.3, p.265-73, May 1982.

50. NAKABAYASHI, N.; WATANABE, A.; GENDUSA, N.J. Dentin adhesion of "modified" 4-META/MMA-TBB resin: function of HEMA. Dent. Mater., v. 8, n. 4, p. 259-64, July 1992.

51. NAKAJIMA, M. et al. Tensile bond strength and SEM evaluation of cariesaffected dentin using dentin adhesives. J dent Res., v. 74, n. 10, p. 1679-88, Oct. 1995.

52. NAKAJIMA, M. et al. Comparative microtensile bond strength and SEM analysis of bonding to wet and dry dentin. Amer. J. Dent., v. 13, n. 6, p. 324-8, Dec. 2000.

53. NAKAMICHI, I.; IWAKU, M.; FUSAYAMA, T. Bovine teeth as possible substitutes in the adhesion test. J. Dent. Res., v. 62, n. 10, p. 1076-81, Oct. 1983.

54. ORTEGA, R. C. S.; SOUZA JR, M.H.S.; FRANCO, E.B. Influência de diferentes condicionadores ácidos na resistência adesiva de uma resina composta ao esmalte. Revista Brasileira de Odontologia, v. 54, n. 5, p. 268- , Set/ Out, 1997.

55.PASHLEY, D.H. Dentine: A dynamic substrate- a review. Scanning Microscopy, v. 3, p. 161-176, 1989.

56. PASHLEY, D.H. In vitro simulations of in vivo bonding conditions. Amer. J. Dent., v. 4, n. 5, p.237-40, Oct. 1991.

57.PASHLEY, D.H.; HORNER, J.A.; BREWER, P.D. Interactions of conditioners on the dentin surface. Oper. Dent., suppl. 5, p. 137-50, 1992.Review 
58. PASHLEY, D.H. et al. Permeability of dentin to adhesive agents. Quint. Int., v.24, n.9, p.618-31, Sept. 1993.

59. PASHLEY, D.H. et al. Bond strength versus dentin structure. Archs Oral Biol, v. 40, n. 12, p. 1109-18, Dec. 1995a.

60. PASHLEY, D.H. Adhesion testing of dentin bonding agents: a review. Dent. Mater., v. 11, n. 2, p. 117-25, Mar. 1995b.

61. PASHLEY, D.H.; CARVALHO, R.M. Dentin permeability and dentin adhesion. J.Dent.,v. 25, n.5, p.355-72, Sept 1997.

62. PASHLEY, D.H. et al. The microtensile bond test: a review. J. Adhes. Dent., v. 1, n. 4, p. 299-309, 1999.

63. PASHLEY, D.H. et al. Solvation of dried dentin matrix by water and other polar solvents. Amer. J. Dent., v. 15, n. 2, p. 97-102, Apr. 2002.

64. PAUL, S.J. et al. Effect of water content on the physical properties of model dentin primer and bonding resins. J Dent., v. 27, n. 3, p. 209-14, Mar. 1999.

65. PERDIGÃO, J.; DENEHY, G.E.; SWIFT JR, E.J. Silica contamination of etched dentin and enamel surfaces: a scanning electron microscopic and bond strength study. Quint. Int., v. 25, n. 5, p. 327-33, May 1994.

66. PERDIGÃO, J. et al. Field emisión SEM comparison of four post-fixation drying for human dentin J. Biom. Mater. Res, v. 29, n. 9, p. 1111-20, Sept. 1995.

67. PERDIGÃO, J. et al. The effect of depth of dentin demineralization on bond strengths and morphology of the hybrid layer. Oper Dent., v. 25, 3, p. 186-94, May- Jun. 2000.

68. PRATI, C. et al. Thickness and morphology of resin-infiltrated dentin layer in young, old, and sclerotic dentin. Oper. Dent., v. 24, n. 2, p. 66-72, Mar./Apr. 1999. 
69. REIS, A.; LOGUERCIO, A.D.; CARVALHO, R.M. GRANDE, R.H.M. Durability of resin dentin interfaces: effects of surface moisture and adhesive solvent component. Dent. Mater., v. 20, n. 7, p. 669-76, Sept. 2004.

70. RETIEF, D.H. The intra-oral factors affecting adhesion. J.dent. Ass. S.Afr., v.25, n.11, p.392-9, Nov.1970.

71. RETIEF, D.H. et al. Extracted human versus bovine teeth in laboratory studies. Amer. J. Dent., v. 3, n. 6, p. 253-8, Dec. 1990.

72. RETIEF, D.H. Standardizing laboratory adhesion tests. Amer.J.Dent., v.4, n.5, p.231-6, Oct. 1991.

73. RETIEF, D.H. et al. Phosphoric acid as dentin etchant. Amer.J.Dent.,v.5, n.1, p.24-8, Feb. 1992.

74. RETIEF, D.H. Do adhesives prevent microleakage? Int. Dent. J., v. 44, n. 1, p. 19-29, Feb. 1994.

75. RIGSBY, D.F. et al. Marginal leakage and marginal gap dimensions of three dentinal bonding systems. Amer. J. Dent., v.3, n.6, p.289-94, Dec. 1990.

76. RITTER, A.V.; BERTOLI, C.; SWIFT JR, E.J. Dentin bond strength as a function of solvent and glutaraldehyde content. Amer. J. Dent., v. 14, n. 4, p. 221-6, Aug. 2001.

77. SANO, H. SHONO, T.; TAKATSU, T, et al. Relationship between surface area for adhesion and tensile bond strength. Dent. Mater. v. 10, n. 4, p. 236-40, July 1994.

78. SANO, H. et al. Effect of operator variability on dentin adhesion: students vs. dentists. Dent Mater, v. 17, n. 1, p. 51-8, Mar. 1998.

79. SCHILKE, R. et al. Bovine dentin as a substitute for human dentin in shear bond strength measurements. Amer. J. Dent., v. 12, n. 2, p. 92-6, Apr. 1999. 
80. SOMPHONE, P.; PEREIRA, P.N.R.; TAGAMI, J. Enhanced bond strength of compomers using two dentin bonding systems. Amer. J. Dent., v. 15, n. 5, p. 325-9, Oct. 2002.

81. STANINEC, M.; KAWAKAMI, M. Adhesion and microleakage tests of a new dentin bonding system. Dent. Mater., v. 9, n. 3, p. 204-8, May 1993.

82. SUDSANGIAM, S.; VAN NOORT, R. Do dentin bond strength tests serve a useful purpose? J. Adhes. Dent., v. 1, n. 1, p. 57-67, 1999.

83. SUNICO, M.C. et al. Effect of surface conditioning and restorative material on the shear bond strength and resin-dentin interface of a new one-bottle nanofilled adhesive. Dent. Mater., v. 18, n. 7, p. 535-42, Nov. 2002.

84. SWIFT, E.J.; DENEHY, G.E, BECK, M.D. Use of phosphoric acid etchants with Scotchbond Multi-Purpose. Amer.J.Dent., v.6, n.2, p.88-90, Apr. 1993.

85. TAY, F.R.; GWINNETT, A.J.; WEI, S.H. Micromorphological spectrum from overdrying to overwetting acid-conditioned dentin in water-free acetone based, single-bottle primer/ adhesives. Dent. Mater., v. 12, n. 4,p. 23644, Jul. 1996.

86. TAY, F.R; GWINNETT, J.A.; WEI, S.H.Y. Relation between water content in acetona/alcohol-based primer and interfacial ultraestructure. J. Dent, v. 26, n. 2, p. 147-56, Mar.1998.

87. TITLEY, K.C. et al. Adhesion of composite resin to bleached and unbleached bovine enamel. J. dent Res., v. 67, n. 12, p. 1523-8, Dec. 1988.

88. TITLEY, K. C. et al. An SEM examination of etched dentin and the structure of the hybrid layer. J.Canad. Dent. Ass., v.61, n.10, p.887-94, Oct. 1995a. 
89. TITLEY, K. C. et al. The composition and ultrastructure of resin tags in etched dentin. Amer. J. Dent., v.8, n.5, p.224-30, Oct. 1995b.

90. TITLEY, K; CALDWELL, R.; KULKARNI, G. Factors that affect the shear bond strength of multiple component and single bottle adhesives to dentin. Amer. J. Dent., v. 16, n. 2, p. 120-4, Apr. 2003.

91. TJAN, A.H.L.; CASTELNUOVO, J.; LIU, P. Bond strength of multi-step and simplified-step systems. Amer. J. Dent., v. 9, n. 6, p. 269-72, Dec. 1996.

92. TOLEDANO, M., et al. Effect of acid etching and collagen removal on dentin wettability and roughness. J. Biomed. Mat. Res., v. 47, n. 2, p. 198-203, Mar. 1999.

93. TOLEDANO, M. et al. Influence of $\mathrm{NaOCl}$ deproteinization on shear bond strength in function of dentin depth. Amer. J. Dent., v. 15, n. 4, p. 252-5, Aug. 2002.

94. TORII, Y. et al. Effect of phosphoric acid etching prior to self-etching primer application on adhesion of resin composite to enamel and dentin. Amer. J. Dent., v. 15, n. 5, p. 305-8, Oct. 2002.

95. TORII, Y. et al. Effect of EDTA conditioning on bond strength to bovine dentin promoted by four current adhesives. Amer. J. Dent., v. 16, n. 6, p. 395-400, Dec. 2003.

96. UNO, S.; FINGER, W.J. Phosphoric acid as a conditioning agent in the gluma bonding system. Amer. J. Dent., v. 8, n. 5, p. 236-41, Oct. 1995a.

97. UNO, S.; FINGER, W.J. Function of the hybrid zone as a stress-absorbing layer in resin-dentin bonding. Quintessence Int, v. 26, n.10, p. 733-8, Oct. $1995 b$.

98. UNO, S.; FINGER, W.J. Effects of acid conditioners on dentin demineralization and dimension of hybrid layers. J. Dent, v. 24, n. 3, p. 211-6, May 1996. 
99. VARGAS, M.A.; COBB, D.S.; DENEHY, G.E. Interfacial micromorphology and shear bond strength of single-bottle primer/adhesives. Dent Mater. , v. 13, n. 5, p. 316-24, Sept. 1997.

100. VAN MEERBEEK, B. et al. Factors affecting adhesion to mineralized tissues. Oper. Dent.,v. 17, supl 5, p. 111-124, 1992a.

101. VAN MEERBEEK, B. et al. Morphological aspects of the resin-dentin interdiffusion zone with different dentin adhesive systems. J. dent. Res., v. 71, n. 8, p. 1530-40, Aug. 1992b.

102. VAN MEERBEEK, B. et al. Correlative transmission electron microscopy examination of nondemineralized and desmineralized resin-dentin interfaces formed by two dentin adhesive systems. J.dent.Res., v.75, n.3, p.879-88, Mar.1996.

103. VAN MEERBEEK, B. et al. A TEM study of two water-based adhesive systems bonded to dry and wet dentin. J. dent. Res., v. 77, n. 1, p. 50-9, Jan. 1998.

104. VAN NOORT, R. et al. A critique of bond strength measurements. J Dent. , v. 17, n. 2, p. 61-7, Apr. 1989.

105. VELAZQUEZ, E. et al. Effect of primer solvent and curing mode on dentin shear bond strength and interface morphology. Quint. Int., v. 34, n. 7, p. 548-55, July/ Aug. 2003.

106. WANG, Y; SPENCER, P. Physicochemical interactions at the interfaces between self-etch adhesive systems and dentine. J.Dent., v. 32, n. 7, p. 567-79, Sept. 2004.

107. WATANABE, I.; NAKABAYASHI, N. Bonding durability of photocured phenyl-P in TEGDMA to smear layer- retained bovine dentin. Quint. Int., v. 24, n. 5, p. 335-42, May 1993. 
108. WATANABE, I.; NAKABAYASHI, N. Measurement methods for adhesion to dentine: the current status in Japan. J.Dent., v.22, n.2, p.67-72, Apr. 1994.

109. WATANABE, L.G.; MARSHALL, G.W.Jr; MARSHALL, S.J. Dentin shear strength: effects of tubule orientation and intratooth location. Dent Mater., v. 12, n. 2, p. 109-15, Mar. 1996.

110. YANAGAWA, T.; FINGER, W.J. Relation between degree of polymerization of resin composite and bond strength to Gluma-treated dentin. Amer. J. Dent., v. 7, n. 3, p. 157-60, June, 1994.

111. YOSHIYAMA, M. et al. Interfacial morphology and strength of bonds made to superficial versus deep dentin. Amer. J. Dent., v. 8, n. 6, p. 297-302, Dec. 1995.

112. YOUSSEF, M.N; GUARALDI, E.; SATO, C.T.; HAYASHI, R.F. Estudo comparativo de quarto filosofias adesivas quanto à penetração na dentina. Rev. APCD, v. 52, n. 3, p. 236-9, Maio/Junho 1998. 